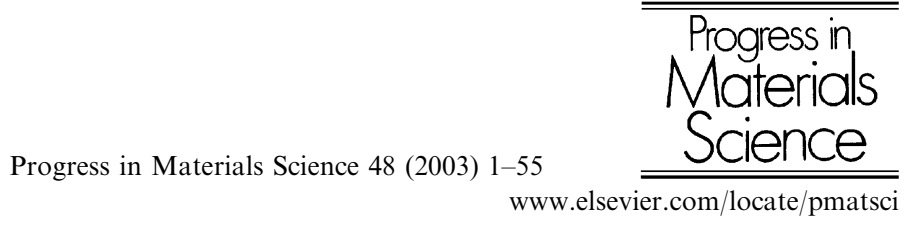

\title{
Durability of nanosized oxygen-barrier coatings on polymers
}

\author{
Yves Leterrier* \\ Laboratoire de Technologie des Composites et Polymères (LTC), Ecole Polytechnique \\ Fédérale de Lausanne (EPFL), CH-1015 Lausanne, Switzerland
}

Received 15 October 2001; accepted 17 December 2001

\begin{abstract}
Research on silicon oxide thin films developed as gas-barrier protection for polymer-based components is reviewed, with attention paid to the relations between (i) coating defects, cohesive strength and internal stress state, and (ii) interfacial interactions and related adhesion to the substrate. The deposition process of the oxide from a vapor or a plasma phase leads in both cases to the formation of covalent bonds between the two materials, with high adhesion levels. The oxide coating contains nanoscopic defects and microscopic flaws, and their respective effect on the barrier performance and mechanical resistance of the coating is analyzed. Potential improvements are discussed, including the control of internal stresses in the coating during deposition. Controlled levels of compressive internal stresses in the coating are beneficial to both the barrier performance and the mechanical reliability of the coated polymer. An optimal coating thickness, with low oxygen permeation and high cohesive strength, is determined from experimental and theoretical analyses of the failure mechanisms of the coating under mechanical load. These investigations are found relevant to tailor the interactions and stress state in the interfacial region, in order to improve the reliability of the coating/substrate assembly. (C) 2002 Elsevier Science Ltd. All rights reserved.
\end{abstract}

\section{Contents}

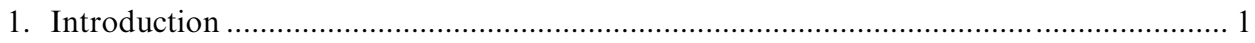

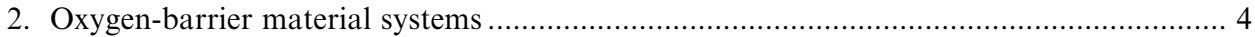

* Tel.: + 41-21-693-4848; fax: +41-21-693-5880.

E-mail address: yves.leterrier@epfl.ch 


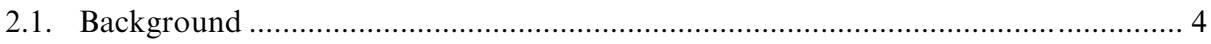

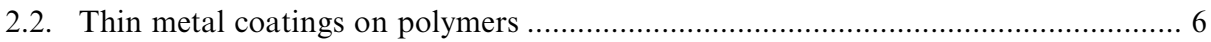

2.3. Thin metal oxide coatings on polymers ............................................................. 7

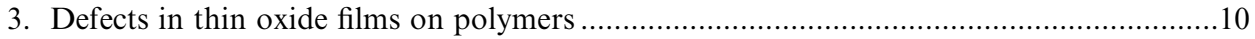

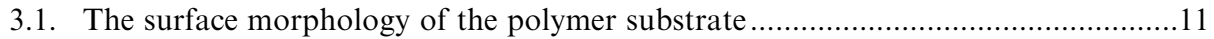

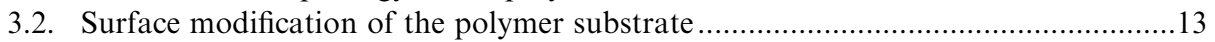

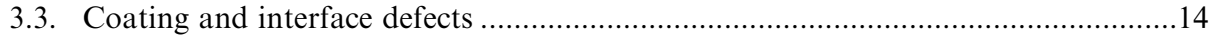

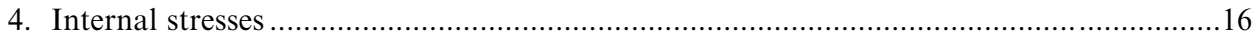

4.1. Generation of internal stresses in thin coatings on polymers ............................... 18

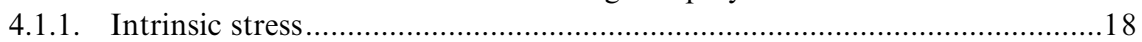

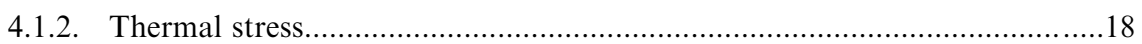

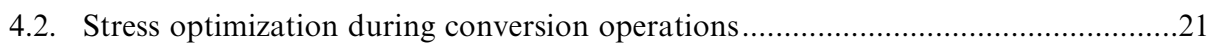

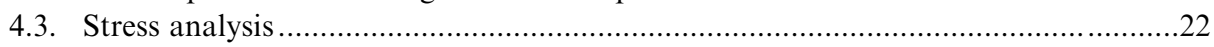

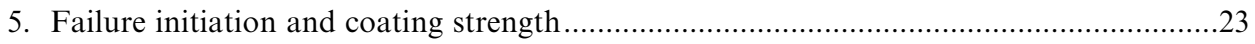

5.1. Linear elastic fracture mechanics approach for crack onset prediction ..................26

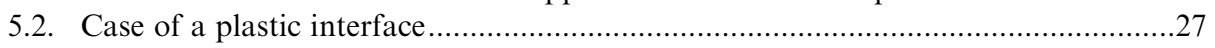

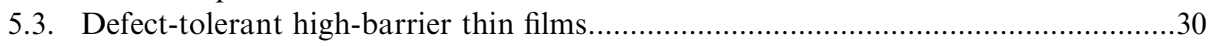

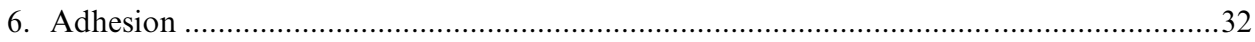

6.1. Adhesion measurements of thin oxide films on polymer substrates .........................32

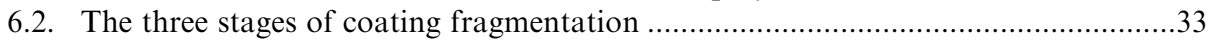

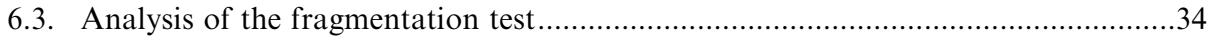

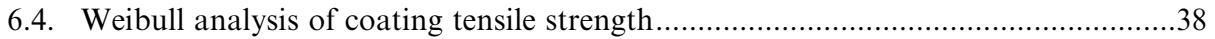

6.5. Role of internal stresses on interfacial shear strength

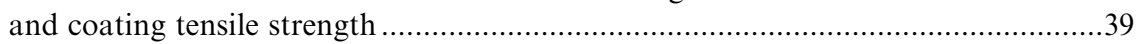

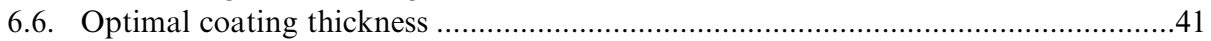

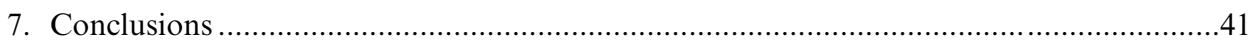

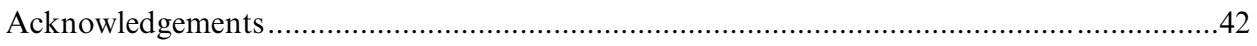

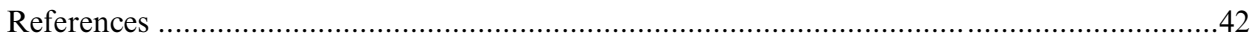

\section{Introduction}

Thin oxide films deposited on polymer substrates by vapor deposition techniques are used in a broad variety of applications. The combination of polymer materials with functional and protective coatings offers a number of key advantages over alternative bulk materials, such as light weight, complex shape and design freedom, transparency or tailored optical characteristics, and also cost-effectiveness [1]. The past decades have seen a regular increase of the research effort to better understand such material systems and improve corresponding technology, with approx. 3000 scientific papers currently published yearly on this topic, among which over 300 deal with coatings on polymers, with an increase rate close to $10 \%$. The numerous applications fields include dielectric antireflection coatings based on $\mathrm{SiO}_{2} / \mathrm{TiO}_{2}$, 
$\mathrm{SiO}_{2} / \mathrm{ZrO}_{2}$ or $\mathrm{SiO}_{2} / \mathrm{HfO}_{2}$ multilayers for optical components [2-5], transparent conducting tin-doped indium oxide (ITO) coatings, high refraction index and high permittivity $\mathrm{TiO}_{2}$ coatings, and $\mathrm{ZnO}$ films for flat panel displays, solar cells, and other opto- and micro-electronic devices [6-10], atomic-oxygen protective coatings of $\mathrm{SiO}_{2}$, silicon oxinitrides, $\mathrm{Al}_{2} \mathrm{O}_{3}$, ITO or $\mathrm{SnO}_{2}$ for spacecraft components [11-15]. The present review focuses on transparent silicon oxide $\left(\mathrm{SiO}_{x}\right)$ thin coatings on thermoplastic substrates, which have emerged in the 1980's as an alternative to metallized plastics, to protect pharmaceuticals [16,17] and food products [18-23] from oxygen (e.g. review [24]). These systems proved also to be efficient barriers towards ingression of other small penetrants such as moisture, as also aroma losses. The versatility of the deposition technology has led to new applications including coating of bottles [25] and natural polymers [26], and opens considerable potential for further applications. These include the protection of polymers against photo-degradation [27] and of microdevices and flat panel displays from oxygen and moisture ingression [28,29], the prevention of conversion efficiencies decrease of solar cells [30], as well as patrimony conservation purposes [31]. As will be detailed in Section 2 of this report, $\mathrm{SiO}_{x}$ coatings of thickness of the order of 10 to $100 \mathrm{~nm}$ decrease the oxygen permeability of polymer films by typically two orders of magnitude [24]. In the past two decades, most of the research has been devoted to the physical and chemical analyses of the barrier system, which includes the characterization of the apparent permeability of the coated polymer with respect to the deposition process, and resulting coating and interface defect structure. The main studies and related developments are presented in Sections 2 and 3.

The importance of mechanical analyses of $\mathrm{SiO}_{x}$ coated polymers, in terms of coating strength, internal stress state, and adhesion to the substrate, motivated additional research, although to a lesser extent than the above-mentioned physical and chemical analyses. Theses features are nevertheless among the most important coating/substrate properties, as depicted in Fig. 1. [32]. The reliability of the barrier function is controlled by the cohesion of the brittle coating, and by its adhesion to

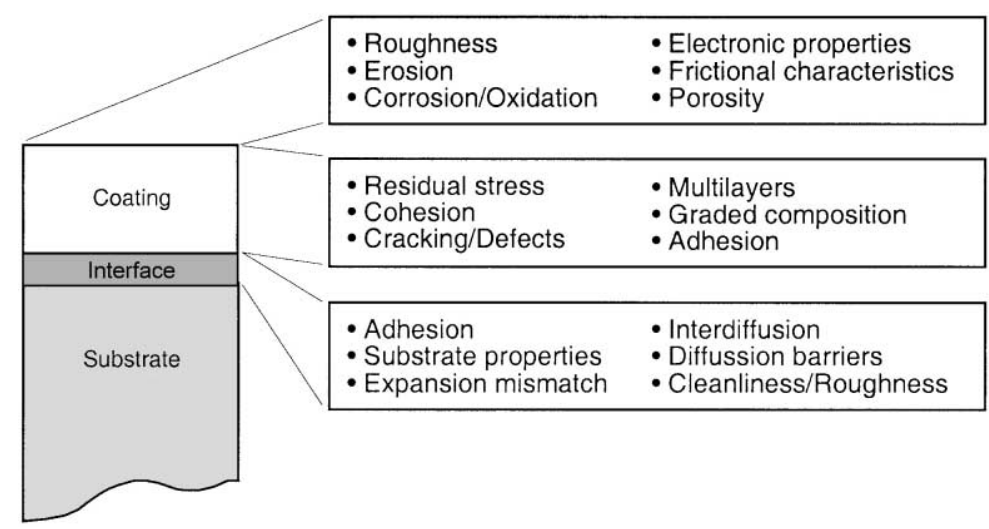

Fig. 1. Important coating/substrate properties for technological applications. Reproduced from Ref. [32] with permission. 
the polymer, both being influenced by the process-induced internal stress state of the coated assembly. In gas-barrier coated polymers, and, more generally, in all the applications previously mentioned, the intrinsic resistance of the coating to thermal and mechanical loads, its thickness and its adhesion to the substrate are among the key characteristics to tailor for both performance and cost optimization. Reduced thickness without impaired reliability enables cost savings. However, coatings with thickness down in the nanometer range are often associated with growth heterogeneities and high residual stresses generated during the deposition process. Moreover, during all the conversion processes usually encountered in the manufacture of the above-mentioned products, and during service, the thin, brittle oxide coating and coating/substrate assembly must resist externally-applied mechanical and hygrothermal loads. Section 4 presents the activities related to characterization and modeling of process-induced stresses. Sections 5 and 6 review the various analyses of (i) cohesive properties and (ii) adhesive properties of gas-barrier coatings, with attention paid to the role of internal stresses.

\section{Oxygen-barrier material systems}

\subsection{Background}

Gas-barrier systems are developed to protect manufactured goods and components from degradation, particularly that resulting from oxidative processes. Early developments of gas-barrier thin films on polymer substrates date back in 1959 with aluminum metallization techniques. Typical barrier improvement factor (ratio of permeation rates of uncoated to coated polymer [24]) of the order of 100 was achieved with $15 \mathrm{~nm}$ thick Al coatings formed by resistive evaporation [33]. For food packaging applications, the oxygen transmission rate (OTR) of the packaging film should be of the order of $1 \mathrm{~cm}^{3}(\mathrm{STP}) / \mathrm{m}^{2} /$ day/bar [24,34]. For a $100 \mu \mathrm{m}$ thick film, this OTR value corresponds to a permeability of the order of $10^{-16} \mathrm{~cm}^{3}(\mathrm{STP}) \cdot \mathrm{cm} / \mathrm{cm}^{2} / \mathrm{s} / \mathrm{Pa}$. Polymers are permeable towards diffusion of small molecules, including oxygen, however with considerable differences depending on the physical interactions between the polymer and the penetrant molecule (e.g. [35]). The oxygen permeabilities, $P_{\mathrm{O}_{2}}$, of a variety of polymers are reported in Table 1. Additional information may be found in the compilation of Pauly [36] and in the work of Ryder on commercial polymers used for food packaging [18]. Low density polyethylene (LDPE) has a very high $P_{\mathrm{O}_{2}}$, equal approximately to $2500 \cdot 10^{-16} \mathrm{~cm}^{3}(\mathrm{STP}) \cdot \mathrm{cm} / \mathrm{cm}^{2} / \mathrm{s} / \mathrm{Pa}$, by contrast with high barrier polymers such as poly(acrylonitrile) (PAN), poly(vinylidene chloride) (PVDC), and ethylene vinyl alcohol $(\mathrm{EVOH})$, whose $\mathrm{P}_{\mathrm{O}_{2}}$ are of the order of $1 \cdot 10^{-16} \mathrm{~cm}^{3}(\mathrm{STP})$ $\mathrm{cm} / \mathrm{cm}^{2} / \mathrm{s} / \mathrm{Pa}$. Liquid-crystalline polymers also offer very low oxygen permeabilities, but suffer from their high price [37]. Multilayer films based on linear low-density polyethylene grafted maleic anhydride (LLDPE-gMA), coextruded with polyamide (PA) [38], and tailored blends, such as reactive blends of ternary blends composed of poly (vinyl-alcohol)/polyamide 6/poly(ethylene-co-ethyl acrylate) (PVOH/PA6/PEEA) [39], or blends possessing a process-induced laminar morphology [40,41] are devel- 
Table 1

Oxygen permeability of polymers and multiphase polymer systems

\begin{tabular}{|c|c|c|c|}
\hline Polymer & Coating & $\begin{array}{l}\text { Permeability, } \mathrm{P}_{\mathrm{O} 2} \\
\left(10^{16} \mathrm{~cm}^{3}(\mathrm{STP}) \cdot\right. \\
\left.\mathrm{cm} / \mathrm{cm}^{2} / \mathrm{s} / \mathrm{Pa}\right)\end{array}$ & Ref. \\
\hline Polyethylene, low density (LDPE) & - & $\sim 2500$ & {$[18,35,36]$} \\
\hline Polyethylene, high density (HDPE) & - & 500 & {$[35]$} \\
\hline Polypropylene (PP) & - & $530-1700^{\mathrm{a}}$ & {$[18,24,36,305]$} \\
\hline Polystyrene (PS) & - & 2000 & \\
\hline Poly(carbonate) (PC) & - & 1050 & \\
\hline Poly(vinyl acetate) (PVAC) & - & 367 & \\
\hline Poly(ethylene terephthalate) (PET) & - & $10-30^{\mathrm{a}}$ & {$[18,24,36,306]$} \\
\hline poly(vinylchloride) (PVC) & - & 5.9 & [18] \\
\hline Polyamide 6 (PA6) & - & $5-25^{\mathrm{a}}$ & {$[18,36,128,307]$} \\
\hline Poly(acrylonitrile) (PAN) & - & $0.15-5$ & {$[18,36]$} \\
\hline Poly(vinylidene chloride) (PVDC) & - & $0.38-4$ & {$[18,36]$} \\
\hline Poly(ethylene vinyl alcohol) (EVOH) & - & $0.05-6.65^{\mathrm{b}}$ & {$[18,36]$} \\
\hline LDPE/EVOH blends & - & 3.8 & {$[40]$} \\
\hline PET/EVOH blends & - & 5.1 & [308] \\
\hline Polypropylene/polyamide 6 blends & - & $1.7-850^{\mathrm{c}}$ & [309] \\
\hline $\begin{array}{l}\text { Thermotropic liquid-crystalline } \\
\text { polymers }\end{array}$ & - & $<0.1-0.4$ & {$[37,310]$} \\
\hline $\begin{array}{l}\text { Alkylsulfonylmethyl-substituted } \\
\text { poly(oxyalkylene) }\end{array}$ & - & $0.7-3.6$ & {$[43]$} \\
\hline Poly(hydroxy amide ethers) & - & $1-20$ & {$[311-313]$} \\
\hline $\begin{array}{l}\mathrm{PET} \text { copolymer } / \text { talc } 32 \% \mathrm{wt} \\
\text { composite }\end{array}$ & - & 14 & {$[44]$} \\
\hline $\begin{array}{l}\text { Polyethylene } / \text { mica } 10 \mathrm{wt} \% \\
\text { composite }\end{array}$ & - & $\sim 2000$ & [314] \\
\hline $\begin{array}{l}\text { Polyamide } 6 / \text { layered silicate } \\
\text { nanocomposite }\end{array}$ & - & $\sim 10$ & {$[46]$} \\
\hline Polyethylene & $\mathrm{SiO}_{x} 40 \mathrm{~nm}(\mathrm{PECVD})$ & 85 & [128] \\
\hline Polyamide & $\mathrm{SiO}_{x} 40 \mathrm{~nm}(\mathrm{PECVD})$ & 0.07 & {$[128]$} \\
\hline Polycarbonate (PC) & $\mathrm{SiO}_{x} \mathrm{C}_{x} \mathrm{H}_{z} / \mathrm{TiO}_{2} 100 \mathrm{~nm}$ (PICVD) & $\sim 3$ & {$[17]$} \\
\hline \multirow[t]{5}{*}{ Polypropylene, oriented (OPP) } & $\mathrm{SiO}_{\mathrm{x}}($ React.sputter $\mathrm{Si})$ & 50 & [315] \\
\hline & $\mathrm{SiO}_{\mathrm{x}}$ (React. evap.SiO) & 50 & {$[315]$} \\
\hline & $\mathrm{SiO}_{\mathrm{x}}(\mathrm{PECVD})$ & 2 & [82] \\
\hline & ORMOCER $^{\ltimes}$ & 37 & [213] \\
\hline & $\mathrm{SiO}_{\mathrm{x}} / \mathrm{ORMOCER}^{\circledR}$ & 0.12 & [213] \\
\hline \multirow[t]{9}{*}{ Poly(ethylene terephthalate) (PET) } & $\mathrm{Al}<15 \mathrm{~nm}$ React. evap. & $\sim 0.15$ & {$[33]$} \\
\hline & Silica-poly(vinyl alcohol) & $\sim 1$ & [316] \\
\hline & SiN (PECVD) & 0.15 & {$[317]$} \\
\hline & $\mathrm{ZnO}$ (Reactive sputtering) & 1.2 & [19] \\
\hline & $\mathrm{SiO}_{\mathrm{x}} 70 \mathrm{~nm}$ (Reactive evaporation) & 0.3 & {$[20]$} \\
\hline & $\mathrm{SiO}_{\mathrm{x}} 12 \mathrm{~nm}(\mathrm{PECVD})$ & 0.15 & [318] \\
\hline & $\mathrm{SiO}_{\mathrm{x}}(\mathrm{PECVD})$ & 0.12 & [133] \\
\hline & $\mathrm{SiO}_{\mathrm{x}}(\mathrm{PECVD})$ & 0.04 & [74] \\
\hline & ORMOCER $^{\circledR} / \mathrm{SiO}_{\mathrm{x}}$ & 0.069 & [213] \\
\hline
\end{tabular}

a Depends on crystallinity, orientation, and water vapor in case of polyamides [307].

b Depends on ethylene content.

c Depends on composition. A marked decrease is observed for PA6 fractions greater than $60 \%$. 
oped for improved barrier performance. In addition, research on novel polymers with low oxygen permeabilities is currently being carried out. These include poly(1,1-bis(hydroxymethyl)-2-vinylcyclopropane) [42] or alkylsulfonylmethyl-substituted poly(oxyalkylene)s [43], the latter achieving oxygen permeabilities lower than $10^{-16} \mathrm{~cm}^{3}(\mathrm{STP}) \cdot \mathrm{cm} / \mathrm{cm}^{2} / \mathrm{s} / \mathrm{Pa}$. Layered composites have also been developed for the same purpose, such as talc-filled semicrystalline thermoplastics [44]. A promising development is found in the field of layered silicate nanocomposites [45], particularly those based on polyamide 6 (PA6) [46].

An alternative to the synthesis of new polymers is the use of thin gas-barrier coatings, formed by means of vapor-deposition processes. The reason is, in a first approximation, the transport of small penetrants through bilayer films can be expressed following a parallel-type equation [47]:

$$
\frac{h}{P}=\frac{h_{\mathrm{c}}}{P_{\mathrm{c}}}+\frac{h_{\mathrm{s}}}{P_{\mathrm{s}}}
$$

where $h, h_{\mathrm{c}}$ and $h_{\mathrm{s}}$ represent the coated film, coating and substrate thicknesses, respectively. $P$ is the apparent oxygen permeability of the coated film, and $P_{\mathrm{c}}$ and $P_{\mathrm{s}}$ are the oxygen permeabilities of the coating and substrate, respectively. The apparent permeability of the coated film $P$ thus decreases with increasing coating thickness, by typically two orders of magnitude, as shown in Fig. 2 for $\mathrm{SiO}_{x} / \mathrm{PET}$ materials processed with various techniques. This, in fact, is only verified in a narrow range of small coating thickness, and does not capture the observation of a flat minimum in $P$ values when coating thickness is increased to beyond a given threshold (Fig. 3). Common deposition technologies [48] are based on physical vapor deposition (PVD process) such as reactive evaporation, and chemical vapor deposition (CVD). PVD processes operate under reduced pressure, and comprise evaporation and sputtering, characterized by the absence of chemical reactions in the gas phase and at the substrate surface (at the exception of reactive evaporation where a partial pressure of oxygen is used). An overview of PVD processes can be found in Ref. [49]. Both evaporation and sputtering techniques use solid precursors with low boiling points from which atoms are removed, either by thermal means in the evaporation process, or through impact by gaseous ions in the sputtering process. CVD processes use volatile precursors, which are decomposed by means of heat, photons, or plasma. The latter technique, termed plasma enhanced CVD (PECVD), is applicable for thermally sensitive substrates such as polymers, and has become the mostly used process for the deposition of $\mathrm{SiO}_{x}$ coatings. The following considers the case of metallic coatings, and then the case of oxides.

\subsection{Thin metal coatings on polymers}

A considerable amount of work has been dedicated to aluminized polymers in the past decades, the main emphasis being put on the analysis of interface interactions and chemistry [50-56]. In these works, the good adhesion between $\mathrm{Al}$ and a number of polymers, particularly polyesters, was attributed to the formation of covalent 


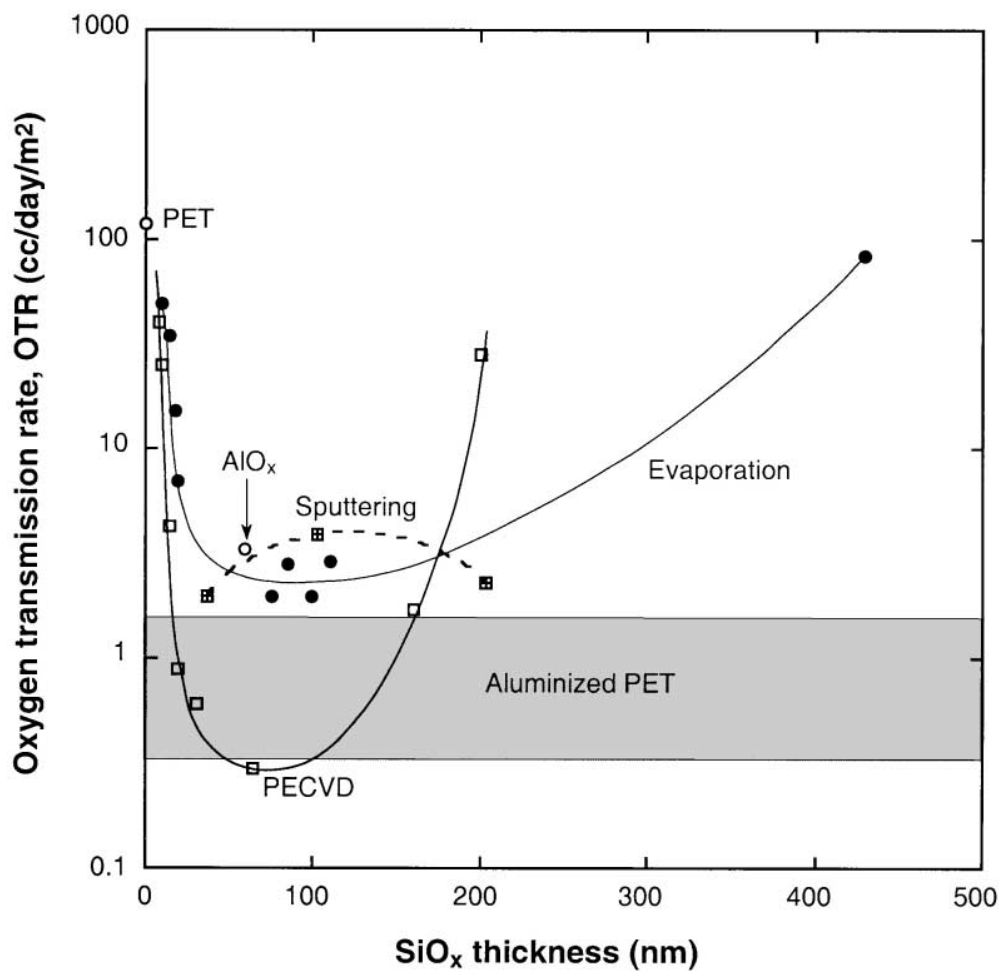

Fig. 2. Oxygen transmission rate (OTR) of $\mathrm{SiO}_{x}$ coated PET vs. coating thickness, for different deposition technologies (data after refs [24,304]). Also shown is the OTR of Al/PET.

bonds (Al-O-C oxi-carbide complex and carbide bonds), whereas hydrogen bonds were found to have a negligible influence on adhesion [53]. There exist also numerous analyses of interfacial interactions between metals and polymers, mostly poly(ethylene terephthalate) (PET). These metals comprise Mg (thermal evaporation) [57,58], $\mathrm{K}$ and $\mathrm{Cr}$ (evaporation) [59], $\mathrm{Si}$ and $\mathrm{Cu}$ (thermal evaporation) [57]. All these metals (M) form complexes with the polymer, particularly carboxylic groups, and lead to $\mathrm{M}-\mathrm{O}-$ $\mathrm{C}$ and $\mathrm{M}-\mathrm{C}$ bonds. By contrast with $\mathrm{Al}, \mathrm{Cu}$ presents weak adhesion to PET [52], unless an $\mathrm{O}_{2}$ plasma treatment is applied to the polymer, which increases the polar component of the polymer surface energy [60], and leads to the formation of a $\mathrm{Cu}-$ O-C metal complex [51].

\subsection{Thin metal oxide coatings on polymers}

Besides their excellent transparency, compared to thin metallic films, metal oxides such as silicon oxide $\left(\mathrm{SiO}_{x}\right)$ possess excellent barrier properties. Transparent barrier $\mathrm{SiO}_{x}$ coatings were originally industrialized in 1969 [61]. The very tight interstitial spaces of the $\mathrm{Si}-\mathrm{O}$ lattice and broad ranges in thermal stability leads to oxygen 


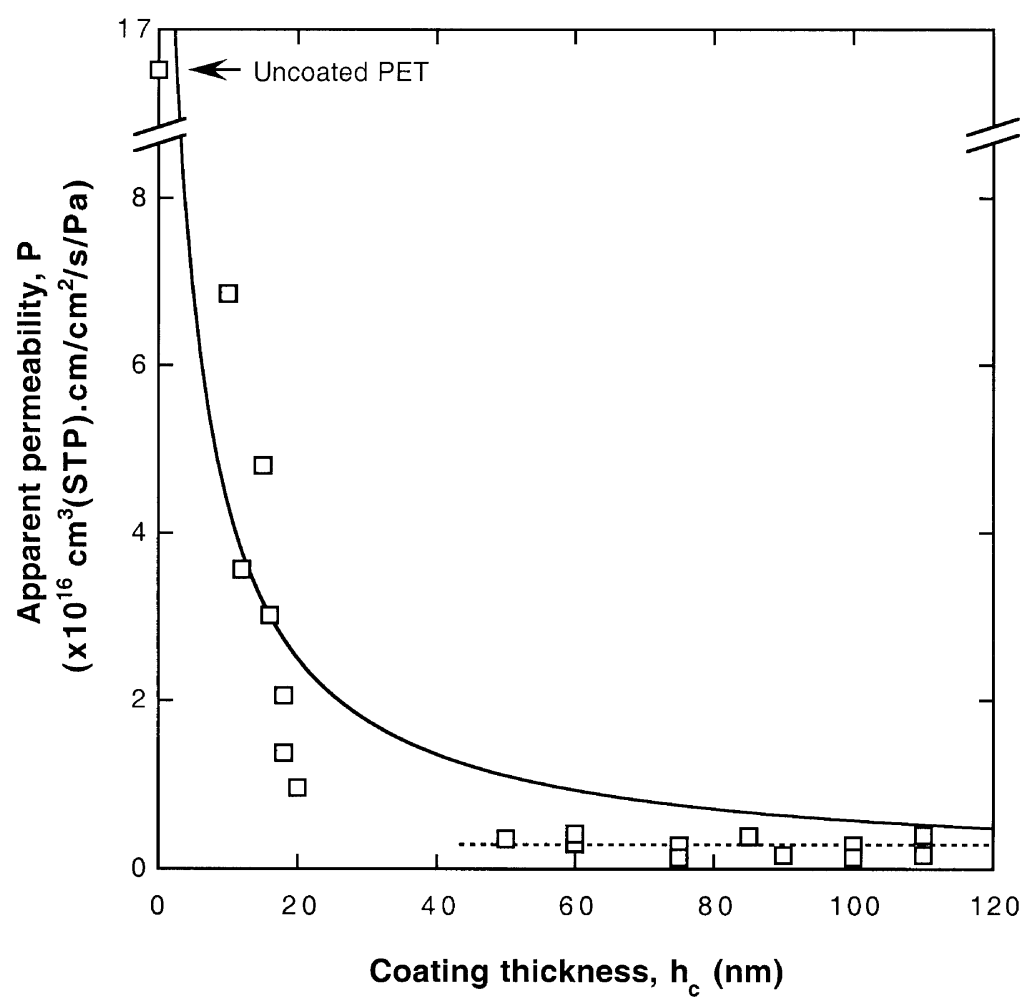

Fig. 3. Apparent permeability of $\mathrm{SiO}_{x} /$ PET films (dots: experimental data after refs [24,304], line: Eq. (1), with $h_{\mathrm{s}}=12 \mu \mathrm{m}, P_{\mathrm{s}}=16.5 \cdot 10^{-16} \mathrm{~cm}^{3}(\mathrm{STP}) \cdot \mathrm{cm} / \mathrm{cm}^{2} / \mathrm{s} / \mathrm{Pa}$ and $\left.P_{\mathrm{c}}=4.9 \cdot 10^{-19} \mathrm{~cm}^{3}(\mathrm{STP}) . \mathrm{cm} / \mathrm{cm}^{2} / \mathrm{s} / \mathrm{Pa}\right)$.

diffusivities in the range $10^{-5}-10^{-9} \mathrm{~cm}^{2} / \mathrm{s}$. An in-depth analysis of oxygen and water vapor transport through magnetically enhanced CVD $\mathrm{SiO}_{x}$ coated PET barrier films was performed by Trophsa and Harvey [62]. The authors concluded that the oxide coating acted as simple defective blocks to oxygen transport, as depicted in Fig. 4, and that the dominant transport mechanism was permeation through the polymer substrate, followed by flux through available defects in the coating. This is in contrast to the behavior of water molecules that are believed to interact and react with deposited metal and oxide coatings [63]. In spite of the reported defects, the oxygen permeation of the coated polymer is typically two orders of magnitude lower than that of the uncoated polymer, as indicated in Table 1.

The numerous analyses of the interfacial interactions between silicon oxide coatings and various polymer substrates revealed the presence of $\mathrm{Si}-\mathrm{C}$ and $\mathrm{Si}-\mathrm{O}-\mathrm{C}$ covalent bonds [53,64-77]. The influence of deposition conditions and pretreatments, such as plasma activation of the polymer surface, are reviewed by Benmalek and Dunlop in case of $\mathrm{SiO}_{x}$ and $\mathrm{Al}_{y} \mathrm{O}_{z}$ coatings on polymer substrates [65]. The authors observed that the barrier depends on coating thickness, and rougher surfaces, such as that of 

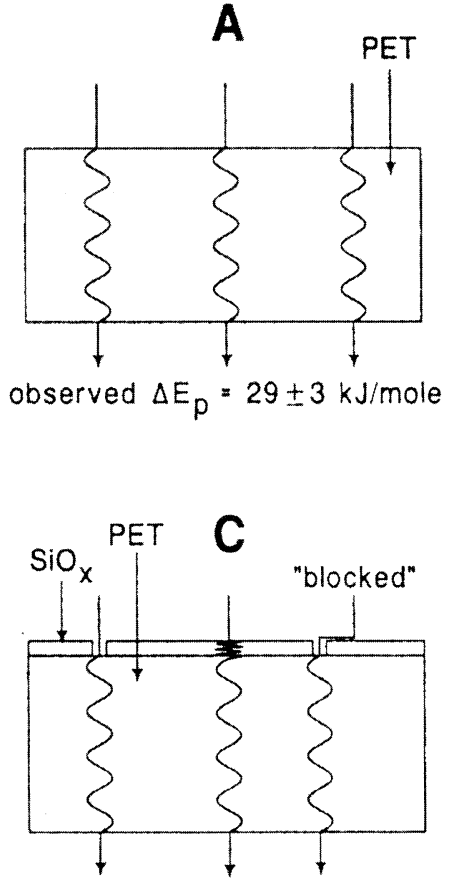

observed $\Delta E_{p}=29 \pm 3 \mathrm{~kJ} / \mathrm{mole}$
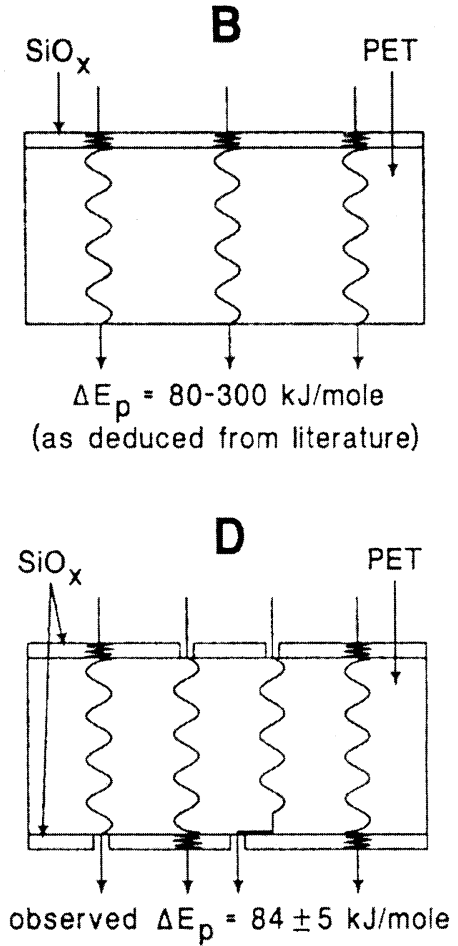

Fig. 4. Empirical model of oxygen transport through (a) uncoated PET, (b) PET film coated on one side with a hypothetically defect free, continuous layer of "glass", (c) PET film coated on one side with an imperfect, non-continuous layer of $\mathrm{SiO}_{x}$, and (d) PET film coated on two sides with imperfect, non-continuous layers of $\mathrm{SiO}_{x}$. The apparent free energies of activation for the transport of oxygen are indicated for each case. Reproduced from Ref. [62] with permission.

polyethylene, require thicker coatings. The contribution of polar, hydrogen bonds to adhesion was found to be negligible, and strong adhesion between $\mathrm{SiO}_{x}$ and polymers requires the presence of oxygen at the interface to form the above mentioned covalent bonds [53].

Among the other relevant studies devoted to the deposition of oxides onto polymer substrates, one may cite $\mathrm{TiO}_{2}$ coatings. Titania, due to unique UV-absorption characteristics, would constitute interesting barrier material to protect polymers against photodegradation. $\mathrm{TiO}_{2}$ coatings can be formed by laser ablation deposition [6], r.f. magnetron sputtering in an oxygen-argon plasma from a titanium target (reactive process) [7], and in a pure argon plasma from a titania target (non-reactive process) [78]. $\mathrm{Ti}-\mathrm{O}-\mathrm{C}$ covalent bonds were identified by XPS between PET and $\mathrm{TiO}_{2}$ in the case of the reactive magnetron sputtering, with corresponding high adhesion level. By contrast, no chemical reaction seemed to occur between the PET and the titanium oxide film sputtered under a pure argon plasma [78], and the adhesion resulting from mechanical interlocking was reported to be weaker than in the previous case. 
To summarize, covalent bonds are formed during the vapor deposition of thin metal or metal oxide films onto polymer substrates, and these bonds leads to high levels of adhesion, as will be detailed in Section 6 of this report. This, however, is a necessary but not sufficient condition for coating performance. Of equal importance is the cohesive strength of the thin film, which results from a complex interplay between interface structure, coating growth, defects, and internal stress state.

\section{Defects in thin oxide films on polymers}

In their permeation study of polymer barrier systems, Rossi and Nulman found that many small holes in a barrier layer lead to a much higher permeation than few large holes, of same total area [79]. It was moreover established that the barrier performance of coated polymers depends on coating thickness [80], on substrate roughness [72,81], as also on coating density, as shown in Fig. 5 in case of an hexamethyldisiloxane/oxygen ( $\mathrm{HMDSO} / \mathrm{O}_{2}$ ) coating on polypropylene (PP) [82]. These factors (defect size, coating thickness, coating density, and substrate roughness) are all likely to affect the mechanical behavior of the coating. Particularly, rougher surfaces require thicker coatings for maintained barrier properties, which tend to promote cracking $[65,83]$. It is therefore essential to have a detailed understanding of the initial surface morphology of the polymer substrate, of its evolution during the deposition process, and the resulting final structure of the coating.

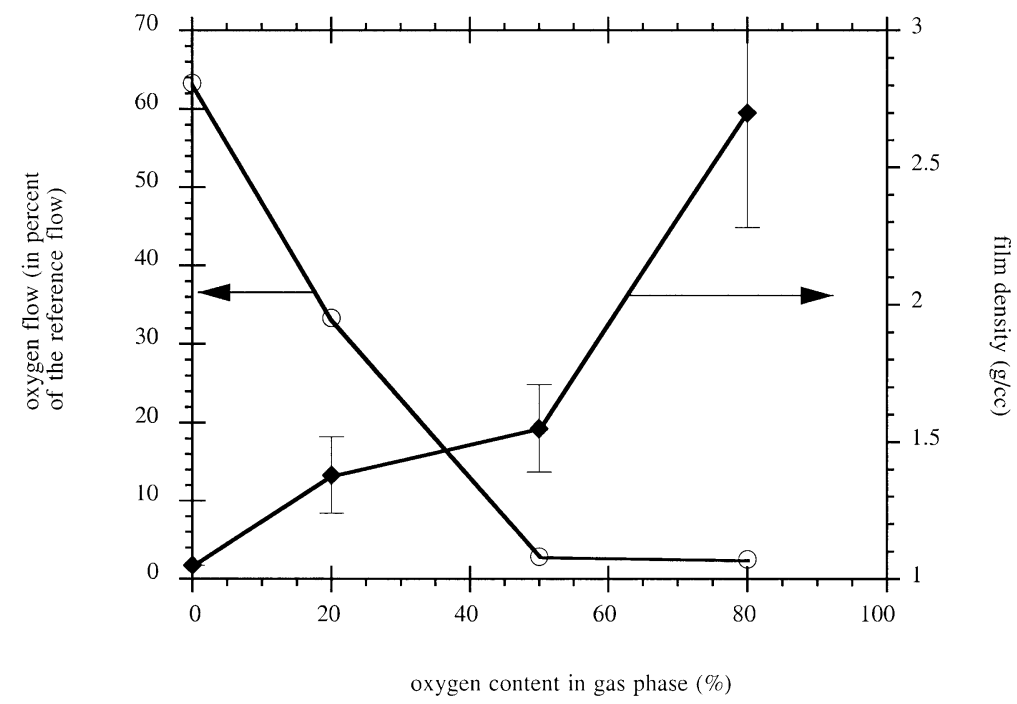

Fig. 5. Oxygen flow across membranes and density of $\mathrm{HMDSO} / \mathrm{O}_{2}$ plasma polymer films on PP (with error bars due to thickness incertitude of deposits) for different gas-phase compositions. Uncoated PP reference flow $=600 \mathrm{~cm}^{3} / \mathrm{m}^{2}$ day. Initial gas total pressure $=10^{-1} \mathrm{mbar}$; power density $=100 \mathrm{~mW} / \mathrm{cm}^{2}$; deposition time $=10 \mathrm{~min}$. Reproduced from Ref. [82] with permission. 


\subsection{The surface morphology of the polymer substrate}

The surface of polymers, particularly semi-crystalline thermoplastics, are characterized by complex microstructures, and have been the subject of detailed investigations in the last decade, with the advent of surface probe techniques. The surface of amorphous [84], semi-crystalline [85], unixially stretched [86], and biaxially stretched [87] PET films was largely studied. Surface restructuration upon exposure to air or water was detected and modeled in the former case [84]. In the latter case, attention was paid to the influence of the progressive molecular orientation towards the extension direction, and eventual strain-induced crystallization, on surface energetics [88] and surface topology [85-87]. Unger and co-workers reported a preferential orientation of the PET surface chain segments, with the benzene ring being parallel to the surface plane [89], that gradually diminishes upon exposure to an oxygen plasma [90]. Using interfacial force microscopy, Graham et al [91] measured the mechanical properties of crystallized PET surfaces with nanometer resolution, and reported Young's moduli equal to 2.2 GPa in amorphous regions, and to 11.8 $\mathrm{GPa}$ on crystalline regions. A value of $4.3 \mathrm{GPa}$ was also measured in the close vicinity of the latter regions, which was attributed to an intermediate amorphous region, with some degree of order. A detailed characterization of the surface macrolattice of extruded PET could be achieved by means of contact-mode atomic force microscopy [85]. Keeping in mind the limited resolution of the pyramidal AFM tip, various measurements led to mean surface roughness of the crystalline regions in the range $2.3-13 \mathrm{~nm}$, and of amorphous regions in the range 23-38 nm. RMS roughness as low as $1.13 \mathrm{~nm}$ was reported for $12 \mu \mathrm{m}$ thick, presumably biaxially oriented, PET films [65], and of approx. $4 \mathrm{~nm}$, for uniaxially oriented PET [86].

Commercial PET films contain a variety of additives including chemical compounds, glass beads, clays, or silicate anti-tack particles, analyzed by XPS and ToFSIMS [92], and by acoustic microscopy [93,94]. Using scanning force microscopy techniques, Ling and Legget observed radial features around silicate particles, that may be attributed to localized strain-induced crystallization [87]. The diameter of the particles, embedded in the polymer superficial layers, was found to lie in the range $150-500 \mathrm{~nm}$, with an average interparticulate spacing of approx. $500 \mathrm{~nm}$. Few particles protruded some $20-40 \mathrm{~nm}$ above the polymer surface, as indicated from lateral force microscopy [86]. Similar studies were performed on magnetic tape PET substrates [95]. The influence of such additives, located in subsurface layers, on the surface topology of PET upon stretching was examined numerically by Gerlach et al. [96], and a detailed theoretical analysis was carried out by Khan and Keener [97]. For PET films drawn to a ratio of 4, the density of anti-blocking particles is of approx. $1000 / \mathrm{mm}^{2}$, and these increase the polymer roughness up to approx. $50 \mathrm{~nm}$. Such analyses are useful as design approaches to the manufacture of polymer films. They could also be useful as input data in the determination of the influence of the initial roughness of the polymer surface on the mechanical strength of the coating. This would first imply that the evolution of the polymer surface during the early deposition stages of the coating is carefully described especially when etching phenomena are present. Fig. 6A is an attempt to summarize the main characteristics of 

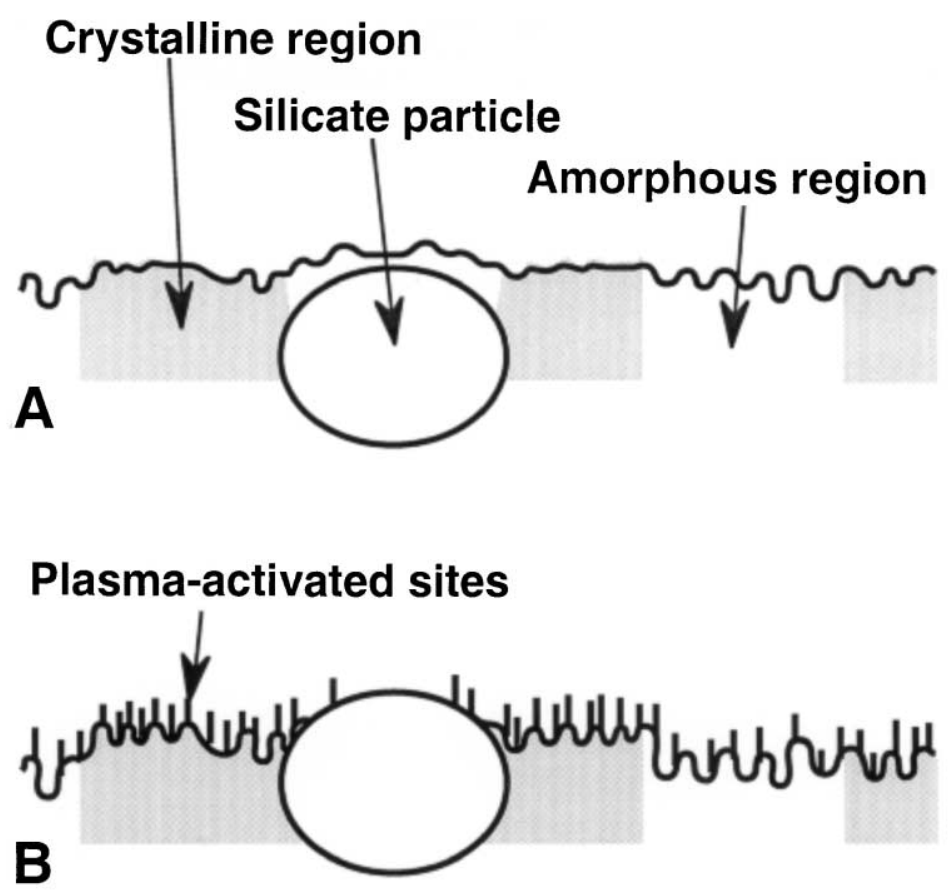

Surface and volume nanodefects

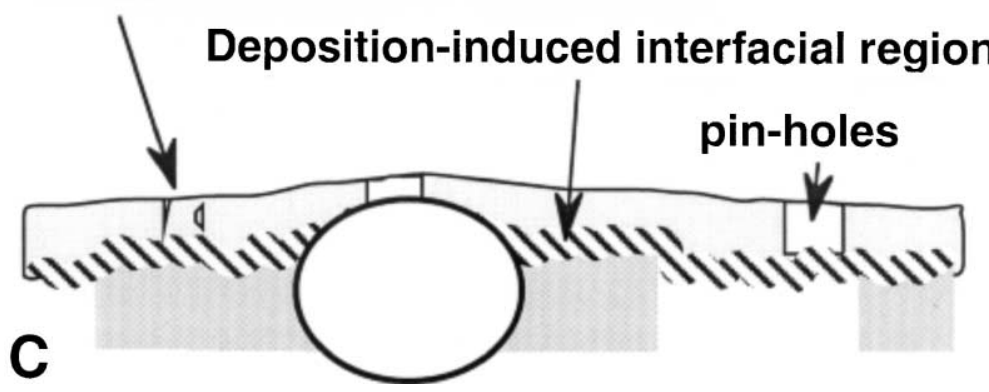

Fig. 6. Schematics of the formation of coating defects during deposition, based on the observations reported in refs. $[85,87,132]$. (a) Cross section of the initial polymer surface, characterized by crystalline and amorphous regions, and subsurface silicate particles. (b) Early stages of the deposition process, with plasma activation of reactive sites and concomitant erosion and surface roughening, preferential in the amorphous domains. (c) Formation of an interfacial region, with covalent bonds between the polymer and the oxide, and growth of the oxide layer, with sharp nanodefects and circular microdefects (pin-holes).

the surface morphology of semi-crystalline PET, based on the observations described in refs. [85,87]. The sketch depicts the alternation of soft and rough amorphous regions with hard and smooth crystalline regions, some of which resulting from nucleating and orientation processes induced on additive sites. 


\subsection{Surface modification of the polymer substrate}

During the early stages of the vacuum deposition of thin films, the initial surface of the polymer substrate undergoes considerable modifications. The surface dynamics of PET are already drastically affected with $\mathrm{SiO}_{x}$ coatings of thickness of less than $5 \mathrm{~nm}$ [98]. These changes determine the formation of the interfacial microstructure and stress state, and, thus, the coating cohesion and adhesion to the substrate. Several techniques were in fact developed to modify the surface polarity of polymers for improved adhesion, amongst which plasmas have become ubiquitous processes [99,100]. Reviews of plasma treatments of polymer surfaces are found in refs. [101103]; the main effects are four-fold, namely cleaning, ablation, crosslinking, and surface modification. Abundant literature reports the influence of various plasma using different gases $\left(\mathrm{O}_{2}, \mathrm{CO}_{2}, \mathrm{He}-\mathrm{O}_{2}\right.$ mixtures, $\left.\mathrm{Ar}\right)$ on polymer surface chemistry, energetics and morphology, particularly PET (e.g. refs. [60,104-109]) and PP [110]. According to Unger and co-workers [111], the phenyl rings in partially crystalline PET provide effective protection against plasma attack, compared for instance to polystyrene, for which the phenyl rings are on side chains. The case of silicon-containing polymers is interesting in the sense that their exposure to oxygen plasma was reported to lead to the formation of thin $\mathrm{SiO}_{x}$ coatings [112]. Oxygen microwave plasma treatments were reported to increase oxygen species on otherwise apolar surfaces such as those of polyethylene and polypropylene, leading to the formation of metal-O-C groups, with corresponding increase in adhesion with $\mathrm{Al}$ and other metals [51,72]. Similar findings were obtained with PET [51], as also using $\mathrm{CO}_{2}$ plasma $[105,113]$. Fig. 7 shows the evolution of the dispersive and polar contributions to the surface energy of PET during short plasma treatment with $\mathrm{CO}_{2}$ [105]. The authors found that the highest adhesion between treated PET and alumina coating was obtained when the polar component of the surface energy was the highest. The same result was reported in case of $\mathrm{SiO}_{x}$ coatings on silylated PET [114]. Whereas plasma led to an increase of PE and PET roughness [51], it resulted in smoothing of PP surface [34,72]. The latter authors further observed that the electrons, ions and UV radiation also present in the oxygen plasma weaken the cohesive strength of the PP by inner chain scissions, and concluded that the atomic oxygen of the plasma should dominate the pretreatment process. In case of an $\mathrm{Ar}$ plasma, and using non-contact mode scanning force microscopy imaging, Beake et al. [108]. observed the formation of ridges, normal to the final draw direction of the film, as a consequence of the preferential erosion of amorphous material, up to 4 $\mathrm{nm} / \mathrm{min}$ at $0.1 \mathrm{mbar}$ Ar pressure. Spacing between adjacent ridges was approx. 50 $\mathrm{nm}$. Similar effects were reported by Gupta et al. [109], with approx. $35 \mathrm{~nm}$ spacing between ridges. These values are more than twice as large as the lamellar periodicity determined on highly drawn films using 2-dimensional small angle X-ray scattering [115], which may result from convolution effects between the AFM tip and the morphological features.

A further important effect is the surface reorganization resulting from annealing at temperature above the glass transition of the polymer, a possible consequence of the heat dissipated into the polymer substrate during coating deposition. For 


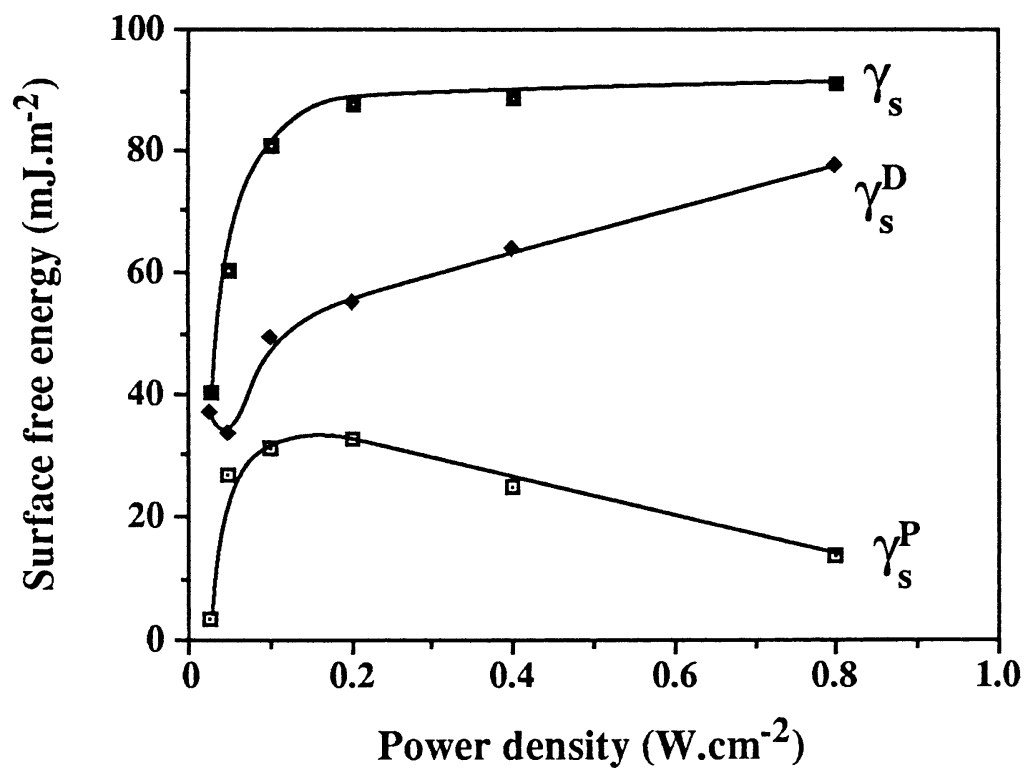

Fig. 7. Variation in dispersive component $\gamma_{\mathrm{s}}^{\mathrm{D}}$ and polar component $\gamma_{\mathrm{s}}^{\mathrm{P}}$ of the PET surface energy $\gamma_{\mathrm{s}}$ vs. r.f. power density. Reproduced from Ref. [105] with permission.

example, Silvain et al [57] reported improved adhesion of metals to annealed PET, due to the reorientation of the aromatic ring parallel to the surface $[89,116]$, which, in turn, favored the formation of metal-polymer complex. Other treatments include low-pressure discharge, applied to PP to increase the polar component of its surface energy and, consequently, its adhesion to $\mathrm{Al}$ [117], and reactive ion assisted interface bonding and mixing followed by annealing, applied to sputter deposited $\mathrm{Al}$ on polytetrafluoroethylene (PTFE) [118], used for interconnects in micro-engineering applications. Corona treatment of PET led to only minor differences of interfacial interactions compared to untreated PET [55]. Heat treatments have been found to improve wet adhesion of $\mathrm{Al}$ to PET [119]. The above findings, in terms of changes in surface roughness and polarity of semi-crystalline PET, are sketched in Fig. 6B. Amorphous regions exhibit increased roughness, whereas a higher density of active sites are found on crystalline regions. Additive particles initially embedded in the surface layers tend to protrude above the eroded polymer surface.

\subsection{Coating and interface defects}

The deposition technique and deposition conditions determine the final coating microstructure, and therefore the barrier performance of the coated polymer [120] as also its mechanical strength. Wertheimer and co-workers reported the superiority of PECVD coatings over PVD coatings [75,76]. In contrast to the former, the latter are characterized by columnar growth morphology, and their lower density explains their lower barrier performance. The presence of Ar gas during deposition of 


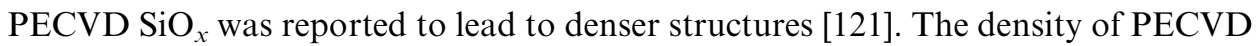
$\mathrm{SiO}_{x}$ coatings, and therefore their oxygen permeability, was found to be strongly dependent on process conditions such as input power, pressure, and $\mathrm{O}_{2} /$ precursor ratio, the maximum density being slightly larger than $2.2 \mathrm{~g} / \mathrm{cm}^{3}$ [122]. The density of evaporated $\mathrm{SiO}_{x}$ coatings was reported to be equal to $2.32 \mathrm{~g} / \mathrm{cm}^{3}$ by Fukugami et al. [123], value which is intermediate between the densities of amorphous $\mathrm{SiO}_{2}$ and bulk crystallized $\mathrm{SiO}_{2}$, respectively equal to approx. 2.2 and $2.6 \mathrm{~g} / \mathrm{cm}^{3}$. The higher density of evaporated silicon oxide thin films, compared to that of amorphous $\mathrm{SiO}_{2}$ goes along with the corresponding values of elastic constants. Young's modulus of fused quartz is equal to $72.9 \mathrm{GPa}$ [124], and the value for $\mathrm{SiO}_{x}$ coatings was reported to be equal to $79.5 \mathrm{GPa}$ from tensile testing of coated PET films [125], and to 93-134 GPa, depending on coating thickness, from Brillouin spectroscopy [126]. A mention should be made at this point as for the difficulty to determine the elastic properties of very thin films, and the bulge test technique appears as an interesting method to this end [127].

Generally speaking, two kinds of defects are found in thin oxide films, namely microdefects and nanodefects. On the one hand, microdefects comprise so-called pin-holes and microcracks [24,128], with sizes of the order of $1 \mu \mathrm{m}$. Microdefects in form of uncoated areas were detected in the case of PE substrates, which were related to the high roughness of the initial polymer surface [65]. A detailed characterization of microdefects was performed by Wertheimer and co-workers, using reactive ion etching in oxygen plasma followed by microscopy analyses [75,120,129]. These authors correlated the residual permeation of PECVD $\mathrm{SiO}_{x}$ on PET films to the measured density of pin-holes, found to be equal to $2000 / \mathrm{mm}^{2}$ for $8 \mathrm{~nm}$ thick coatings, and to $80 / \mathrm{mm}^{2}$ for $70 \mathrm{~nm}$ thick coatings. The latter defects were characterized by an approximately gaussian size distribution of diameters, with an average value equal to $0.6 \mu \mathrm{m}$. It should be pointed out that PECVD of organosilane precursors on polymer substrates leads to the formation of $\mathrm{SiO}_{x} \mathrm{C}_{y} \mathrm{H}_{z}$ films, as detailed by Deville et al [130]. Multilayer structures based on $\mathrm{SiO}_{x} \mathrm{C}_{y} \mathrm{H}_{z} / \mathrm{TiO}_{2}$ films on PC substrates were found to possess low pin-holes densities, of less than $100 / \mathrm{mm}^{2}$ [17]. On the other hand, nanodefects result from the non-equilibrium thermodynamic nature of the vapor process, as recently investigated using Monte Carlo simulations [131]. For nucleation site densities of $2 \mathrm{~nm}^{-2}$ typical of PET, the authors determine porosity as high as approximately $10 \%$. By contrast with the above analyses of microdefects, several studies concluded that nanodefects within the coating, rather than microdefects, control the permeation with oxygen $[62,132,133]$ and water, although with different mechanisms due to interactions with the coating itself $[62,133,134]$. In their permeation modeling of $\mathrm{O}_{2}$ through evaporated $\mathrm{SiO}_{x}$ coatings, Briggs and co-workers report pore size distributions in the range 2.7 to $4 \AA$ in coatings with thicknesses smaller than $90 \mathrm{~nm}$ [132]. In thicker coatings, sub-micron cracks would appear, thus leading to relaxation of deposition-induced internal stresses, as will be detailed in the next section.

The two types of defects are sketched in Fig. 6C. Also depicted is an interfacial region, characterized by a high density of $\mathrm{Si}-\mathrm{O}-\mathrm{C}$ and $\mathrm{Si}-\mathrm{C}$ bonds, as mentioned earlier, which determines the final functionality of the coated barrier film [72]. In the 
case of PECVD coatings, as a result of fragmentation/redeposition mechanisms in the early deposition stages, such a region may also consist of an organosilicon phase with $\mathrm{Si}-\mathrm{CH}_{x}$ bonds of tens of $\mathrm{nm}$, believed to improve adhesion and cohesion of the coated film [76]. The final defect structure of the thin coating is intimately linked to its internal stress state to which we now turn our attention.

\section{Internal stresses}

Internal stresses are inherent to most multimaterial assemblies, where dissimilar materials with different thermo-mechanical properties are processed together. In the case of coated films, such stresses clearly impact coating performance, and therefore must be controlled. Tensile stresses greater than the cohesive strength of the coating lead to cracks, as shown in Fig. 8 [9], and excessive levels of compressive stresses result in buckling phenomena. The influence of internal stresses on the properties of coated systems, particularly the adhesion of thin oxide films, has been examined extensively in case of glass [135] or metallic substrates [136], but, to a far less extent, in case of polymer substrates. The general lack of information is in spite of the fact that internal stresses have been shown to considerably change failure processes such as debonding at the interface, as analyzed by Wheeler and Osaki [137]. However,

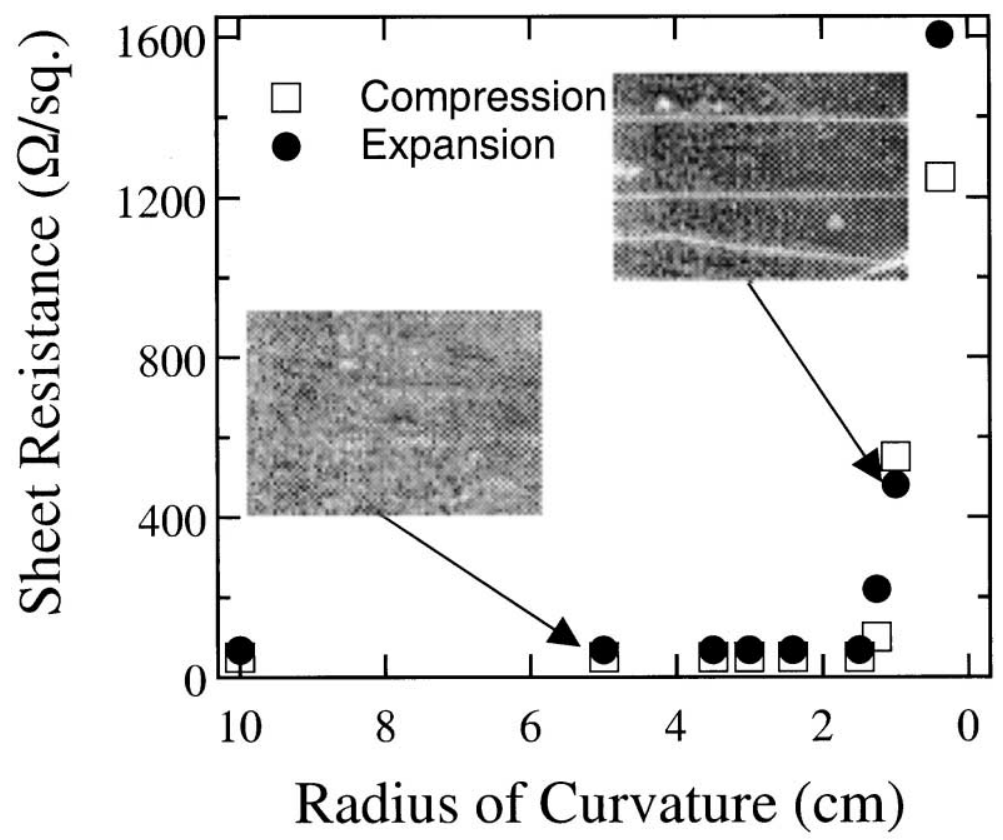

Fig. 8. Sheet resistance of $1.5 \%$ Ga-substituted $\mathrm{ZnO}$ films grown at $190{ }^{\circ} \mathrm{C}$ vs. bending stress. The micrographs were taken using an optical microscope at $\times 40$ magnification. Reproduced from Ref. [9] with permission. 
when such effects are accurately determined, the knowledge of residual stresses proves to be advantageous to measure adhesion, because the stress change providing the driving force for debonding is elastic, whatever the magnitude of the initial coating stress [138]. General overviews on this subject have been given by Atkinson [139] and Clyne [140]. In the former case of glass substrates, compressive residual stresses were found to increase the adherence strength by increasing the resistance to the tensile cracking failure. As shown in Fig. 9, compressive stresses also improve oxygen-barrier efficiency of titania coatings, with related increase in crystallinity and compactness resulting from increased kinetic energy of the sputtered particles [7]. Whether this interesting result holds for $\mathrm{SiO}_{x}$ coatings, which do not crystallize, is open for research.

In brief, the influence of internal stresses on the stress transfer property of an interface is a priori unknown, although, in composite materials, it was recognized that it could be considerable (see for instance Ref. [141]). Let us first examine how internal stresses are generated in the coated film, and how to measure them, after what methods to control these stresses will be presented. The influence of processinduced stresses on coating failure and adhesion to the substrate are treated in following sections. One should note that the essential of the work related to stress

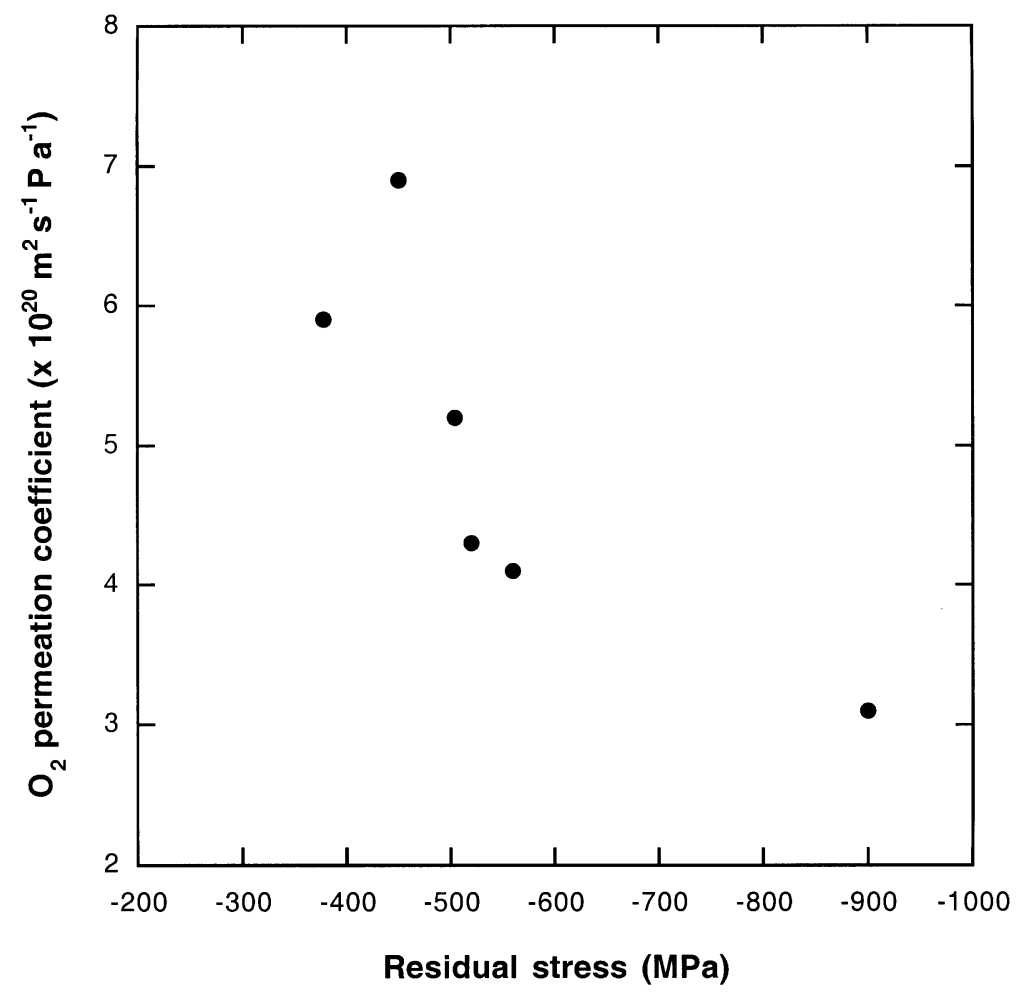

Fig. 9. Oxygen permeation of $\mathrm{TiO}_{2}$ coated PET films vs. coating residual stress (data from Ref. [7]). 
build-up in thin films considers crystalline and epitaxial thin films (see for instance the review of intrinsic stresses in polycrystalline thin films [142], Refs. [143-145], and the monographs of Ohring [48] and Campbell [146]).

\subsection{Generation of internal stresses in thin coatings on polymers}

The two main sources for internal stress generation during deposition of thin oxide coatings on polymer substrates are (i) growth and associated disorder, and (ii) temperature gradients. The former leads to so-called intrinsic stresses, and the latter to thermal stresses, both of which are detailed as follows. Additional internal stresses may result from the subsequent conversion operation, including elastic recovery of the substrate, upon unloading after coating deposition. These stresses, of thermomechanical origin, will add to the two previously mentioned stresses, and the total stress may eventually evolve during long-term use. These subjects are also treated thereafter.

\subsubsection{Intrinsic stress}

Physical as well as chemical vapor deposition techniques, albeit of considerably differing nature, are non-equilibrium thermodynamics processes, and lead to a quenched disorder state in the oxide coating. This disorder is associated with defects in the $\mathrm{Si}-\mathrm{O}$ network, such as nanovoids [62], of sizes ranging from 2 to $4 \AA$ [132], dangling $\mathrm{Si}-\mathrm{OH}$ bonds and, generally speaking, with intrinsic internal stresses. The intrinsic stress is mostly insensitive to the type of substrate, and to coating thickness. This was demonstrated in case of metal coatings on silicon wafer substrates [147], and silica coatings on Si and Ge substrates [136], although, in both works, the possible effects due to the anisotropic nature of the substrate were ignored. In case of sputtered metallic coatings, the rearrangement of deposited atoms with high kinetic energy decreases the intrinsic tensile stress and favors the obtention of high density coatings [148]. On the contrary, $\mathrm{SiO}_{x}$ evaporated on crystalline $\mathrm{Si}$ was reported to be under tensile stress [149], as a result of high porosity, and sputtered oxide films with high density, promote high compressive stress [7].

Following Ohring [48], it appears that no model exists which would provide realistic prediction of the intrinsic stress state in $\mathrm{SiO}_{x}$ coatings on polymer substrates. Such a model for stress build-up has yet to be developed, which, at best, would be limited to specific material systems and type of deposition technique. Most grown oxide coatings are under compression (e.g. Ref. [150,151]).

\subsubsection{Thermal stress}

Besides the generation of quenched disorder in the coating, heat is dissipated in the polymer substrate during the deposition process, resulting in a rapid temperature increase of the substrate. Stresses subsequently build-up during the final cooling of the coated film due to large differences in elastic moduli and in coefficients of thermal expansion between the oxide and the polymer. According to BenAmor et al. [7], the 
thermal stress in titania coatings formed on PET substrates represents approx. 10\% of the total stress. A similar result was reported for TiN coatings on ABS substrates [152]. Assuming a thermo-elastic behavior, the in-plane thermal stress is expressed following:

$$
\sigma_{i ; \text { th }}=\frac{E_{\mathrm{c}}}{\left(1-v_{\mathrm{c}}\right)} \int_{T_{1}}^{T_{2}}\left\{\alpha_{\mathrm{s}}(T)-\alpha_{\mathrm{c}}(T)\right\} \cdot d T
$$

where the prefactor of the RHS represents the coating biaxial modulus, $E_{\mathrm{c}}$ and $v_{\mathrm{c}}$ being the coating Young's modulus and Poisson's ratio, respectively, and $\alpha_{\mathrm{s}}$ and $\alpha_{\mathrm{c}}$ are the linear coefficients of thermal expansion (LCTE) of the substrate and coating, respectively, both being a-priori temperature dependent factors. The average LCTE of $\mathrm{SiO}_{2}$ between 20 and $320{ }^{\circ} \mathrm{C}$ is equal to approx. $0.5 \cdot 10^{-6} \mathrm{~K}^{-1}[153,154]$. The average value of the LCTE of $\mathrm{SiO}_{x}$ between $23{ }^{\circ} \mathrm{C}$ and $350{ }^{\circ} \mathrm{C}$ was reported to be equal to $2.7 \cdot 10^{-6} \mathrm{~K}^{-1}$, where the stoichiometric index $x$ reflects the presence of a mixture of $\mathrm{SiO}_{2}, \mathrm{SiO}_{1.5}, \mathrm{SiO}$ and $\mathrm{SiO}_{0.5}$ [155]. $T_{1}$ represents the temperature of the coated film at the end of the deposition operation, and $T_{2}$ represents the service temperature. Very few studies have investigated the evolution of the temperature of polymer substrates during thin film deposition. Gonzalez et al. report the chemical vapor deposition of dense and adherent silicon oxide films at substrate temperatures of $100{ }^{\circ} \mathrm{C}$ [156], and remote plasma-enhanced CVD techniques may be used also to limit substrate heating [157]. Yamamoto et al. [158], in spite of a very confusing presentation, report temperature increases as low as $0.4-3{ }^{\circ} \mathrm{C}$ for a $12 \mu \mathrm{m}$ thick PET substrate during plasma irradiation. The temperature of PET during RF-magnetron sputtering of $\mathrm{TiO}_{2}$ was estimated to be of the order of several $10^{\circ} \mathrm{C}$, from the data reported in the work of Ben Amor et al. [7]. Similar values were measured by Wendt et al. [159], for the deposition of $\mathrm{ZnO}: \mathrm{Al}$ thin films, and by Trakhtenberg et al. [160]. in their analysis of DLC sputtering on PE substrates. These authors found that optimal adhesion was achieved when the substrate temperature was in the close vicinity of the polymer melting point. In addition to the generation of thermal stress, water vapor can be released from the polymer due to substrate heating, thus increasing the oxygen content in the deposited thin film [161]. Modeling of the kinetics of substrate temperature were recently carried out by Mohnjuk et al. in the case of a RF plasma deposition [162], and by Andritschky et al. [148] in case of magnetron sputtering. Taking the LCTE of $\mathrm{SiO}_{x}$ equal to $2 \cdot 7 \cdot 10^{-6} \mathrm{~K}^{-1}$ into account, Young's modulus $E_{\mathrm{c}}$ equal to $80 \mathrm{GPa}$, Poisson's ratio $v_{\mathrm{c}}$ equal to 0.2 , and assuming an average LCTE of the polymer substrate $\alpha_{\mathrm{s}}$ equal to $5 \cdot 10^{-5} \mathrm{~K}^{-1}$, a final deposition temperature $T_{1}$ equal to $100{ }^{\circ} \mathrm{C}$ and a service temperature $T_{2}$ equal to $20^{\circ} \mathrm{C}$, one calculates a typical value for the compressive thermal stress $\sigma_{i}$; th $=$ $\left(E_{c} /\left(1-v_{\mathrm{c}}\right)\right)\left(\alpha_{\mathrm{s}}-\alpha_{\mathrm{c}}\right) \cdot\left(T_{2}-T_{1}\right)=-378 \mathrm{MPa}$, which corresponds to a compressive strain, of thermal origin, equal to approximately $-0.5 \%$. This value is in fact comparable to the residual strains of evaporated $\mathrm{SiO}_{x}$ coatings on PET films, reported in Fig. 10. This result suggests that the thermal stress dominates the total stress for this type of coating. 


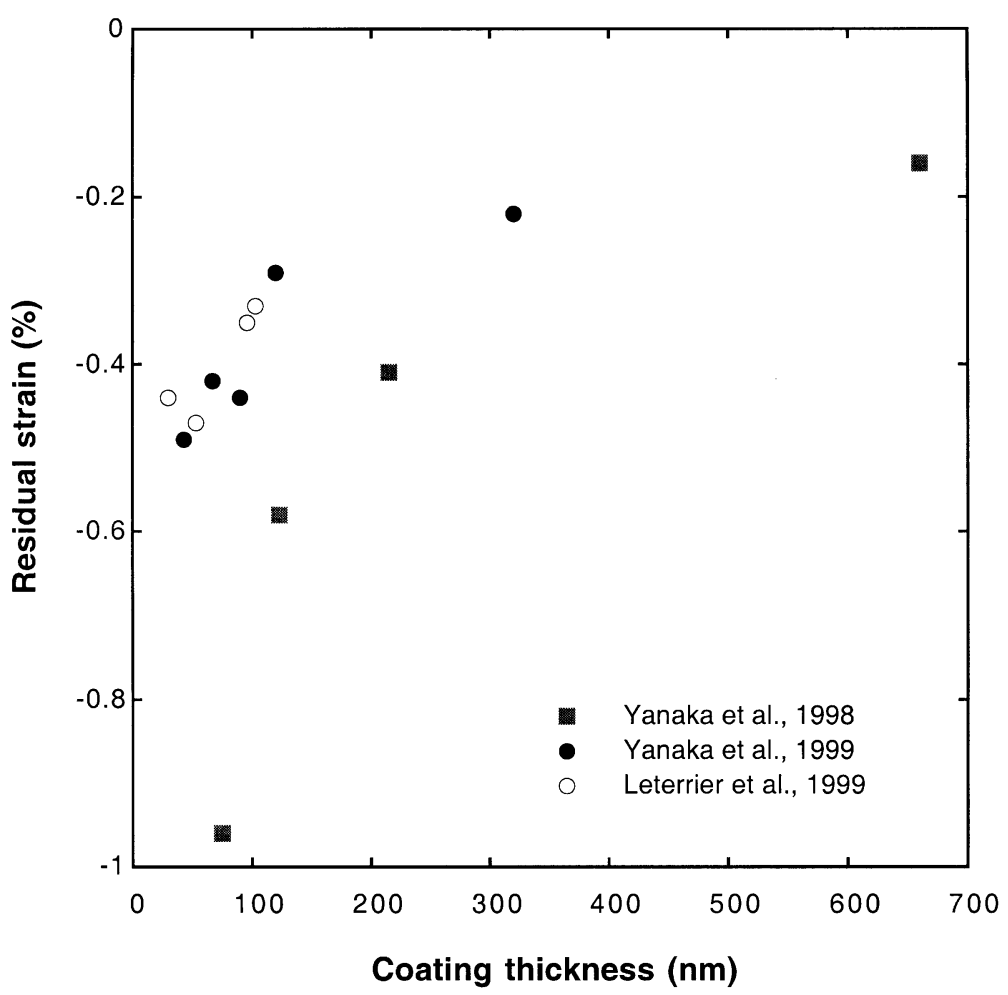

Fig. 10. Residual compressive stress vs. coating thickness for evaporated $\mathrm{SiO}_{\mathrm{x}}$ coatings on PET films (data from refs. [163-165]).

Takeda and co-workers $[132,163,164]$ and Leterrier et al. [165] found that, in case of evaporated $\mathrm{SiO}_{x}$ coatings on PET, thicker coatings are associated with lower compressive stresses, thus indicating that stress relaxation processes occur as the coating growths. These relaxation processes result from the formation of nanoscopic cracks, as was indicated in the preceding section. The same tendency for the compressive stress was observed by Grimberg et al. [152] for crystalline TiN coatings on ABS. Stress relaxation was, in that case, attributed partly to improved microstructure of thicker films, and partly to the presence of a ductile metallic underlayer. These results are contrary to those of Ben Amor et al. [7], who report increasing stress in $\mathrm{TiO}_{2}$ coatings on PET at higher coating thickness, due to the accumulation of growth defects and impurities. By contrast, decrease compressive stress is obtained at increased oxygen partial pressure, due to the development of a columnar microstructure, which favors the adsorption $\mathrm{OH}$-groups, and corresponding enhancement of attractive forces in the coating microstructure. This latter finding could also be relevant to the case of PECVD $\mathrm{SiO}_{x}$ coatings, also characterized by columnar microstructures $[62,133]$. Increasing compressive stress in $\mathrm{SiO}_{2}$ thin films was observed with increasing film density [166]. 


\subsection{Stress optimization during conversion operations}

In their study of stoichiometric $\mathrm{SiO}$ films formed by molecular-beam deposition (MBD) in high vacuum, Chand et al. [155] found that the thin films were under a tensile stress smaller than $100 \mathrm{MPa}$, which is significantly lower than that observed in other dielectric films. In fact, this result may be due to an inappropriate use of Stoney's stress calculation [167] detailed thereafter, only valid in the limit of very small coating/substrate thickness ratio. At low deposition rates and at high pressures of oxygen, $\mathrm{SiO}_{x}(1 \leqslant x \leqslant 2)$ films were obtained. Introduction of a small amount of oxygen during deposition reduces the tensile stress; at an $\mathrm{O}_{2}$ pressure of $5 \cdot 10^{-7}$ Torr and above, the films were in compression. This allows the tunability of stress, and deposition of films essentially free from stress.

In addition to the above-mentioned intrinsic and thermal stresses, the conversion operations in which the coated polymer is processed into the final product are likely to change the overall stress state of the coated film. In the case of web coating applications, the polymer film is usually unwound under tension to ensure flatness during the deposition process. The unloading of the coated film during any subsequent conversion operation will give rise to additional compressive stress within the thin coating, the value of which can be directly approximated from the tensile force applied in the web process. In previous investigations, the amount of tensile force during PECVD deposition of $\mathrm{SiO}_{x}$ on various polymer films, was in fact controlled to tailor the state of stress in the coating [168]. Moreover, calendering processes with other polymer films susceptible to shrinkage will induce further compressive stresses in the thin coating [169]. Heat-set treatments were developed to overcome orientation relaxation and crystallization shrinkage of the polymer if the temperature is high enough. An example is the sterilization cycle routinely applied to pharmaceutical packaging, in which the multilayer film is held for $20 \mathrm{~min}$ at $121{ }^{\circ} \mathrm{C}$, i.e. in the cold-crystallization regime of the polymer substrates such as PET. Generally speaking, process temperature cycles can be optimized to tailor the stress state in the thin coating prior to the use phase of the product, to avoid potential damage, and loss of barrier performance [170].

Eventually, during use, the internal stress state of the coated polymer changes with time. This is due, once the one hand, to the time-dependent nature of polymers and, on the other hand, to aging phenomena in the oxide thin film, particularly those resulting from interactions with moisture [166]. Polymers are organic materials that exhibit so-called viscoelastic properties, and which are usually brought out of thermodynamic equilibrium when cooled to below their glass transition temperature. The resulting time dependent phenomena have been particularly studied in the case of biaxially stretched PET films [171,172]. Polymers are also permeable to small molecules, which may lead to physical swelling phenomena, hence, to changes in stress state. The issue of long-term evolution of process-induced internal stresses, and related changes in interfacial adhesion between PET and $\mathrm{SiO}_{x}$ are detailed in a recent work, in which a proportional relation between both factors was established $[169,173]$. In addition, long-term exposure of thin oxide films to ambient air may affect their stress state. As shown in Fig. 11, hydration of $\mathrm{SiO}_{2}$ thin films by water vapor during aging leads to a relaxation of the deposition-induced compressive 


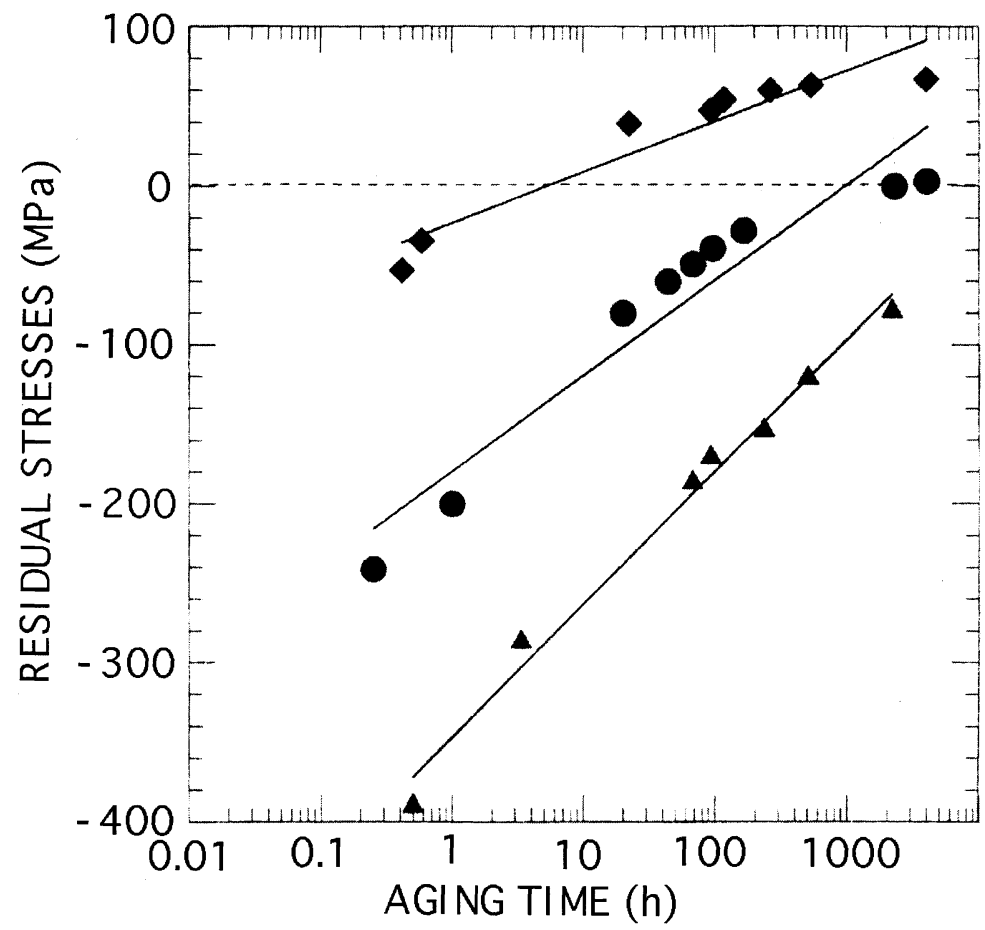

Fig. 11. Aging time effect on the residual stresses in $\mathrm{SiO}_{2}$ films deposited on $\mathrm{Si}$ substrates at room temperature with a base pressure of $2 \cdot 10^{-5} \mathrm{mbar}(\boldsymbol{\Delta})$ or under an oxygen partial pressure of $1 \cdot 10^{-4} \mathrm{mbar}(\mathbf{O})$ and $3 \cdot 10^{-4}$ mbar $(\bullet)$; the mass density of these films were $1.97,1.79$, and $1.49 \mathrm{~g} \mathrm{~cm}^{-3}$, respectively. Reproduced from Ref. [174] with permission.

stress, and to a compressive-to-tensile transition [136,174]. Corrosion stress cracking was observed in mechanically constrained plasma polymerized hexamethyldisiloxane (HMDSO) thin films, initially under compressive stress, upon exposure to alcohols [175]. Also, changes in intrinsic stress in $\mathrm{SiO}_{x}$ films, formed by PECVD using a tetraethoxysilane (TEOS) precursor, upon long-term exposure of to an ambient atmosphere were reported to lead to cracks [176]. This problem was overcome using an ethyltrimethylsilane (ETMS) precursor, which allowed higher film density. Similar stress changes upon annealing were reported by Haque et al. [177]. The authors indicate that moisture plays a key role in such phenomena, as it diffuses into the film and reacts with strained $\mathrm{Si}-\mathrm{O}$ bonds and reconstructs them into a minimum energy configuration. Capping the $\mathrm{SiO}_{2}$ film with $\mathrm{Si}_{x} \mathrm{~N}_{y}$ to prevent moisture diffusion leads to considerable improvement in stress stability.

\subsection{Stress analysis}

The presence of internal stresses leads to a curling of the coating/substrate assembly: stresses are compressive in the coating when it is located on the convex side of the curl. Any change in the internal stress state will result in a change in the 
radius of curvature. Extensive studies have examined and modeled this phenomenon, as reviewed by Benadbi and Roche [178]. Most of these works follow the onedimensional analysis of Stoney [167], who derived the classic expression relating the radius of curvature of the coated film, $R$, to its internal stress, $\sigma_{i}$ :

$$
\sigma_{i}=-\frac{E_{\mathrm{s}} h_{\mathrm{s}}^{2}}{6 R h_{\mathrm{c}}}
$$

where $E_{\mathrm{s}}$ is the Young's modulus of the substrate, $h_{\mathrm{s}}$ and $h_{\mathrm{c}}$ are the substrate and coating thickness, respectively. The usual convention, where compressive stresses are negative, was adopted. The above equation disregards the effect of substrate Poisson's ratio and of coating thickness, which, in the case of a (oxide) coating-to(polymer) substrate thickness ratio larger than approx. $10^{-3}$ can not be ignored. Timoshenko [179] initially proposed to correct for higher orders of the thickness ratio, $h_{\mathrm{c}} / h_{\mathrm{s}}$, and refined corrections to Stoney's equation [Eq. (3)], accounting for different values of Poisson's ratio and different substrate thickness and substrate width have since been derived. Such corrections turn out to be less than a few percent if the radius of curvature, $R$, is greater than, or approximately equal to $W^{2} / h_{\mathrm{s}}$, where $W$ represents substrate width [146]. The case of thick films was treated by Brenner and Senderoff [180]. Stoney's equation was corrected by Hofmann for the case of biaxial in-plane stress [181]. Alternative expressions derived in the past decades are numerous, as reported in Table 2, a critical assessment of which can be found in Refs. [178,182]. The use of the biaxial in-plane modulus provides relevant determination of in-plane stress in case of anisotropic substrates possessing thirdorder or higher z-axis symmetry such as single crystals [183]. The case of an anisotropic stress state, related to magnetostriction effects, is treated by van de Riet [184]. Further theoretical analyses of stress distributions were carried out by Townsend et al. for the general case of multilayer laminates [185].

\section{Failure initiation and coating strength}

The strength of brittle oxide materials depends on the behavior of microcracks under stress [186]. Fig. 12 shows crack initiation in PECVD $\mathrm{SiO}_{x}$ coating on PET [254], and PECVD $\mathrm{SiO}_{x}$ coatings on PA12 [188]. In both instances, crack initiation on microscopic defect sites is evident, as also described in Ref. [187]. A remarkable observation is that the spherulitic crystalline structure of the PA12 substrate does not affect crack initiation mechanisms. In thin films, microcracks comprise growth heterogeneities and surface flaws, related to the initial surface morphology of the polymer substrate. Indeed, the evolution of the size of sputtered $\mathrm{TiO}_{2}$ fragments on PET under tension shown in Fig. 13, measured by BenAmor et al. [78], suggest that untreated PET provides the highest coating crack onset strain, and various cold plasma treatments decrease this value. An interesting study, where calibrated particles were purposely introduced at the coating/substrate interface, confirmed the detrimental effect of stress concentrations on coating strength [189]. 
Table 2

Theoretical expressions of the coating internal stress

\begin{tabular}{|c|c|c|c|c|c|}
\hline Author & Coating internal stress $\sigma_{i}^{\mathrm{a}}$ & Eq. & $\begin{array}{l}\text { Stress ratio }{ }^{\mathrm{b}} \\
\sigma_{i} / \sigma_{\text {Stoney }}\end{array}$ & Remarks & Ref. \\
\hline Stoney, 1909 & $\sigma_{\text {Stoney }}=-\frac{E_{\mathrm{s}} h_{\mathrm{s}}^{2}}{6 R h_{\mathrm{c}}}$ & (3) & 1 & $\begin{array}{l}\text { Valid in the limit of infinitely thin coatings; } \\
\text { no-in-plane deformation of the substrate }\end{array}$ & [167] \\
\hline Timoshenko, 1925 & $-\frac{E_{\mathrm{s}} h_{\mathrm{s}}^{2}}{6 R h_{\mathrm{c}}}\left(\frac{1+2 \alpha \beta\left(2+3 \beta+2 \beta^{2}\right)+\alpha^{2} \beta^{4}}{1+\beta}\right) \mathrm{c}$ & (4) & 1.619 & $\begin{array}{l}\text { Case of thick coatings; no in-plane } \\
\text { deformation of the substrate }\end{array}$ & {$[179,319]$} \\
\hline $\begin{array}{l}\text { Brenner and } \\
\text { Senderoff, } 1949\end{array}$ & $-\frac{E_{\mathrm{s}} h_{\mathrm{s}}^{2}}{6 R h_{\mathrm{c}}}\left(1+\frac{h_{\mathrm{c}}}{h_{\mathrm{s}}+h_{\mathrm{c}}}\left(4 \frac{E_{\mathrm{c}}}{E_{\mathrm{s}}}-1\right)\right)$ & $(5)$ & 1.612 & $\begin{array}{l}\text { Case of thick coatings; the original equation } \\
\text { was derived for biaxial stress state, and the } \\
\text { second and higher order terms in thickness } \\
\text { ratio are omitted here. }\end{array}$ & {$\left[180,320^{\mathrm{d}}\right]$} \\
\hline Inoue, 1958 & $-\frac{E_{\mathrm{s}} h_{\mathrm{s}}^{2}}{6 R h_{\mathrm{c}}}\left(\frac{\left(1-\alpha \beta^{2}\right)^{3}(1-\alpha)+(\alpha \beta(\beta+2)+1)^{3}+\alpha\left(\alpha \beta^{2}+2 \beta+1\right)^{3}}{2(1+\beta)\left(1+\alpha \beta^{3}\right)}\right) \mathrm{c}$ & (6) & 2.165 & $\begin{array}{l}\text { Case of thick coatings; accounts for in- } \\
\text { plane substrate deformation }\end{array}$ & {$[321]$} \\
\hline Glang et al., 1965 & $-\frac{E_{\mathrm{s}} h_{\mathrm{s}}^{2}}{(6 R-3 \delta) h_{\mathrm{c}}}$ & (7) & - & $\begin{array}{l}\text { The original equation was derived for } \\
\text { biaxial stress state; } \delta \text { stands for substrate } \\
\text { deflection over half of a wafer length }\end{array}$ & {$[322]$} \\
\hline Röll, 1976 & $-\frac{E_{\mathrm{s}} h_{\mathrm{s}}^{2}}{6 R h_{\mathrm{c}}}\left(1+\frac{h_{\mathrm{c}}}{h_{\mathrm{s}}}\left(4 \frac{E_{\mathrm{c}}}{E_{\mathrm{s}}}-1\right)\right)$ & (8) & 1.617 & $\begin{array}{l}\text { Second and higher order terms in thickness } \\
\text { ratio neglected; no in-plane deformation of } \\
\text { the substrate; homogeneous through- } \\
\text { thickness stress distribution }\end{array}$ & {$[323]$} \\
\hline Atkinson, 1995 & $-\frac{E_{\mathrm{s}} h_{\mathrm{s}}^{3}}{6 R h_{\mathrm{c}}^{2}\left(1+h_{\mathrm{s}} / h_{\mathrm{c}}\right)}$ & (9) & 0.992 & $\begin{array}{l}\text { The initial equation was derived for biaxial } \\
\text { stress state }\end{array}$ & {$\left[139,324^{\mathrm{e}}\right]$} \\
\hline Yanaka, 1998 & $-\frac{E_{\mathrm{s}} h_{\mathrm{s}}^{2}}{6 R h_{\mathrm{c}}}\left(\frac{1+4 \alpha \beta}{(1+\beta)(1+\alpha \beta)}\right) \mathrm{c}$ & (10) & 1.394 & $\begin{array}{l}\text { Based on 2D formula for thermal } \\
\text { transformation of cross-ply laminates }\end{array}$ & {$[163]$} \\
\hline
\end{tabular}

a Uniaxial in-plane stress state (i.e. Poisson's ratio effects are neglected). In case of biaxial in-plane stresses, the expression should be divided by $1-v_{\mathrm{s}}$, where $v_{\mathrm{s}}$ is the Poisson's ratio of the polymer substrate.

b The ratio was calculated with the following values: $h_{\mathrm{c}}=100 \mathrm{~nm} ; h_{\mathrm{s}}=12 \mu \mathrm{m} ; E_{\mathrm{c}}=75 \mathrm{GPa} ; E_{\mathrm{s}}=4 \mathrm{GPa}$.

c $\alpha=E_{\mathrm{c}} / E_{\mathrm{s}}$ (uniaxial stress) or $\alpha=E_{\mathrm{c}}\left(1-v_{\mathrm{s}}\right) / E_{\mathrm{s}}\left(1-v_{\mathrm{c}}\right)$ (biaxial stress), and $\beta=h_{\mathrm{c}} / h_{\mathrm{s}}$

d The authors have used an approximation of the original equation derived in [180].

e Reference is made to Ref. [181]. 


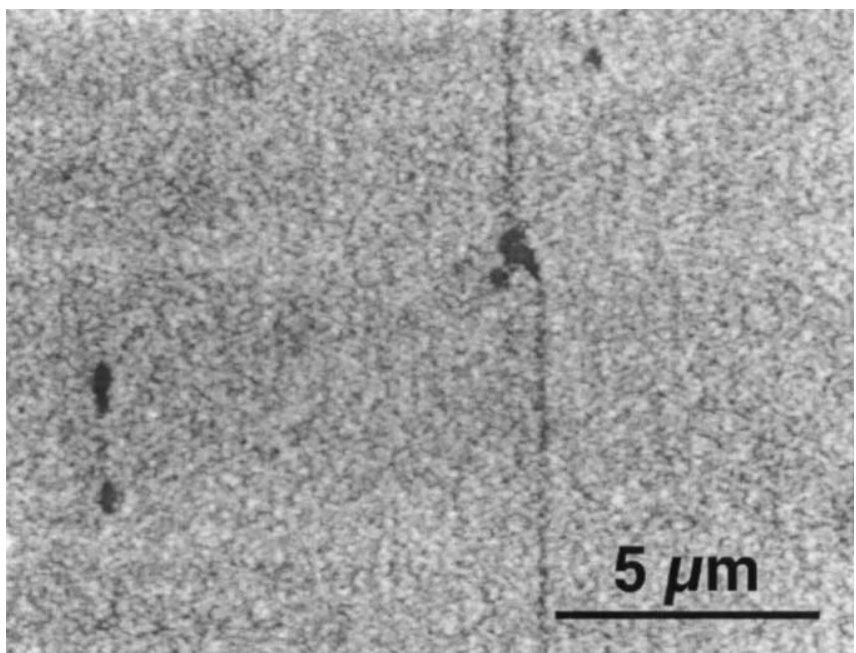

(a)

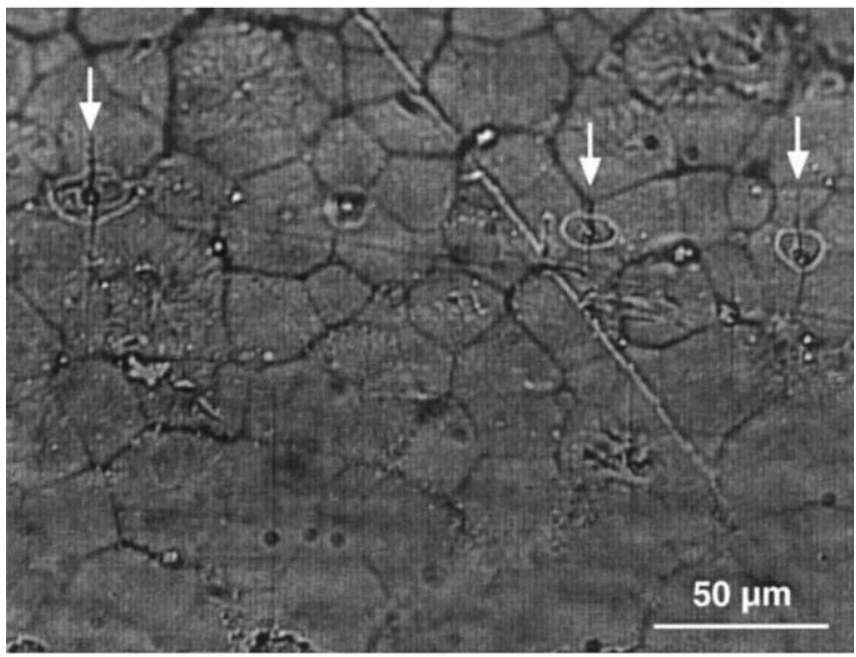

(b)

Fig. 12. Micrographies of crack initiation sites. PECVD $\mathrm{SiO}_{x}$ coating on PET (a) [254]. PECVD $\mathrm{SiO}_{x}$ coating on PA12 (b) [188].

It should be pointed out that an accurate measurement of the coating crack onset strain, within $0.1 \%$ error, is required to use the models described in the next sections. Due to elastic recovery of the substrate, any cracks present on samples strained to less than the substrate yield strain will close and will not be visible if the sample is unloaded. In-situ tests, where the material is maintained under stress, resolve this drawback [190]. 


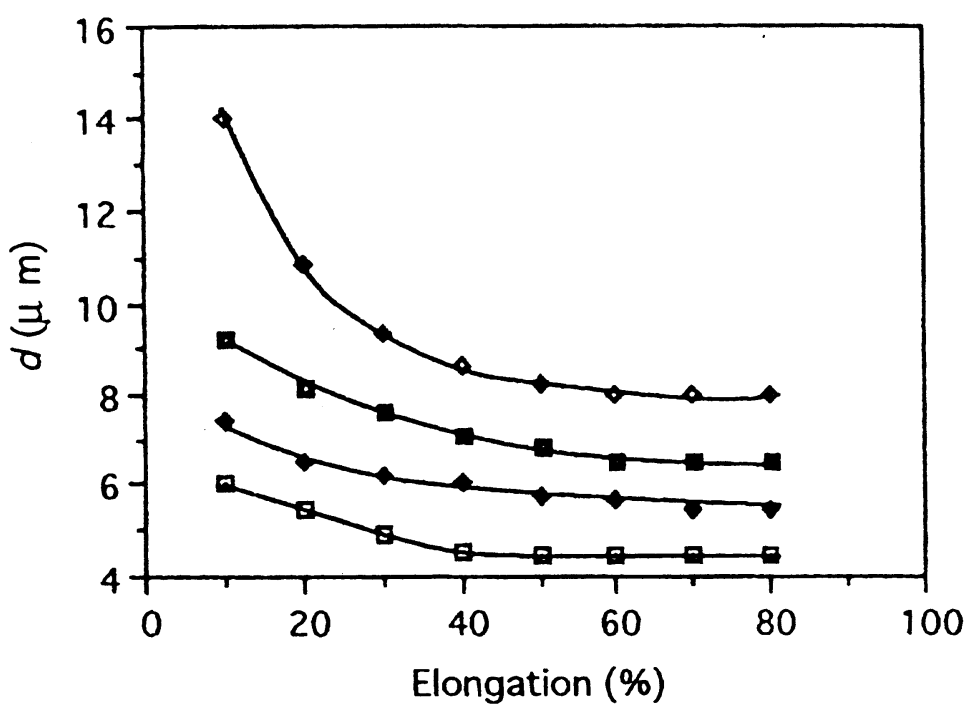

Fig. 13. Fragment widths in titania coatings deposited by reactive sputtering vs. elongation for a reference sample $(\diamond)$ and for samples in which the PET surface was treated by different cold plasmas: (ם) Ar,

$(\diamond) \mathrm{Ar}+5 \% \mathrm{O}_{2},(\square) \mathrm{CO}_{2}$. Reproduced from Ref. [78] with permission.

\subsection{Linear elastic fracture mechanics approach for crack onset prediction}

To start with, the classical energy-balance analysis of the extension of an isolated crack in a solid under stress by Griffith [191] provides a rough estimate of typical flaw size. In uniaxial tension, this analysis leads to the following failure criteria, which relates the strength, $\sigma_{\max }$, to coating properties (Young's modulus, $E_{\mathrm{c}}$ and surface energy, $\gamma_{\mathrm{c}}$ ), and to half of the critical crack length, $c$ :

$$
\sigma_{\max }=\left(2 E_{\mathrm{c}} \gamma_{\mathrm{c}} / \pi c\right)^{1 / 2}
$$

Assuming a strength $\sigma_{\max }$ of the coating of infinite size equal to $3 \mathrm{GPa}$, a modulus equal to $80 \mathrm{GPa}$, and a surface energy $\gamma_{\mathrm{c}}$ equal to $5 \mathrm{~J} / \mathrm{m}^{2}$ leads to a critical flaw size, $2 c$, of approximately $50 \mathrm{~nm}$, that is, of comparable dimension of coating thickness. The various kinds of flaws are associated with stress concentrations, whose magnitude depends on the shape of the flaw, as initially studied by Inglis in the case of an elliptical hole in a plate [192]. The theoretical analysis of the corresponding plane stress field in the hole vicinity can be found in Ref. [193]. Real coatings contain a distribution of flaws, hence a distribution of strength, whose statistical nature will be treated in a further section.

Linear elastic fracture mechanics (LEFM) models have been successfully employed for crack onset and crack density prediction in laminated composites [194], and also extended to coating cracking analysis under uniaxial loading [195]. The energy balance equation for crack propagation implies that the strain energy released due to crack growth equals coating fracture toughness, $G_{\mathrm{c}}: G_{\mathrm{c}} h_{\mathrm{c}}=\Delta A-\Delta W$, where $\Delta A$ and 
$\Delta W$ are the work done by the applied load, and the strain energy released due to crack extension through the coating (all per unit width of the film). Since the random nature of fracture is not considered, fracture strain depends on geometrical parameters, that is coating and substrate thickness. A direct implication of the energetic approach is that, for elastic materials, the coating strain at failure scales with the inverse of the square root of its thickness [195-200], which is also the case for cross-ply laminate composites [194,201]. Expressions for crack onset strain are reproduced in Table 3.

The simplest analytical approach for stress redistribution calculation is the shear lag model. This approach was adopted by Laws and Dvorak [201] to solve the energy release rate equation, using a non-dimensional shear lag parameter, $\xi$, determined by fitting the experimental data. The corresponding crack onset expression was found to scale with the inverse of the square root of coating thickness [Eq. (12) in Table 3]. A further expression for strain energy release rate was derived by Nairn and Kim $[195,200]$ by minimizing the complementary energy of the film, assuming that the axial stress in coating and substrate does not depend on the thickness coordinate [Eq. (13) in Table 3]. Both shear-lag and variation mechanics solutions can be applied to extrapolate crack onset strain vs. coating thickness, providing that the parameter $\xi$ or the coating toughness $G_{\mathrm{c}}$ are fitted by testing one film with a given coating thickness. Another approach was proposed recently by Takeda and co-workers [163] to calculate the crack onset stress, with the assumption that the additional displacement in the substrate due to cracking varies linearly in the thickness direction [Eq. (14) in Table 3]. The corresponding crack onset strain is found inversely proportional to $h_{\mathrm{c}}^{1 / 4}$.

The above derivations [Eqs. (12)-(14) in Table 3] are reproduced in Fig. 14 against experimental data obtained for $\mathrm{SiO}_{x}$ coatings of thickness ranging from 30 to 160 $\mathrm{nm}$, formed by reactive evaporation on PET substrate. Since a direct measurement of the coating fracture toughness $G_{\mathrm{c}}$ was not available, curve fit to experimental data was done with adjustable $\xi$ [Eq. (12)] or adjustable $G_{\mathrm{c}}$ [Eqs. (13) and (14)] values. The measured decrease of crack onset strain with increasing coating thickness is reproduced with reasonable accuracy by the models, however with considerably different values of the fitting parameters. The first shear lag model [Eq. (12)] is hampered by the presence of the empirical parameter $\xi$. The apparent coating toughness $G_{\mathrm{c}}$ is found to be equal to $60 \mathrm{~J} / \mathrm{m}^{2}$ in the case of the variational model [Eq. (13)], and to $76 \mathrm{~J} / \mathrm{m}^{2}$ in the case of the shear lag model including the linear variation of the additional displacement in the substrate due to cracking [Eq. (14)]. Both values are very high, compared to the fracture toughness of bulk glass, of the order of $10 \mathrm{~J} / \mathrm{m}^{2}$ [202], value which is obviously an upper bound for the defect containing oxide coating. This discrepancy is likely to arise from neglecting plastic effects in the substrate, at the interface vicinity.

\subsection{Case of a plastic interface}

For a ductile substrate, crack propagation can also involve small-scale yielding at the coating-substrate interface, and introduces a dissipative term in the energy balance: $G_{\mathrm{c}} h_{\mathrm{c}}+W_{\mathrm{d}}=\Delta A-\Delta W$. The term $W_{\mathrm{d}}$ is the energy dissipated by deforming the plastic interface per unit width of the film, found to dominate the total work of 
Table 3

Theoretical expression for crack onset strain vs. coating thickness, $h_{\mathrm{c}}$. The parameters $E_{\mathrm{s}}, E_{\mathrm{c}}$, and $E$ are the substrate, coating and film moduli, respectively, and $h_{\mathrm{s}}$ is the substrate thickness

\begin{tabular}{llll}
\hline Author & Crack onset strain $\epsilon_{\text {onset }}$ & Eq. Scaling & Remark \\
\hline Laws and Dvorak, 1989 & $\sqrt{\frac{2 G_{\mathrm{c}} \xi h_{\mathrm{s}} E_{\mathrm{s}}}{h_{\mathrm{c}}\left(h_{\mathrm{s}}+h_{\mathrm{c}}\right) E_{\mathrm{c}} E}}$ & (12) $h_{c}^{-1 / 2}$ & $\begin{array}{l}\text { The factor } \xi \text { is a non-dimensional shear lag parameter } \\
\text { determined by fitting the above equation to } \\
\text { experimental data. }\end{array}$
\end{tabular}

Nairn and Kim, 1992

$$
\sqrt{\frac{G_{\mathrm{c}}}{E_{\mathrm{c}}^{2} C_{3} h_{\mathrm{c}} \lim _{D \rightarrow 0} Y(D)}}-\varepsilon_{\mathrm{rc}}^{\mathrm{a}}
$$

Minimization of the complementary energy of the film, assuming that the axial stress in coating and substrate does not depend on the thickness coordinate. $\mathrm{C}_{3}$ is a geometrical parameter, and $\mathrm{Y}(\mathrm{D})$ is a calibration function which depends on crack density.

Takeda and co-workers, $1998 \sqrt{\frac{2 G_{c}}{3 E_{\mathrm{c}}^{3 / 2} \sqrt{\left(1+v_{\mathrm{c}}\right) h_{\mathrm{c}} h_{\mathrm{s}} / E_{\mathrm{s}}}}}-\varepsilon_{\mathrm{rc}}^{\mathrm{a}}$

Assumes that the additional displacement in the substrate due to cracking varies linearly in the thickness direction.

Hu and Evans, 1989

$$
G_{\mathrm{c}}=\left(\frac{\sigma_{\text {onset }}^{2} h_{\mathrm{c}}}{E_{\mathrm{c}}}\right)\left(\frac{\sigma_{\text {onset }}}{3 \tau}+\pi F(\Sigma)\right)
$$

Leterrier and Andersons, $2000 \frac{1-v_{\mathrm{c}}^{2}}{1-\nu v_{\mathrm{c}}} 3 \sqrt{\frac{3 G_{\mathrm{c}} \tau}{E_{\mathrm{c}}^{2} h_{\mathrm{c}}\left(1-v_{\mathrm{c}}^{2}+\frac{E_{\mathrm{c}} h_{\mathrm{c}}}{E_{\mathrm{s}} h_{\mathrm{s}}}\left(1-v_{\mathrm{s}}^{2}\right)\right)}}-\varepsilon_{\mathrm{rc}} \frac{1+v_{\mathrm{c}}}{1-\nu v_{\mathrm{c}}}(1)$
(16) $h_{\mathrm{c}}^{-1 / 3}$
Assumes that interface yield is controlled by a constant [197] shear stress $\tau$, and where $F(\Sigma)$ is an elastic function.

Explicit formulation, based on elementary laminated plate theory, and assuming that interface yield is controlled by a constant shear stress $\tau$.

\footnotetext{
${ }^{\text {a }} \varepsilon_{\mathrm{rc}}$ represents the coating internal strain.
} 


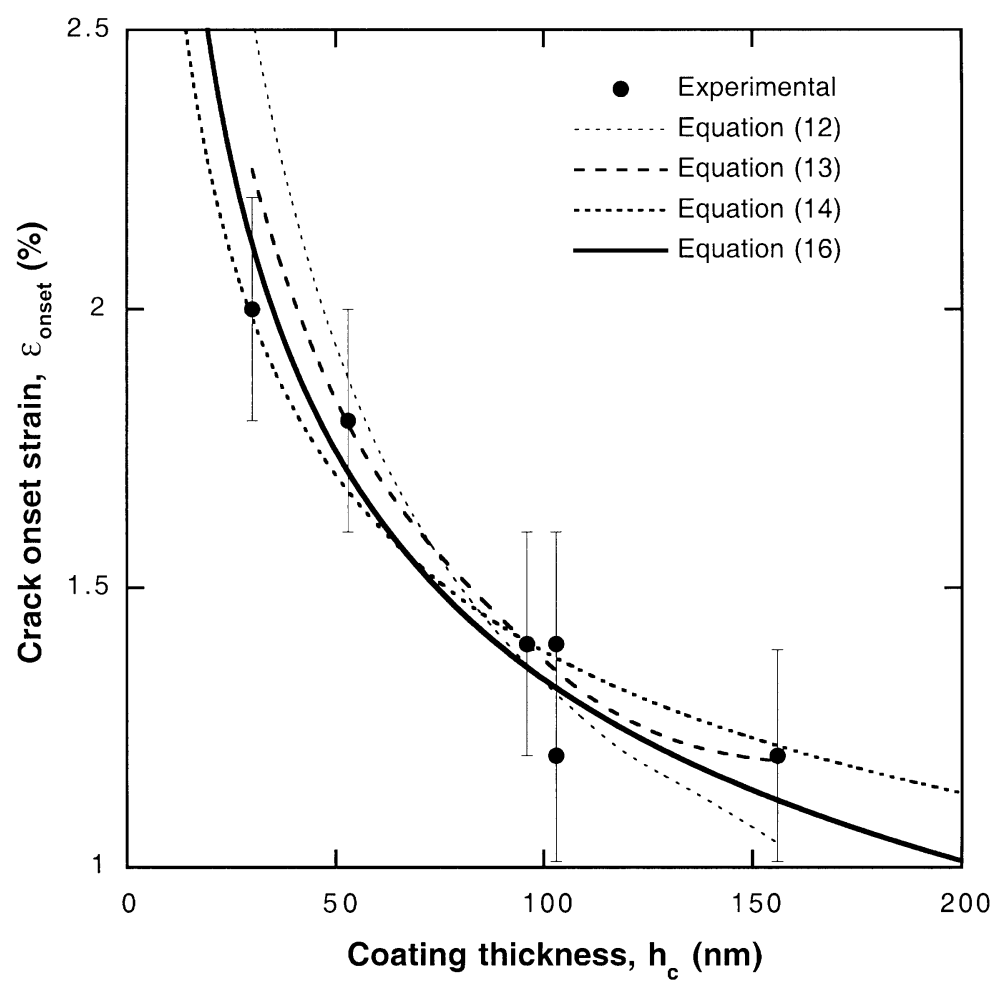

Fig. 14. Thickness dependence of crack onset strain of evaporated $\mathrm{SiO}_{x}$ coatings on PET under uniaxial tension (after refs $[165,259]$ ). The models discussed in the present Section are compared (see text for details).

fragmentation [203]. Hu and Evans solved the problem, assuming that interface yield is controlled by a constant shear stress $\tau$ [197], through the use of an elastic function $F(\Sigma)$ [Eq. (15) in Table 3]. The crack onset strain is subsequently derived as function of material parameters $G_{\mathrm{c}}$ and $\tau$, from the crack onset stress, $\sigma_{\text {onset }}=E_{\mathrm{c}} \cdot\left(\varepsilon_{\text {onset }}+\varepsilon_{\mathrm{rc}}\right)$, following intricate resolution, as the real root of Eq. 15 . Curve fitting the data in Fig. 14 using the solution of Eq. 15 with adjustable $G_{\mathrm{c}}$ and $\tau$ values was carried out, assuming that $F(\Sigma)=0.8$ [197], and the result of the procedure is shown in Fig. 15. For any selected value of $G_{\mathrm{c}}$, there exists one optimal value of $\tau$ which fits best the measured crack onset strain values, and vice-versa. Interestingly, as depicted in the Fig. 15, if the strength $\tau$ of the perfectly plastic interface is taken equal to $50 \mathrm{MPa}$, a typical value for the von Mises yield shear stress of biaxially stretched PET substrates, as derived from tensile measurements [204-206], then the best $G_{\mathrm{c}}$ value if found to be equal to approx. $7 \mathrm{~J} / \mathrm{m}^{2}$. In spite of the need of numerical calculation of the function $F(\Sigma)$, it is worthwhile to point out that such fracture toughness value appears to be a very reasonable estimate for silicon oxide, compared to the fracture toughness of bulk silica, of the order of $10 \mathrm{~J} / \mathrm{m}^{2}$ as mentioned above. In addition, as also shown in Fig. 15, it is evident that neglecting residual strains leads to important overestimation of coating toughness. 


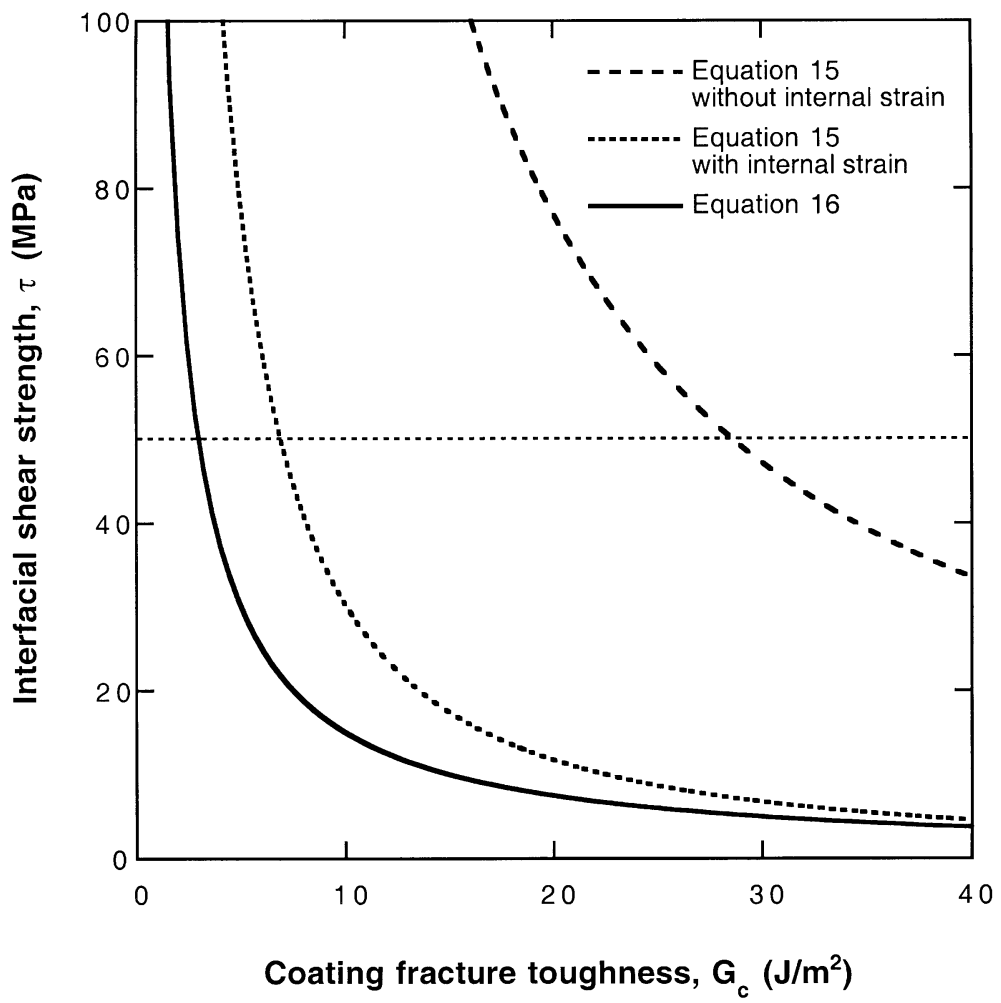

Fig. 15. Relation between interfacial shear strength, $\tau$, and coating fracture toughness, $G_{c}$, which provides best fit to the crack onset strain data reproduced in Fig. 14, using either Eq. (15), with or without internal strain $\varepsilon_{\mathrm{rc}}$ [197] or Eq. (16) [165]. The following values were used in the calculation: coating's modulus $E_{\mathrm{c}}=80 \mathrm{GPa}$ and Poisson's ratio $v_{\mathrm{c}}=0.2$; substrate modulus $E_{\mathrm{s}}=4 \mathrm{GPa}$ and Poisson's ratio $v_{\mathrm{s}}=0.44$; Poisson's ratio of coated film $v=0.4$; elastic function, used in Eq. $(15), F(\Sigma)=0.8$.

Furthering this approach, and to overcome the need of numerical tools, Leterrier et al. derived an explicit solution of the energy balance, based on elementary laminated plate theory [Eq. (16) in Table 3] [165]. The solution is reproduced in Fig. 14, using an interfacial shear strength $\tau$ equal to $50 \mathrm{MPa}$. As shown in Fig. 15, the corresponding coating fracture toughness is found to be equal to approx. $3 \mathrm{~J} / \mathrm{m}^{2}$. This value corresponds to a Griffith flaw size equal to approximately $300 \mathrm{~nm}$.

\subsection{Defect-tolerant high-barrier thin films}

The reduction of the size of the critical Griffith flaws was at the base of the considerable development in sizing agents, systematically applied to brittle glass filaments such as the ones used as reinforcements in composite materials. These molecules form aggregates of typical dimensions of the order of $150 \mathrm{~nm}$, that penetrate into the nanoscopic cracks, thus increasing the radius of the defect tip [207], as schematically depicted in Fig. 16. Similar phenomena could explain the superior 


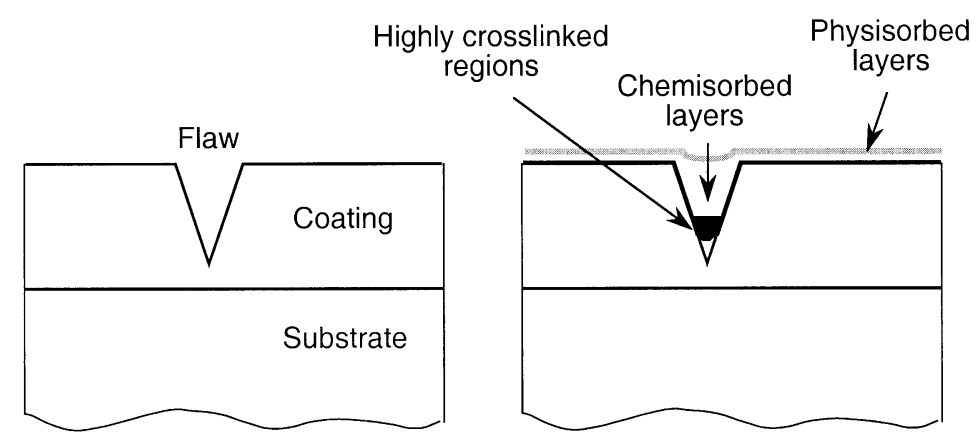

Fig. 16. Schematics of the effect of sizing on surface flaws (after Ref. [207]).

performance of polymer/oxide/polymer multilayer systems [208,209], and hybrid polymers with inorganic and organic structural units. These materials comprise organically modified oxides [210], plasma-polymerized HMDSO coatings [211,212], so-called organically modified ceramics (ORMOCER [213]) and organically modified silicates (ORMOSIL [214]). One could also mention the hydrogenated amorphous carbon coatings [215-217], such as those developed by Moser et al. that combine ductility and efficient barrier properties [218-220]. An alternative to develop new types of defect-tolerant high-barrier thin films could be based on theoretical analyses of mechanical contacts, that lead to optimal coatings with gradient in mechanical properties [221]. Such gradient, represented in Fig. 17, could be achieved for instance through a control of the oxygen partial pressure during PECVD deposition from an organosilane precursor vapor, to eventually generate a gradient in carbon composition in the oxide. Further research is obviously required to explore this concept.

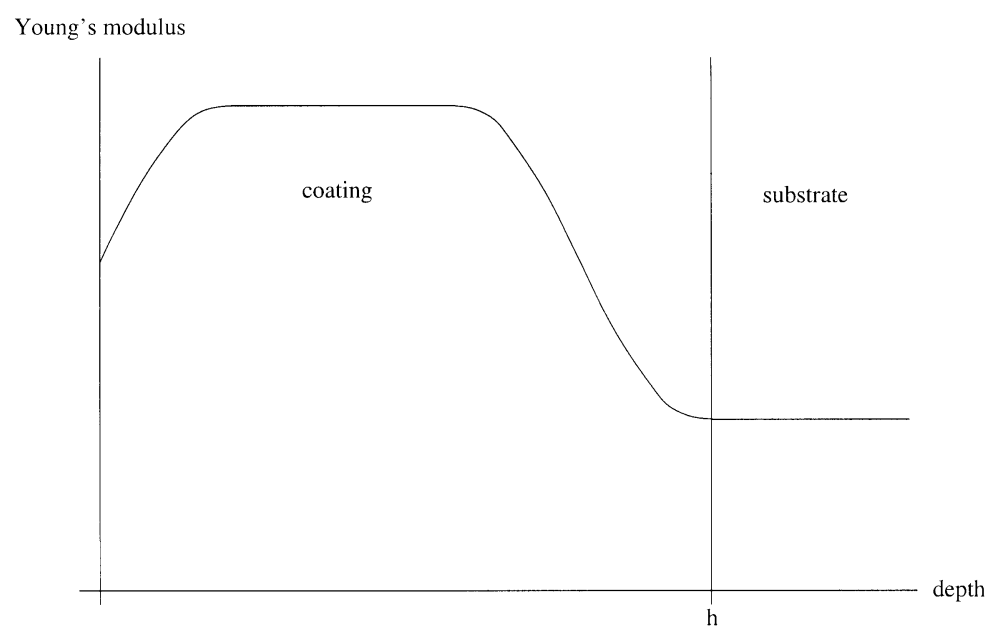

Fig. 17. "Optimal" coating structure with gradient in Young's modulus in case of a polymer substrate, and under mixed (normal and shear) load conditions. Reproduced from Ref. [221] with permission. 


\section{Adhesion}

Besides coating internal stress state and cohesive strength, the interfacial adhesion of the coating/substrate assembly is a key feature. It is controlled, on the one hand, by the type of interactions present at the interface between the oxide and the polymer and, on the other hand, by the level of process-induced internal stresses. The high density of covalent bonds formed during vacuum deposition between oxides and polymer, such as $\mathrm{Si}-\mathrm{C}$ and $\mathrm{Si}-\mathrm{O}-\mathrm{C}$ reported in Section 2, are expected to lead to very high adhesion levels. The following summarizes the benefits and limitations of the methods used to determine the adhesion between thin oxide films and ductile polymer substrates, with special attention paid to the so-called fragmentation test. The influence of internal stresses on interfacial adhesion is subsequently addressed.

\subsection{Adhesion measurements of thin oxide films on polymer substrates}

There exist a large variety of methods developed to measure the adhesion between thin films and polymer substrates. The reader is referred to the abundant information on this subject compiled by Mittal and other researchers in the past decades [222-226]. A recent review (in French) of methods to determine the mechanical properties and adhesion of thin films was made by Ignat and co-workers [227]. An important aspect of adhesion testing is the determination of the locus of failure, i.e., whether adhesive failure is the dominant failure mechanism, or cohesive failure of one of the phases has also taken place. Chemical methods to address this issue are discussed by Baun [228], such as the time-of-flight secondary ion mass spectroscopy (ToF-SIMS, used in Ref. [229] in case of $\mathrm{SiO}_{x}$ coatings on plasma-treated PET substrates). Three main adhesion test methods are used in the case of thin oxide barrier films on polymer substrates, namely the peel test, the indentation and related scratch techniques, and the tensile or fragmentation test.

In the peel test, the thin coating is peeled from the substrate of well-defined width, at a specified angle, usually 90 or $180^{\circ}$, using a backing material such as ethylene acrylic acid (EAA). This technique, or derivatives, have been largely used to test the adhesion of thin metal films on polymers [57,60,113,230-234] and oxides on polymers [7,78]. In the case of metal oxide thin films on PET and PVC, Bichler et al. concluded that the peel strength often exceeds the measurement limit, and the thin films cannot be peeled off due to high adhesion levels [53,71,72]. Another limitation of the peel test is the introduction of third body, the adhesive backing, in the system, which seriously complicates the determination of absolute value of coating adhesion.

In the scratch test, developed by Weaver and co-workers (e.g. Ref. [235]), a stylus is drawn across the coating under increasing vertical load [32,236-239]. The critical load at coating failure is often taken as a semi-quantitative measure of adhesion [5,6769,240]. A related technique, the nanoindentation, was developed for the specific purpose of thin films characterization [241]. Novel developments of the scratch test based on scanning force microscope techniques have been reported [242]. The models developed to analyze the critical normal force (see review of Bull, Rickerby, et al. [32,239]) do not seem appropriate in the case of soft and ductile polymer substrates. Indeed, 
the main drawback of the scratch test is, again, the introduction of a third body, the stylus, in the system, which yields a complex triaxial stress field in the polymer substrate, resulting from the ploughing effort of the indenter. If the test is unable to provide an absolute value of coating adhesion [243], it is nevertheless very useful for comparative purposes and coating optimization. Progress in numerical analyses of the stress field and in standardization methods should improve further the usefulness of the scratch test [244,245].

The fragmentation test proved its relevance in the case of a variety of thin brittle films on ductile metal [197,199,246-250] and polymer substrates [10,137,251-255], particularly PET $[78,105,125,163,164,187,256-266]$. In this technique, the evolution of crack patterns in the brittle coating is monitored as a function of the tensile load applied to the substrate. In-situ optical [190] or scanning electron microscopy $[254,267,268]$ are usually employed for the detection of cracks. An acoustic emission technique was also reported, but was limited to films of thickness larger than $500 \mathrm{~nm}$ [269]. In the fragmentation test, the adhesion, usually represented by the interfacial shear strength (IFSS), is related to the density of coating cracks, measured in the saturation stage of the fragmentation process, i.e., when no more cracks are formed as the strain is increased. A variant of the test, applied to prenotched coatings, was proposed by Dillard et al. [270]. The fragmentation test was used to determine the effects of changes in surface energy of the substrate (e.g. Fig. 13) [78,105,114], of coating thickness $[163,164,259]$, and of temperature [125,263] on coating adhesion. The fragmentation test usually operates in uniaxial tension; the application of equibiaxial tension was further investigated to provide additional information regarding coating failure mechanisms [165,271,272].

Correlations were reported between the IFSS values determined from fragmentation and scratch tests [243], and, more specifically between the crack density at fragmentation saturation, and the critical normal force measured during scratching, as shown in Fig. 18 [229]. This is a solid indication that both techniques detect an intrinsic property of the coating/substrate assembly, usually considered to be either the interfacial toughness, or the interfacial shear strength (IFSS), that will be detailed in the next Section.

Other tests include acoustic microscopy, particularly suited for defect detection [93,94], pull-off methods [273,274], laser spallation [275], and blister tests [276-278], the latter three being hardly applicable in case of thin, flexible polymer substrates.

\subsection{The three stages of coating fragmentation}

The phenomenology of coating fragmentation comprises three main stages [137], shown in Fig. 19. In the first stage, termed random cracking, crack interaction is negligible, therefore the rate of crack generation is governed solely by the coating strength distribution and the crack location is determined by the defect distribution in the coating (Fig. 19A). The stress state in a coating fragment is equal to the equivalent far field stress, except along some critical distance from the edges, where stress relaxes to zero. The second fragmentation stage, mid-point cracking, corresponds to crack spacing becoming small with respect to twice the critical length 


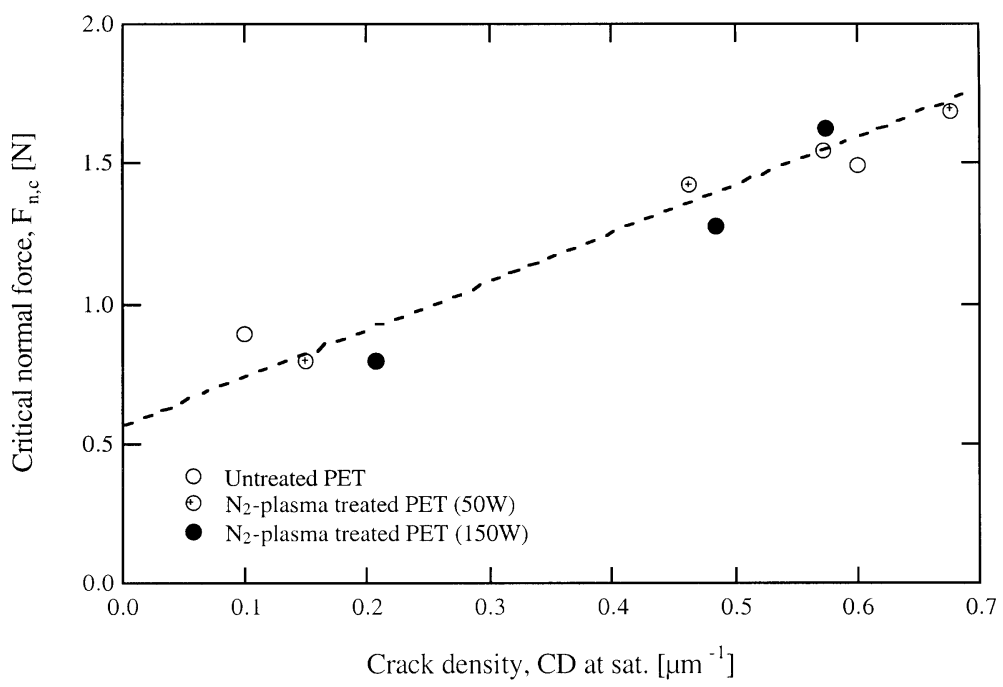

Fig. 18. Correlation between the critical normal force, measured during scratch test, and the crack density at saturation, determined during fragmentation test, for sputtered PVD $\mathrm{SiO}_{x}$ coatings on plasma treated PET substrates. Reproduced from Ref. [229] with permission.

(Fig. 19B). As a result, the maximum stress in a fragment cannot reach the unperturbed far-field level, which leads to a marked reduction of the fragmentation rate. The first two stages are in fact intimately correlated, as was demonstrated by Handge et al. [279]. Transverse buckling failure of coating fragments is often observed during this second stage, due to lateral contraction of the substrate resulting from Poisson's ratio effects [83,280-282] (Fig. 19B). The third and final stage begins with the delamination of the coating, and the fragmentation rate virtually stops (Fig. 19C). The same three stages occur in case of equibiaxial loading, with, however, important differences with respect to the uniaxial case. Whereas transverse buckling is absent in the 2D geometry, dynamic fracture processes were reported, that lead to a considerable broadening of the fragment size distribution [272]. This phenomena is illustrated in Fig. 20, with crack patterns in thin $\mathrm{SiO}_{x}$ coatings on PP and PET substrates under equibiaxial tension. The unique features of the $2 \mathrm{D}$ fragmentation, particularly the broad distribution of fragment areas compared to the $1 \mathrm{D}$ case, relate to the presence of high stresses in the stress recovery zone, as briefly explained in the figure. A detailed insight into this topic is beyond the scope of the present work, and the reader is referred to previous studies on relevant phenomena, observed in various materials at a broad range of length scales [283,284].

\subsection{Analysis of the fragmentation test}

Models and simulations of fiber or coating cracking during straining have been reported in several studies, most of which consider the evolution of crack spacing as a function of applied strain. In their earlier work, Grosskreutz and McNeil [285] introduced a stress relaxation mechanism at the coating/substrate interface, in which 

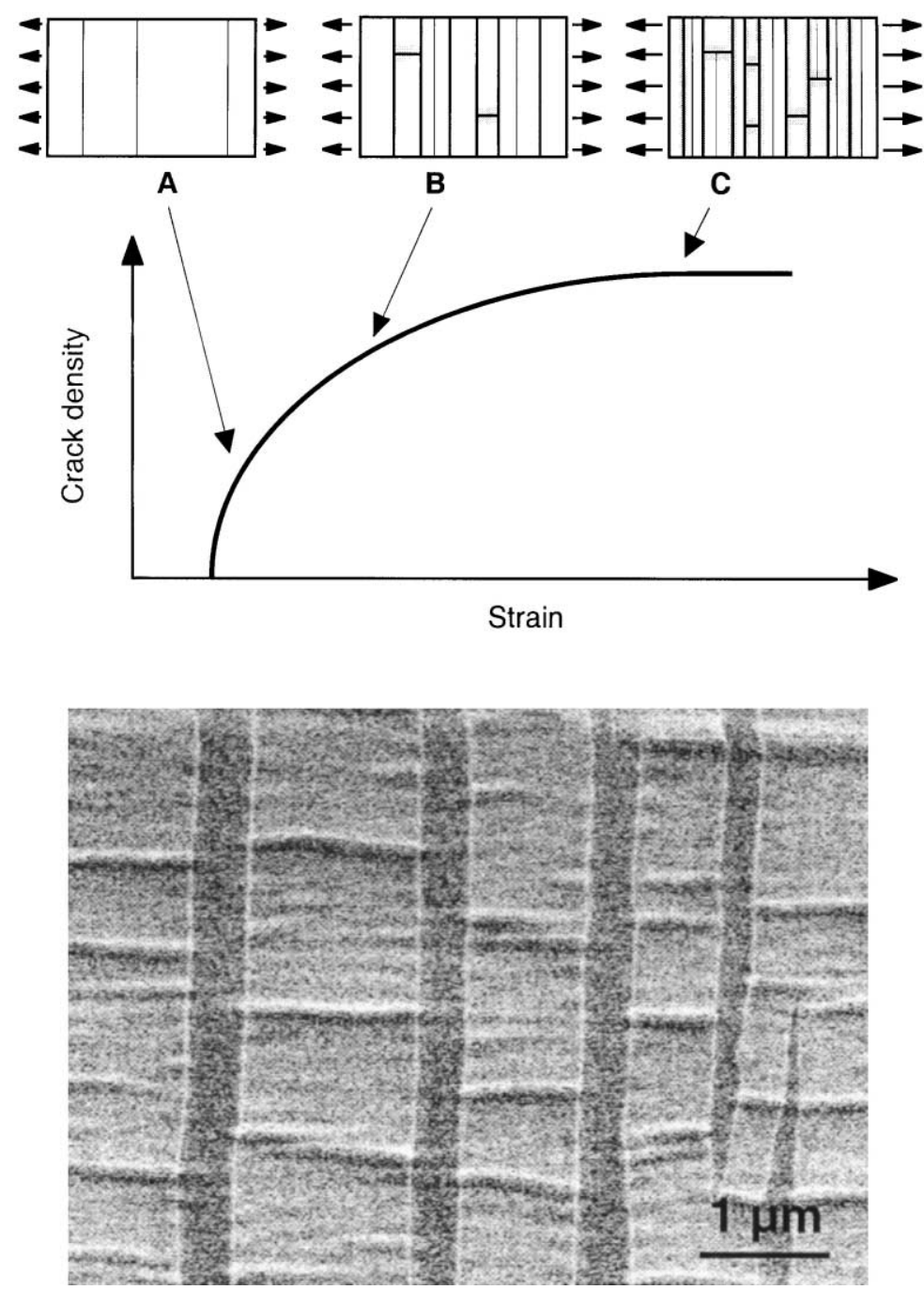

Fig. 19. The three main stages of coating fragmentation (after Ref. [137]). A: random cracking. B: mid-point cracking, and initiation of transverse buckling. C: delamination. Stages B and C are evident on the scanning electron micrograph of a $20 \mathrm{~nm} \mathrm{PECVD} \mathrm{SiO}_{x}$ coating on PET under $50 \%$ strain, shown on the bottom.

the stress decay was inversely proportional to the radial distance from the crack [193]. The authors, neglecting the important effect of coating thickness, derived the relation $\operatorname{Ln}\left(\varepsilon / \varepsilon_{0}\right)=(4 \mathrm{~g} / \mathrm{d}) \cdot\left(1-d / d_{0}\right)$ where $\mathrm{g}$ is a constant which reflects the form of the interfacial shear stress, $\varepsilon_{0}$ is the crack onset strain, $\varepsilon$ is the actual strain, $d_{0}$ is the crack spacing at strain $\varepsilon_{0}$, and $d$ is the crack spacing at strain $\varepsilon$. The relevant literature is summarized in the study of Wojciechowski and Mendolia [252,253], who propose an explicit dependence of crack density on coating thickness, however based on the strong assumption of constant substrate modulus. A further semi-empirical development, 

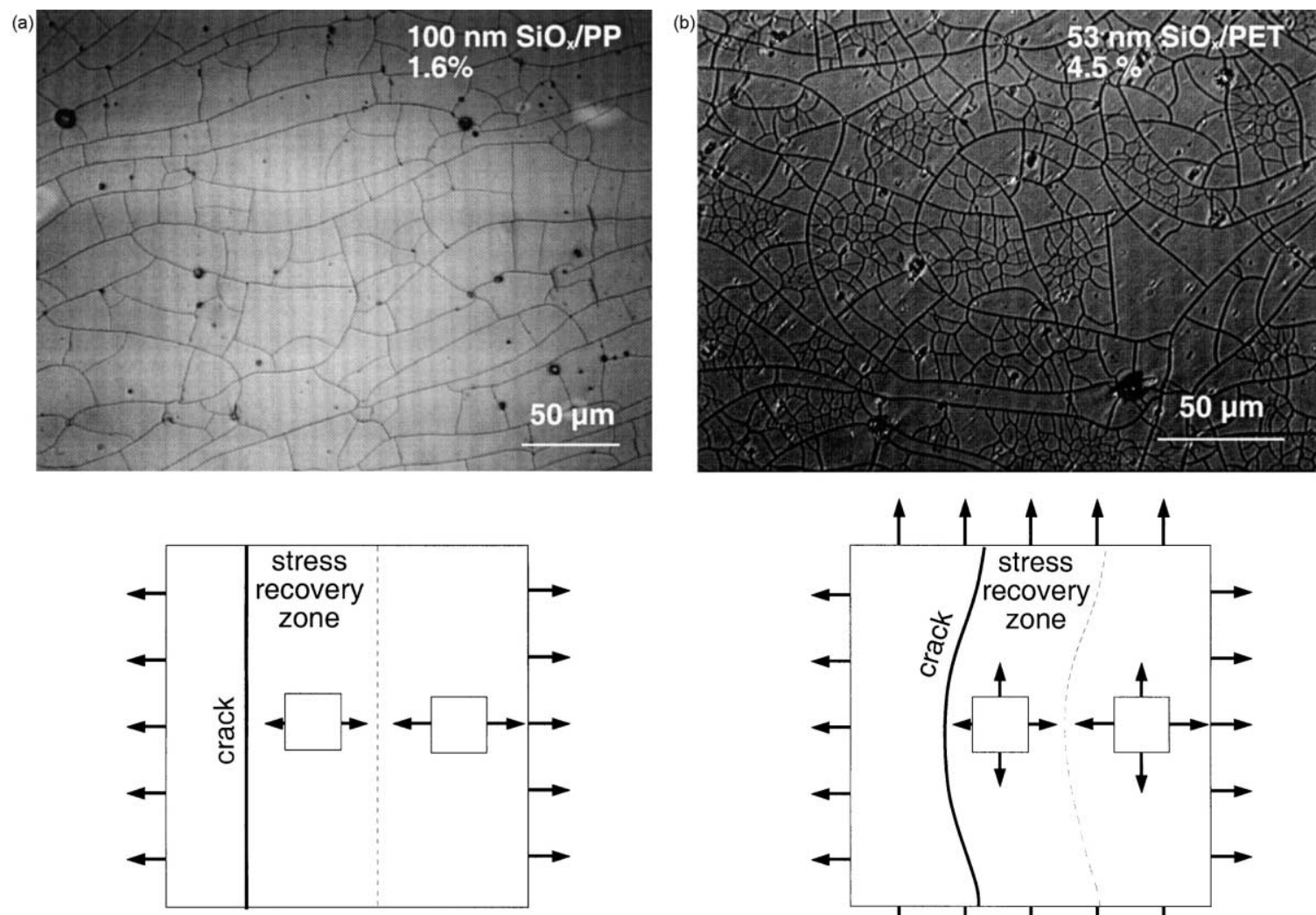

(c)

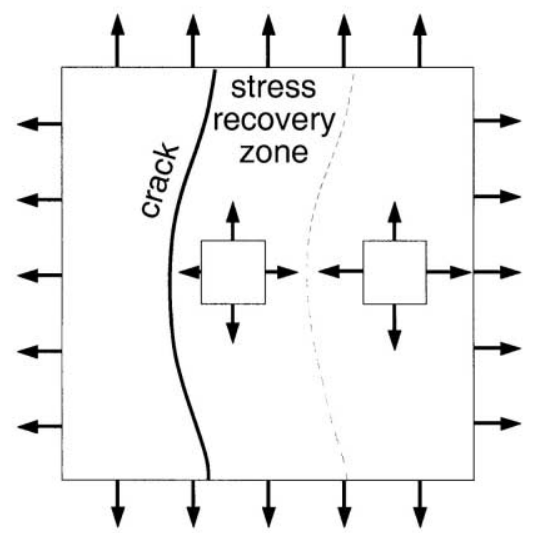

Fig. 20. Fragmentation patterns of a $100 \mathrm{~nm}$ thick evaporated $\mathrm{SiO}_{x}$ coating on $\mathrm{PP}$ under $1.6 \%$ equibiaxial strain (a), and $53 \mathrm{~nm}$ thick evaporated $\mathrm{SiO}$ coating on PET under $4.5 \%$ equibiaxial strain (b), and schematics of the stress field in the vicinity of an existing crack, under uniaxial loading (c) and equibiaxial loading (d). 


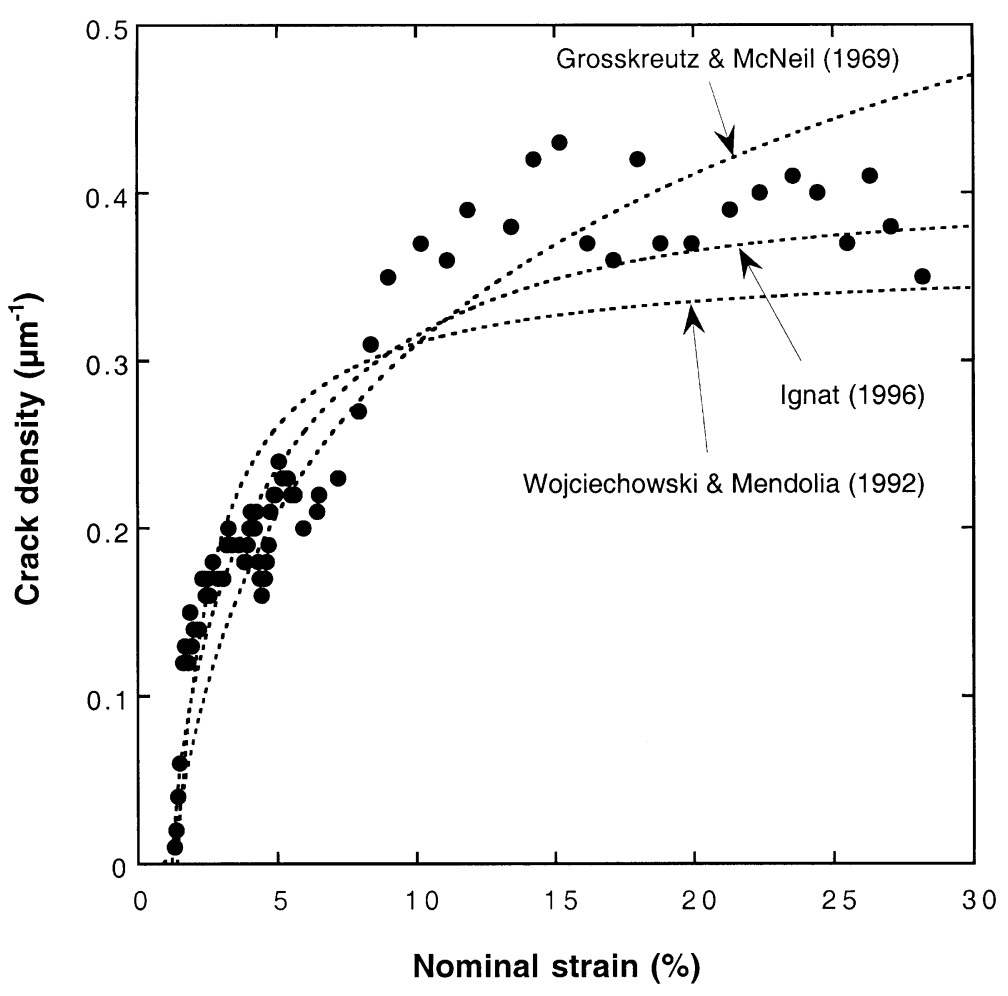

Fig. 21. Modeling of the fragmentation process of a $100 \mathrm{~nm}$ thick $\mathrm{SiO}_{x}$ coating on PET (data reproduced from Ref. [259]). See text for details on the models.

based on Weibull statistics, was developed by Mezin et al. and reported by Ignat and co-workers $[250,286]$ in the form of an stretched exponential function of the strain. These various analytical treatments are compared in Fig. 21 with experimental data of the fragmentation of a $100 \mathrm{~nm}$ thick $\mathrm{SiO}_{x}$ coating on PET. More sophisticated simulations of the fragmentation process based on statistical treatments of the rupture process were carried out, following stress [287-291] or fracture mechanics [195,292] approaches.

The pure geometry of the fragmentation test, together with the absence of third body interactions, allows for a good control of the stress state in the material during its elongation, similar to the classic single fiber fragmentation test originally described by Fraser et al. [293]. The single fiber composite test has become one of the key methods to study failure mechanisms in fiber-reinforced composites, and most of the theoretical treatments of the fragmentation test can be found in the corresponding literature (e.g. refs. [294-296]). In both coating/substrate and fiber/matrix geometry, modeling the load transfer at the interface is a typical shear-lag analysis [297]. The two central features in this analysis are, on the one hand, the critical stress transfer length [298], also related to so-called ineffective length [293], recovery length [299], shielded or exclusion zone [291], and, on the other hand, the statistical nature of the coating or fiber failure [300], for which Weibull statistics was found appropriate [301]. 
The classical stress transfer approach of Kelly and Tyson [298] assumes a perfectly plastic behavior of the coating/substrate interface, i.e., a constant IFSS. In spite of its simplicity, the assumption of a constant IFSS in the exclusion zone is very robust [295]. This results from the fact that the stress in the brittle coating is much larger than the typical IFSS values, so that the size of the exclusion zone is proportional to the coating stress. In that sense, calculated IFSS value from fragmentation data reflects some effective shear property of the interfacial region. For ductile polymer substrates, a constant IFSS assumption is often preferable to alternative elastic models due to the plastic flow of the polymer in the strain range of coating fragmentation. Based on this approach, the resolution of the mechanical equilibrium of an infinitesimal coating element adhering onto a substrate under uniaxial tension leads to the following stress transfer equation [197]:

$$
\tau=2 h_{\mathrm{c}} \sigma_{\max }\left(l_{\mathrm{c}}\right) / l_{\mathrm{c}}
$$

where $h_{\mathrm{c}}$ is the coating thickness, $\sigma_{\max }$ its size-dependent tensile strength, characteristic of its defect-controlled cohesion, and $l_{\mathrm{c}}$ is the critical stress transfer length defined as the minimum coating length in which the maximum allowable coating stress $\left(\sigma_{\max }\right)$ is achieved. The length $l_{\mathrm{c}}$ is not a measurable quantity, and was related using a stochastic failure approach to the average fragment length at saturation, $\bar{l}_{\text {sat }}$, that is, the average length when an increase in strain does not lead to further fragmentation of the coating: $\bar{l}_{\text {sat }}=0.67 l_{\mathrm{c}}$ [257]. Important to point out that, since internal stresses are not explicitly accounted for, the IFSS defined in Eq. (17) represents an apparent, or effective, strength, that is, a value of practical adhesion, and not an intrinsic property of the coating/substrate system. The same goes for the coating tensile strength $\sigma_{\max }$.

\subsection{Weibull analysis of coating tensile strength}

The tensile strength $\sigma_{\max }$ of brittle materials is defect controlled and exhibits sizedependent effects, which can be accounted for by the Weibull weakest-link model [301,302]. In case only one population of defects (e.g., volume defects) control the strength of the material, the Weibull model is written as a two-parameter equation:

$$
\sigma_{\max }(l)=\sigma_{0}\left(l / l_{0}\right)^{-1 / m} \Gamma(1+1 / m)
$$

where $l_{0}$ is a normalization factor, chosen equal to $1 \mu \mathrm{m}, \Gamma$ is the gamma function, and $\sigma_{0}$ and $m$ are the Weibull scale and shape factors, respectively. For thin coatings, these two factors are usually derived from a linear approximation of the initial part of the fragmentation diagram, where the average fragment size is reported as a function of applied strain, in logarithmic coordinates [125]. Weakest link models used to describe the strength of brittle materials easily account for the internal stress $\sigma_{i}$ as an additional model parameter. Nonetheless, this approach is hardly applicable to nanosized coatings, for which too few experimental data are available in practice in the strain range of interest, to derive the internal stress with reasonable accuracy. 
As a consequence, in the presence of internal stresses, the value of $\sigma_{\max }$ derived from the two-parameter Weibull model [Eq. (18)] represents an apparent strength.

\subsection{Role of internal stresses on interfacial shear strength and coating tensile strength}

Internal stresses were reported to change to a considerable extent the hardness, coefficient of friction, and practical adhesion of ITO coatings on glass [303], as also the IFSS of $\mathrm{SiO}_{x}$ coatings on PET [169]. The relaxation of internal stresses upon coating delamination further contributes to the energy release rate [138], thus it is essential to include these in the analysis of the fragmentation test. The axial stress resulting from tensile loading of the substrate add to the initial axial internal stress in the oxide layer. Upon fragmentation, the average coating stress relaxes, as the average stress in the fragments decreases when their size decreases. Since at fragmentation saturation $\bar{l}_{\text {sat }}=0.67 l_{\mathrm{c}}$, and with the assumption of constant shear stress, one eventually obtains a linear dependence between the apparent IFSS $\tau$, (sum of an intrinsic term, $\tau^{*}$, and an internal stress term, $\tau_{\mathrm{i}}$ ) and coating internal stress, $\sigma_{i}[169]$ :

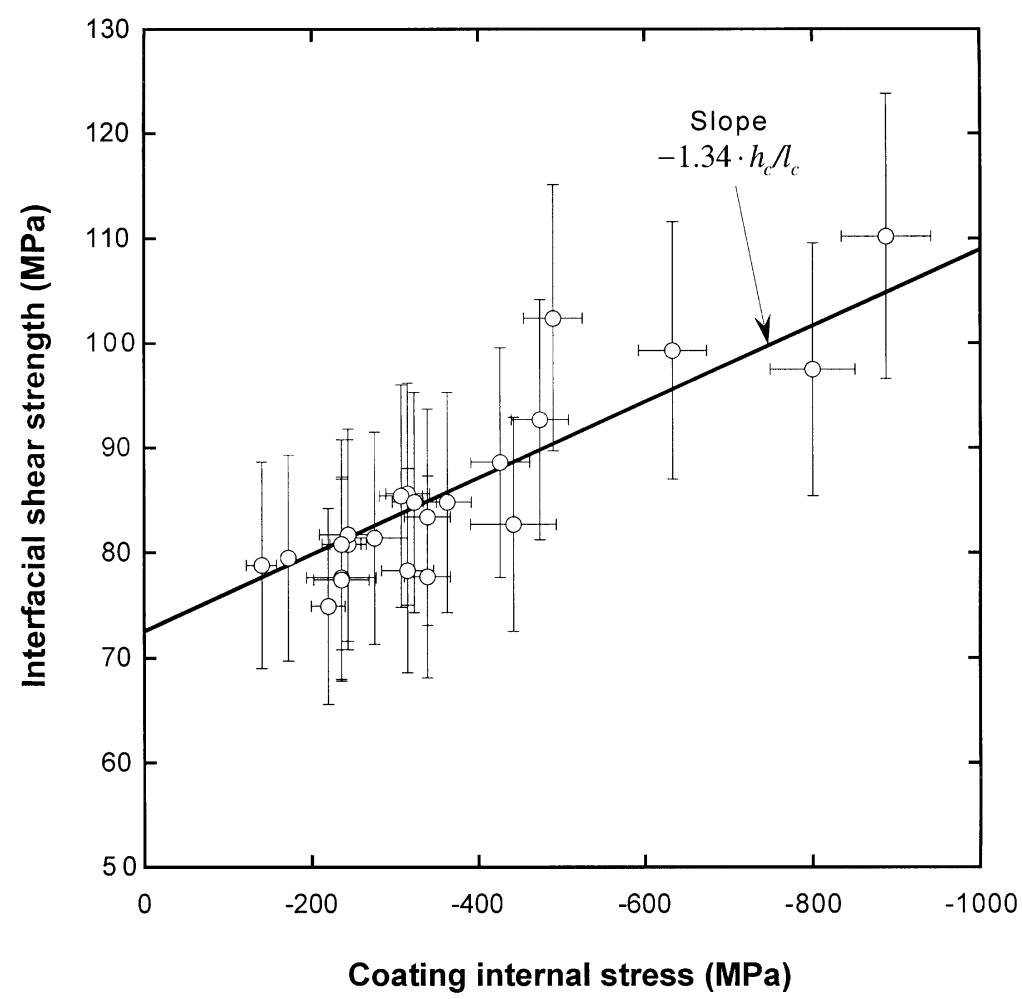

Fig. 22. Comparison between the apparent $\mathrm{SiO}_{x} / \mathrm{PET}$ interfacial shear strength (open circles) and the theoretical prediction [Eq. (19); solid line], versus coating internal compressive stress. Reproduced from Ref. [169] with permission. 


$$
\tau=\tau^{*}+\tau_{\mathrm{i}}=2 h_{\mathrm{c}}\left(\sigma_{\max }^{*}\left(l_{\mathrm{c}}\right)-0.67 \sigma_{\mathrm{i}}\right) / l_{\mathrm{c}}
$$

where the term $\sigma_{\max }^{*}\left(l_{c}\right)$ represents the intrinsic tensile strength of the coating at critical length, which can be determined from the values of apparent strength $\sigma_{\max }\left(l_{\mathrm{c}}\right)$ and of internal stress $\sigma_{\mathrm{i}}: \sigma_{\max }^{*}\left(l_{\mathrm{c}}\right)=\sigma_{\max }\left(l_{\mathrm{c}}\right)+0.67 \sigma_{\mathrm{i}}$. Any change in internal stress level, $\Delta \sigma_{\mathrm{i}}$, will result in a proportional change in apparent IFSS, $\Delta \tau=$ $-\left(1.34 h_{\mathrm{c}} / l_{\mathrm{c}}\right) \cdot \Delta \sigma_{\mathrm{i}}$, as shown in Fig. 22 for $\mathrm{SiO}_{x}$ coatings formed by reactive PVD on PET [169]. The extrapolation of the data to zero internal stress gives a value of intrinsic IFSS equal to $73 \mathrm{MPa}$. This very high value is intermediate between the Von Mises yield stress in shear of the PET substrate, equal to $55 \mathrm{MPa}$ [204], and its shear strength, equal to approximately $150 \mathrm{MPa}$, which thus demonstrates the strain hardening ability of the interfacial region [125,259]. It also reflects the high density of covalent bonds mentioned in Section 2. IFSS values comparable to the bulk shear strength of the polymer substrate were also found for PECVD coatings on low density polyethylene [254] and polyamide 12 [29]. Clearly, there is no need to improve interfacial adhesion of oxide thin films on polymer substrates, because then, cohesive failure of the underlying polymer substrate will take place [114].

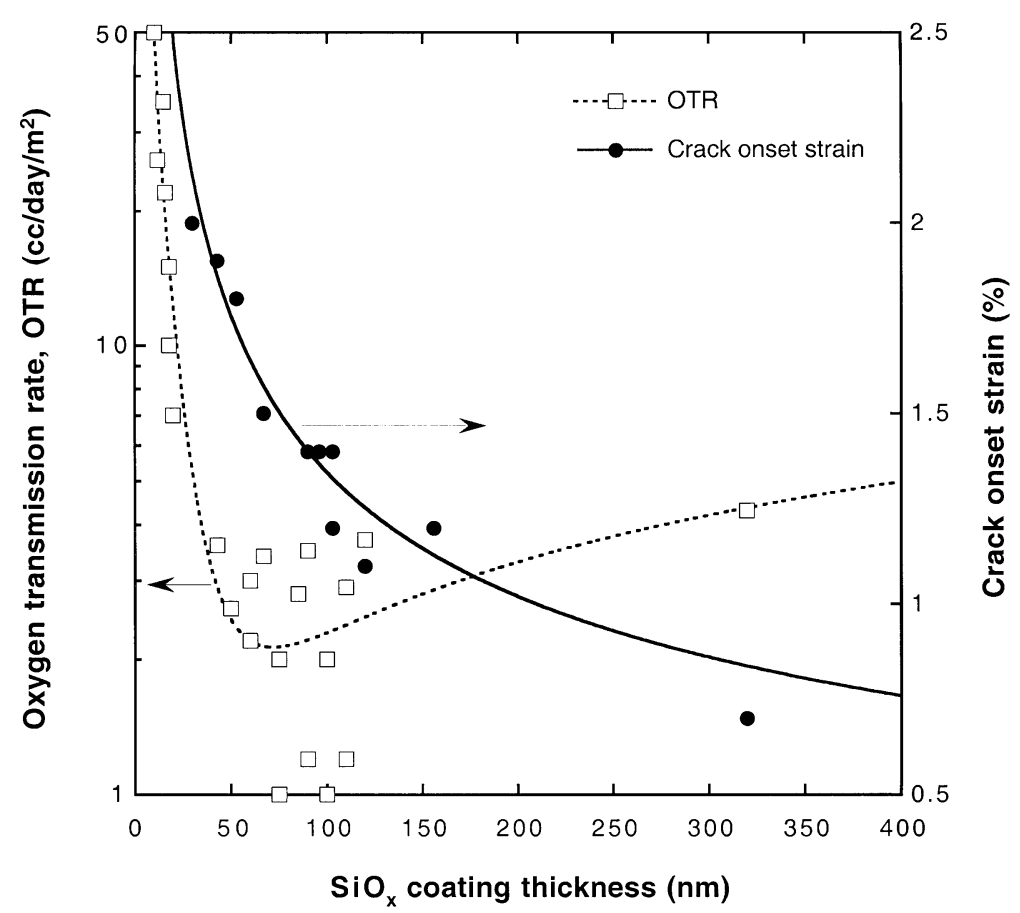

Fig. 23. Effect of coating thickness on oxygen transmission rate (OTR [24,164,304], open squares; the dotted line is a fit to the data) and crack onset strain (filled dots, experimental [164,259]; line, theoretical derivation [165]), for PVD $\mathrm{SiO}_{x}$ coatings on $12 \mu \mathrm{m}$ PET. 


\subsection{Optimal coating thickness}

Fig. 23 represents the coating thickness dependence of the oxygen transmission rate (OTR) and crack onset strain and IFSS, in the case of evaporated $\mathrm{SiO}_{x} / \mathrm{PET}$ films. The OTR drops from $120 \mathrm{cc} / \mathrm{day} / \mathrm{m}^{2}$ for uncoated, $12 \mu \mathrm{m}$ thick PET, to an optimal value equal to $2 \pm 1 \mathrm{cc} / \mathrm{day} / \mathrm{m}^{2}$ when the coating thickness is increased in the range from approximately 50 to $100 \mathrm{~nm}$, after which it starts to gradually increase $[24,164,304]$. By contrast, the coating crack onset strain, related to its cohesive strength, continuously decreases with increasing coating thickness, at least up to 300 $\mathrm{nm}[164,259]$. In the same range, the IFSS is approximately constant, and therefore is not a limiting factor [259]. Thus, the optimal coating thickness is the minimum thickness, which provides the lower OTR. For this type of oxide, the optimal coating thickness is of the order of $50 \mathrm{~nm}$.

\section{Conclusions}

The cohesion and adhesion of metal oxide thin films on polymer substrates used as gas-barrier systems have been reviewed, with attention paid to deposition-induced defects and internal stresses. Experimental and theoretical analyses of these factors lead to three main conclusions.

- Vapor deposition processes of oxides on polymers lead to the formation of an interfacial region of thickness in the nanometer range, characterized by a high density of Metal-O-C and Metal-C bonds, and an organosilicon phase with $\mathrm{Si}-\mathrm{CH}_{x}$ bonds in case of PECVD. This region, and the underlying ductile polymer substrate, exhibits strain hardening ability, and results in very high levels of interfacial shear strength, intermediate between the shear yield stress and the shear strength of the bulk polymer substrate. Therefore, there is no need to improve interfacial adhesion of oxide thin films on polymer substrates.

- The oxide coating contains nanoscopic defects and microscopic flaws. The former are characteristic of the frozen-in structure of the oxide, and control both the permeability of oxygen and the cohesion of the oxide material. The latter comprise pin-holes and roughness-induced defects, resulting from the presence of additives in the superficial layers of the substrate. These microscopic flaws do not severely affect the barrier performance of the coating. However, they act as crack initiation sites, and thus significantly affect the mechanical resistance of the coating. New types of defect-tolerant high-barrier thin films, based on organic-inorganic hybrids, or on a gradient in carbon composition, or using sizing agents similar to those used to improve the strength of glass filaments, are promising developments.

- Compressive internal stresses are generated in the coating during deposition. These are beneficial (i) to the barrier performance of the coated polymer, (ii) to the coating tensile strength and, (iii) to the coating/substrate adhesion. 
Novel approaches to control the internal stress level, such as that based on the application of a tensile load on the substrate during coating deposition, should be emphasized in future studies.

Accounting for these various factors enables to define an optimal coating thickness, which combines low oxygen permeation and high cohesion, without sacrificing the quality of interfacial adhesion.

\section{Acknowledgements}

The author acknowledges the Swiss National Science Foundation (projects \#2100037427.93 and \#20-55579.98) and the Swiss Priority Program for Materials Research (project \#3.2B) for financial support. Tetra Pak R\&D, Plasma Technology is gratefully acknowledged for financial support and active collaboration, which includes fruitful discussions with Dr. P. Fayet. He wishes to thank Dr. J. Andersons of the Institute of Polymer Mechanics, Latvian Academy of Sciences, and Prof. A. Blumen and his group of the Theoretical Polymer Physics Laboratory, University of Freiburg, for enthousiastic research interactions.

\section{References}

[1] Boerio FJ, Davis GD, deVries JE, Miller CE, Mittal KL, Opila RL, et al. Polymer-metal (oxide) interfaces. Crit Rev Surf Chem 1993;3:81.

[2] Samson F. Ophtalmic lens coatings. Surf Coat Technol 1993;81:79.

[3] Martinu L. Advances in plasma deposition of optical films and coatings. Proc. 41st Society of Vaccuum Coaters Annual Conference, Boston, April. 18-23, SVC, 111, 1998.

[4] Woodward FE, Peck LC. Porous transition metal oxides on polymeric substrates, Proc. 41st Society of Vaccuum Coaters Annual Conference, Boston, April, SVC 18-23, 385, 1998.

[5] Sarto F, Alvisi V, Melissano E, Rizzo A, Scaglione S, Vasanelli L. Adhesion enhancement of optical coatings on plastic substrate via ion treatment. Thin Solid Films 1999;346:196.

[6] Lobstein N, Millon E, Hachimi A, Muller JF, Alnot M, Ehrhardt JJ. Deposition by laser-ablation and characterization of titanium-dioxide films on poly(ethylene terephthalate). Appl Surf Sci 1995; 89:307.

[7] Ben Amor S, Baud G, Besse JP, Jacquet M. Elaboration and characterization of titania coatings. Thin Solid Films 1997;293:163.

[8] Iwamori S, Miyashita TS, Fukuda S, Nozaki K, Sudoh N. Fukuda, Effect of an interfacial layer on adhesion strength deterioration between a copper thin-film and polyimide substrate. Vacuum 1998; 51:615.

[9] Ott AW, Chang RPH. Atomic layer-controlled growth of transparent conducting $\mathrm{ZnO}$ on plastic substrates. Mater Chem Phys 1999;58:132.

[10] Cairns DR, WitteII RP, Sparacin DK, Sachsman SM, Paine DC, Crawford GP, et al. Straindependent electrical resistance of tin-doped indium oxide on polymer substrates. Appl Phys Lett 2000;76:1425.

[11] Raja Reddy M, Srinivasamurthy N, Agrawal BL. Atomic oxygen protective coatings for Kapton film - a review. Surf Coat Technol 1993;58:1.

[12] Connell JW, Crivello JV, Bi D. Effect of low-earth-orbit atomic oxygen exposure on epoxy functionalized siloxanes. J Appl Polym Sci 1995;57:1251. 
[13] Kleiman JI, Iskanderova ZA, Perez FJ, Tennyson RC. Protective coatings for LEO environments in spacecraft applications. Surf Coat Technol 1995;77:827.

[14] Houdayer A, Cerny G, Klemberg-Sapieha JE, Czeremuszkin G, Wertheimer MR. MeV proton irradiations and atomic oxygen exposure of spacecraft materials with $\mathrm{SiO}_{2}$ protective coatings. Nucl Instr Meth Phys Res B Beam Inter Mater Atoms 1997;131:335.

[15] Iskanderova ZA, Kleiman J, Morison WD, Tennyson RC. Erosion resistance and durability improvement of polymers and composites in space environment by ion-implantation. Mater Chem Phys 1998;54:91.

[16] Mayers CL, Jenke DR. Stabilization of oxygen-sensitive formulations via a secondary oxygen scavenger. Pharm Res 1993;10:445.

[17] Walther M, Heming M, Spallek M. Multilayer barrier coating system produced by plasma-impulse chemical vapor deposition (PICVD). Surf Coat Technol 1996;80:200.

[18] Ryder LB. Oxygen-barrier containers: their design and cost. Plast Eng 1994; May: 41.

[19] Stratton PF, Moore C. Sputtered PET bottles for high barrier. Proc. Int. Packaging Conf, Bristol, 1986.

[20] Krug TG. Transparent barriers for food packaging. Proc. 33th Soc. Vacuum coaters annual conf., SVC, 163, 1990.

[21] Felts JT. Plasma deposited transparent high gas barriers. Proc. 3rd Int. Conf. Vacuum Web Coating. San Antonio: TX; 1989.

[22] Finson E, Felts J. Transparent $\mathrm{SiO}_{2}$ barrier coatings - conversion and production status. Tappi J 1995;78:161.

[23] Seserko P, Löbig G, Ludwig R, Kukla R, Hoffmann G, Steiniger G. Transparent barrier coatings by electron beam evaporation - an update. Proc. 41st Society of Vaccuum Coaters Annual Conference, Boston, April. 18-23, 424, 1998.

[24] Chatham H. Oxygen diffusion barrier properties of transparent oxide coatings on polymeric substrates. Surf Coat Technol 1996;78:1.

[25] Bucklow I, Butler P. Plastic proves it can hold its beer. Materials World, August 14, 2000.

[26] Johansson KS. Plasma deposition of $\mathrm{SiO}_{\mathrm{x}}$ coatings on natural polymer films for enhanced barrier performance. Abstracts of Papers of the Amer Chem Soc 1997;213:140.

[27] Ouyang M, Klemchuk PP, Koberstein JT. Exploring the effectiveness of $\mathrm{SiO}_{\mathrm{x}}$ coatings in protecting polymers against photo-oxidation. Polym Degrad Stab 2000;70:217.

[28] Gill RE, van de Weijer P, Liedenbaum CTH, Schoo HFM, Berntsen A, Vleggaar JJM, Visser RJ. Stability and characterization of large area polymer light-emitting diodes over extended periods. Optical Mater 1999;12:183.

[29] Leterrier Y. Nanosized gas-barrier coatings on polymers. Proc. 1st Korea-Switzerland Symposium on Materials and Interfaces in MEMS Applications, KAIST, Taejon, Korea, June 21-23, and Rochat G, Delachaux A, Favez D, Leterrier Y, Månson J-AE, Fayet P, 2001. Influence of defects and internal stresses on the mechanical resistance and adhesion of thin PECVD oxide films on semi-crystalline polymers. Proc. ECASIA'2001, Avignon (F), September 30-October 5, 2001.

[30] Baik DG, Cho SM. Application of sol-gel derived films for $\mathrm{ZnO} / \mathrm{N}-\mathrm{Si}$ junction solar-cells. Thin Solid Films 1999;354:227.

[31] Gilbert E. Anoxic environments, oxygen scavengers and barrier films: their use in museums, libraries and galleries. Paper Conservation News, 2000; 93.

[32] Bull SJ, Rickerby DS. Evaluation of coatings. Br Ceram Trans J 1989;88:177.

[33] Jamieson EHH, Windle AH. Structure and oxygen-barrier properties of metallized polymer film. J Mater Sci 1983;18:64.

[34] Moosheimer U, Bichler C. Plasma pretreatment of polymer-films as a key issue for high barrier food packagings. Surf Coat Technol 1999;119:812.

[35] Miller KS, Krochta JM. Oxygen and aroma barrier properties of edible films - a review. Trends Food Sci Technol 1997;8:228.

[36] Pauly S. In: Brandrupt J, Immergut EH, editors. Polymer handbook 4th ed. New York: Wiley, 1999.

[37] Lusignea RW. Orientation of LCP blown film with rotating dies. Polym Eng Sci 1999;39:2326. 
[38] Sanchez-Vales S, Orona-Villarreal F, Lopez-Quintanilla M, Yanez-Flores I, RamosdeValle L F, Guerrero-Salazar C. Performance of multilayer films using maleated linear low-density polyethylene blends. Polym Eng Sci 1998;38:150.

[39] Koulouri EG, Kallitsis JK. Miscibility behavior of poly(vinyl-alcohol) nylon-6 blends and their reactive blending with poly(ethylene-co-ethyl-acrylate). Polymer 1998;2373:39.

[40] Lee SY, Kim SC. Laminar morphology development and oxygen permeability of LDPE/EVOH blends. Polym Eng Sci 1997;37:463.

[41] Lee SY, Kim SC. Laminar morphology development using hybrid EVOH-nylon blends. J Appl Polym Sci 1998;67:2001.

[42] Okazaki T, Sanda F, Endo T. Syntheses and radical ring-opening polymerizations of 1,1-bis(hydroxymethyl)-2-vinylcyclopropane and 1,1-bis(methoxymethyl)-2-vinylcyclopropane. Polym Bull 1997;39:141.

[43] Lee JC, Litt MH, Rogers CE. Oxyalkylene polymers with alkylsulfonylmethyl side-chains - gas barrier properties. J Polym Sci B Polym Phys 1998;36:75.

[44] Sekelik DJ, Stepanov EV, Nazarenko S, Schiraldi HDA, Baer E. Oxygen barrier properties of crystallized and talc-filled poly(ethylene terephthalate). J Polym Sci B Polym Phys 1999;37:847.

[45] Alexandre M, Dubois P. Polymer-layered silicate nanocomposites: preparation, properties and uses of a new class of materials. Mater Sci Eng R Reports 2000;28:1.

[46] Scherer C. PA film grade with improved barrier properties for flexible food packaging applications. Proc. New Plastics '99, London, 2-4 February, 1999.

[47] Schrenk P, Alfrey T. Some physical properties of multilayered films. J Polym Eng Sci 1969;9:393.

[48] Ohring M. The materials science of thin films. New York: Academic Press; 1992.

[49] Reichelt K, Jiang X. Preparation of thin films by physical vapour deposition methods. Thin Solid Films 1990;191:91.

[50] Rancourt JD, Hollenhead JB, Taylor LT. Chemistry of the interface between aluminum and polyester films. J Adhesion 1993;40:267.

[51] Ringenbach A, Jugnet Y, Duc TM. Interfacial chemistry in Al and Cu metallization of untreated and plasma-treated polyethylene and poly(ethylene terephthalate). J Adhes Sci Technol 1995;9: 1209.

[52] Travaly Y, Bertrand P. Static SIMS investigation of metal-polymer interfaces. Surf Interf Anal 1995;23:328.

[53] Bichler C, Langowski HC, Moosheimer U, Seifert B. Adhesion mechanism of aluminum, aluminum oxide, and silicon oxide on biaxially oriented polypropylene (BOPP), poly(ethylene terephthalate) (PET), and poly(vinyl chloride) (PVC). J Adhes Sci Technol 1997;11:233.

[54] Sutcliffe R, Lee WW, Gaynor JF, Luttmer JD, Martini D, Kelber J, et al. Characterization and aluminum metallization of a parylene Af-4 surface. Appl Surf Sci 1998;126:43.

[55] Sandrin L, Sacher E. X-ray photoelectron-spectroscopy studies of the evaporated aluminum corona-treated poly(ethylene terephthalate) interface. Appl Surf Sci 1998;135:339.

[56] Ben Amor S, Baud G, Jacquet M, Nansé G, Fioux P, Nardin M. XPS characterisation of plasmatreated and alumina-coated PMMA. Appl Surf Sci 2000;153:172.

[57] Silvain JF, Veyrat A, Ehrhardt JJ. Effect of the temperature on the adhesion and the morphology of thin metal films evaporated on poly(ethylene terephthalate). Thin Solid Films 1992;221:114.

[58] Wong PC, Li YS, Mitchell KAR. Investigations of the interface between magnesium and poly (ethylene terephthalate) by x-ray photoelectron-spectroscopy. Appl Surf Sci 1995;84:245.

[59] Friedrich JF, Koprinarov I, Giebler R, Lippitz A, Unger WES. Reactions and intermediates at the metal-polymer interface as observed by XPS and NEXAFS spectroscopy. J Adhesion 1999;71:297.

[60] Milde F, Goedicke K, Fahland M. Adhesion behavior of PVD coatings on ECR plasma and ionbeam treated polymer films. Thin Solid Films 1996;279:169.

[61] Jones JW. US Patent 3, 442, 686, 1969.

[62] Tropsha YG, Harvey NG. Activated rate theory treatment of oxygen and water transport through silicon oxide poly(ethylene terephthalate) composite barrier structures. J Phys Chem B 1997;101:2259.

[63] Henry BM, Dinelli F, Zhao KY, Grovenor CRM, Kolosov OV, Briggs GAD, et al. A microstructural study of transparent metal oxide gas barrier films. Thin Solid Films 1999;356:500. 
[64] Vallon S, Drévillon B, Sénémaud C, Gheorghiu A, Yakovlev V. Adhesion of a thin silicon oxide film on a polycarbonate substrate. J Electron Spectroscopy and Related Phenomena 1993;64/65:849.

[65] Benmalek M, Dunlop HM. Inorganic coatings on polymers. Surf Coat Technol 1995;76-77:821.

[66] Rotger JC, Pireaux JJ, Caudano R, Thorne NA, Dunlop HM, Benmalek M. Deposition of silicon oxide onto polyethylene and poly(ethylene terephthalate): an X-ray photoelectron spectroscopy interfacial study. J Vac Sci Technol 1995;A13:260.

[67] Vallon S, Hofrichter A, Guyot L, Drevillon B, Klemberg-Sapieha JE, Martinu LF. Poncin-Epaillard adhesion mechanisms of silica layers on plasma-treated polymers. 1. Polycarbonate. J Adhes Sci Technol 1996;10:1287.

[68] Vallon S, Brenot R, Hofrichter A, Drevillon B, Gheorghiu A, Senemaud C, et al. Adhesion mechanisms of silica layers on plasma-treated polymers. 2 Polypropylene, J Adhes Sci Technol 1996;10:1313.

[69] Vallon S, Hofrichter A, Drevillon B, Klemberg-Sapieha JE, Martinu LF. Poncin-Epaillard, Improvement of the adhesion of silica layers to polypropylene induced by nitrogen plasma treatment. Thin Solid Films 1996;291:68.

[70] Pitton Y. Etude de l'adhésion de films minces SiOx déposés sur poly(éthylène téréphtalate), $\mathrm{PhD}$ thesis, EPFL \#1553, 1996.

[71] Bichler C, Kerbstadt T, Langowski HC, Moosheimer U. The substrate-barrier film interface in thin barrier film coating. Surf Coat Technol 1997;97:299.

[72] Bichler C, Kerbstadt T, Langowski HC, Moosheimer U. Plasma-modified interfaces between polypropylene films and vacuum roll-to-roll coated thin barrier layers. Surf Coat Technol 1999;112:373.

[73] Inagaki N, Tasaka S, Makino M. Plasma polymer deposition from mixture of tetramethoxysilane and oxygen on PET films and their oxygen gas barrier properties. J Appl Polym Sci 1997;64:1031.

[74] Inagaki N, Tasaka S, Hiramatsu H. Preparation of oxygen gas barrier poly(ethylene terephthalate) films by deposition of silicon-oxide films plasma-polymerized from a mixture of tetramethoxysilane and oxygen. J Appl Polym Sci 1999;71:2091.

[75] Sobrinho ASD, Latreche M, Czeremuszkin G, Klemberg-Sapieha JE, Wertheimer MR. Transparent barrier coatings on poly(ethylene terephthalate) by single-frequency and dual-frequency plasmaenhanced chemical-vapor-deposition. J Vac Sci Technol, A16 1998:3190.

[76] Sobrinho ASD, Schuhler N, Klemberg-Sapieha JE, Wertheimer MR, Andrews M, Gujrathi SC. Plasma-deposited silicon-oxide and silicon-nitride films on poly(ethylene terephthalate) - a multitechnique study of the interphase regions. J Vac Sci Technol 1998;A16:2021.

[77] Yang MR, Chen KS, Hsu ST, Wu TZ. Fabrication and characteristics of $\mathrm{SiO}_{\mathrm{x}}$ films by plasma chemical vapor-deposition of tetramethylorthosilicate. Surf Coat Technol 2000;123:204.

[78] Ben Amor S, Baud G, Benmalek M, Dunlop H, Frier R, Jacquet M. Titania coatings on poly (ethylene terephthalate) - adhesion and XPS studies. J Adhesion 1998;65:307.

[79] Rossi G, Nulman M. Effect of local flaws in polymeric permeation reducing barriers. J Appl Phys 1993;74:5471.

[80] Felts JT. Thickness effects on thin film gas barriers: silicon-based coatings. Proc 34st Soc Vaccuum Coaters Annual Conf., SVC, 1991.

[81] Wang BC, Tropsha Y, Montgomery DB, Vogler EA, Spontak RJ. Enhanced barrier performance of $\mathrm{SiO}_{\mathrm{x}}$-modified polymer substrates - some morphological considerations. J Mater Sci Lett 1999; $18: 311$.

[82] Agres L, Segui Y, Delsol R, Raynaud P. Oxygen barrier efficiency of hexamethyldisiloxane/oxygen plasma-deposited coating. J Appl Polym Sci 1996;61:2015.

[83] Bordet H, Ignat M, Dupeux M. Analysis of the mechanical response of film on substrate systems presenting rough interfaces. Thin Solid Films 1998;315:207.

[84] Vergelati C, Perwuelz A, Vovelle L, Romero MA, Holl Y. PET surface dynamics in air and water studied by tensiometry and molecular modelling. Polymer 1994;35:262.

[85] Gould SAC, Schiraldi DA, Occelli ML. Analysis of poly(ethylene terephthalate) (PET) films by atomic force microscopy. J Appl Polym Sci 1997;65:1237.

[86] Beake BD, Ling JSG, Leggett GJ. Scanning force microscopy of bulk-filled uniaxially oriented poly(ethylene terephthalate) films. Polymer 2000;41:2241. 
[87] Ling JSG, Leggett GJ. Scanning force microscopy of poly(ethylene terephthalate) surfaces: comparison of SEM with SFM topographical, lateral force and force modulation data. Polymer 1997; 38:2617.

[88] Hermanutz F, Salem DR, Wesson SP. Influence of microstructure developed during drawing on surface properties of poly(ethylene terephthalate) film. Polymer 1994;35:4611.

[89] Lippitz A, Friedrich JF, Unger WES, Schertel A, Woll C. Surface analysis of partially crystalline and amorphous PET samples by X-ray-absorption spectroscopy (NEXAFS). Polymer 1996;37:3151.

[90] Koprinarov I, Lippitz A, Friedrich JF, Unger WES, Woll C. Surface analysis of DC oxygen plasma-treated or chromium evaporated poly(ethylene terephthalate) foils by soft X-ray absorption spectroscopy (NEXAFS). Polymer 1997;38:2005.

[91] Graham JF, Kovar M, Norton PR, Pappalardo P, Vanloon J, Warren OL. Quantitative nanoscale mechanical properties of a phase segregated homopolymer surface. J Mater Res 1998;13:3565.

[92] Lang F-R, Pitton Y, Mathieu HJ, Landolt D, Moser EM. Surface analysis of PET by ESCA and ToF-SIMS. Fresenius J Anal Chem 1997;358:251.

[93] Cros B, Vallat MF, Augereau F. Characterization of aluminum coated poly(ethylene terephthalate) films by acoustic microscopy. J Mater Sci 1997;32:2655.

[94] Cros B, Vallat MF, Despaux G. Characterization by acoustic microscopy of adhesion in poly (ethylene terephthalate) films coated by aluminum. Appl Surf Sci 1997;126:159.

[95] Bhushan B, Koinkar VN. Microtribology of PET polymeric films. Tribology Trans 1995;38:119.

[96] Gerlach CFG, Dunne FPE, Jones DP, Mills PDA, Zahlan N. Modeling the influence of filler particles on surface geometry in drawn PET films. J Strain Anal Eng Des 1996;31:65.

[97] Khan MB, Keener C. An investigation of the spatial and optical behavior of biaxially drawn PET film. Polym Eng Sci 1996;36:1290.

[98] Hyun J, Pope M, Smith J, Park M, Cuomo JJ. Ultrathin DLC and $\mathrm{SiO}_{\mathrm{x}}$ layer deposition on poly(ethylene terephthalate) and restriction of surface dynamics. J Appl Polym Sci 2000;75:1158.

[99] Wertheimer MR, Thomas HR, Perri MJ, Klemberg-Sapieha JE, Martinu L. Plasmas and polymers - from laboratory to large-scale commercialization. Pure Appl Chem 1996;68:1047.

[100] Wertheimer MR, Fozza AC, Hollander A. Industrial processing of polymers by low-pressure plasmas - the role of VUV radiation. Nucl Instr Meth Phys Res B Beam Inter Mater Atoms 1999;151:65.

[101] Yasuda H. Plasma polymerization. New York: Academic Press; 1985.

[102] Liston EM, Martinu L, Wertheimer MR. Plasma surface modification of polymers for improved adhesion - a critical review. J Adhes Sci Technol 1993;7:1091.

[103] Egitto FD, Matienzo LJ. Plasma modification of polymer surfaces for adhesion improvement IBM. J Res Dev 1994;38:423.

[104] Mutel B, Dessaux O, Goudmand P, Gengembre L, Grimblot J. Energy consumption and kinetic evolution of nitrogen fixation on poly(ethylene terephthalate) by remote nitrogen plasma-XPS study. Surf Interf Anal 1993;20:283.

[105] Bodino F, Baud G, Benmalek M, Besse JP, Dunlop HM, Jacquet M. Alumina coating on poly (ethylene terephthalate). Thin Solid Films 1994;241:21.

[106] Placinta G, Arefikhonsari F, Gheorghiu M, Amouroux J, Popa G. Surface properties and the stability of poly(ethylene terephthalate) films treated in plasmas of helium-oxygen mixtures. J Appl Polym Sci 1997;66:1367.

[107] Weidner S, Kuhn G, Decker R, Roessner D, Friedrich J. Influence of plasma treatment on the molar-mass of poly(ethylene terephthalate) investigated by different chromatographic and spectroscopic methods. J Polym Sci A Polym Chem 1998;36:1639.

[108] Beake BD, Ling JSG, Leggett GJ. Scanning force microscopy investigation of poly (ethylene terephthalate) modified by argon plasma treatment. J Mater Chem 1998;8:1735.

[109] Gupta B, Hilborn J, Hollenstein C, Plummer CJG, Houriet R, Xanthopoulos N. Surface modification of polyester films by RF plasma. J Appl Polym Sci 2000;78:1083.

[110] Boyd RD, Kenwright AM, Badyal JPS, Briggs D. Atmospheric nonequilibrium plasma treatment of biaxially oriented polypropylene. Macromolecules 1997;30:5429.

[111] Koprinarov I, Lippitz A, Friedrich JF, Unger WES, Woll C. Oxygen plasma-induced degradation 
of the surface of poly(styrene), poly(bisphenol-A-carbonate) and poly(ethylene terephthalate) as observed by soft X-ray absorption spectroscopy (NEXAFS). Polymer 1998;39:3001.

[112] Chan VZH, Thomas EL, Frommer J, Sampson D, Campbell R, Miller D, et al. Curious morphology of silicon-containing polymer-films on exposure to oxygen plasma. Chem Mater 1998;10:3895.

[113] Le QT, Pireaux JJ, Caudano R, Leclere P, Lazzaroni R. XPS/AFM study of the PET surfacemodified by oxygen and carbon dioxide plasmas-Al/PET adhesion. J Adhes Sci Technol 1998;12: 999.

[114] Leterrier Y, Sutter P, Månson JAE. Thermodynamic and micromechanical approaches to the adhesion between poly(ethylene terephthalate) and silicon oxide. J Adhes 1999;69:13.

[115] Göschel U. Two-dimensional small-angle X-ray scattering studies on oriented poly(ethylene terephthalate) films. Polymer 1995;36:1157.

[116] Orchard GAJ, Spiby P, Ward IM. Oxygen and water-vapor diffusion through biaxially oriented poly(ethylene terephthalate). J Polym Sci B: Polym Phys 1990;28:603.

[117] Garby L, Chabert B, Sage D, Soulier JP, Bosmans R. Surface modification of a polypropylene film by low-pressure discharge and the adhesion of a vacuum-deposited layer of aluminium. Angew Makrom Chem 1993;210:21.

[118] Wu PK, Lu TM. Metal/polymer adhesion enhancement by reactive ion-assisted interface bonding and mixing. Appl Phys Lett 1997;71:2710.

[119] Ziegler P, Vallat MF, Haidara H, Schultz J. Polyester/aluminium adhesion -improvement by heat treatments. J Mater Sci 1997;32:1809.

[120] Sobrinho AD, Czeremuszkin G, Latreche M, Wertheimer MR. A study of defects in ultra-thin transparent coatings on polymers. Appl Phys A Mater Sci Process 1999;68:103.

[121] Song Y, Sakurai T, Kishimoto K, Maruta K, Matsumoto S, Kikuchi K. Optical and structural properties of low-temperature PECVD ETMS SiO x thin-films. Thin Solid Films 1998;334:92.

[122] Lopata ES. Barrier coatings for food packaging. Polym Preprints 1997;38:1047.

[123] Fukugami N, Hishino H, Yanaka M, Tomiyama K, Tsukahara Y. Density measurement of thin glass layers for gas barrier films. J Vac Sci Technol, A17 1999:1840.

[124] Bansal NP, Doremus RH. Handbook of glass properties. New York: Academic Press; 1986.

[125] Leterrier Y, Boogh L, Andersons J, Månson J-AE. Adhesion of silicon oxide layers on poly (ethylene terephthalate) I: effect of substrate properties on coating's fragmentation kinetics. J Polym Sci B Polym Phys 1997;35:1449.

[126] Lefeuvre O, Kolosov OV, Every AG, Briggs GAD, Tsukahara Y. Elastic measurements of layered nanocomposite materials by brillouin spectroscopy. Ultrasonics 2000;38:459.

[127] Vlassak JJ, Nix WD. A new bulge test technique for the determination of Young's modulus and Poisson's ratio of thin films. J Mater Res 1992;7:3242.

[128] Felts JT, Grubb AD. Commercial scale application of plasma processing for polymeric substrate: from laboratory to production. J Vac Sci Technol, A10 1992:1675.

[129] Sobrinho ASD, Czeremuszkin G, Latreche M, Wertheimer MR. Defect-permeation correlation for ultra-thin transparent barrier coatings on polymers. J Vac Sci Technol, A18 2000:149.

[130] Deville JP, Lang B, Raynaud P. An AES study of the influence of carbon on the chemical structure of some oxide - films deposited by PECVD of organosilicon precursors. Appl Surf Sci 1999;137:136.

[131] Burlakov VM, Briggs GAD, Sutton AP, Tsukahara Y. Monte Carlo simulation of growth of porous $\mathrm{SiO}_{\mathrm{x}}$ by vapor deposition. Phys Rev Lett 2001;86:3052.

[132] Henry BM, Roberts AP, Grovenor CRM, Sutton AP, Briggs GAD, Tsukahara Y, Miyamoto et al. Microstructural characterisation of transparent silicon oxide permeation barrier coatings on PET Proc. 41st Society of Vacuum Coaters Annual Conference, Boston, April 18-23, SVC, 434, 1998.

[133] Erlat AG, Spontak RJ, Clarke RP, Robinson TC, Haaland PD, Tropsha Y, et al. $\mathrm{SiO}_{\mathrm{x}}$ gas barrier coatings on polymer substrates - morphology and gas-transport considerations. J Phys Chem B 1999;103:6047.

[134] García-Ayuso G, Martínez-Duart JM, Vázquez L. Atomic force microscopy (AFM) morphological surface characterization of transparent gas barrier coatings on plastic films. Surf Coat Technol 1996;80:203. 
[135] Lin CH, Wang HL, Hon MH. The effect of residual stress on the adhesion of PECVD-coated aluminum oxide film on glass. Thin Solid Films 1996;283:171.

[136] Leplan H, Geenen B, Robic JY, Pauleau Y. Residual stress in evaporated silicon dioxide films: correlation with deposition parameters and aging behavior. J Appl Phys 1995;78:962.

[137] Wheeler DR, Osaki H. In: Metallization of polymers. ACS Symposium Series 440, p. 500, 1990.

[138] Thouless MD, Jensen HM. In: Mittal KL, editor Adhesion measurement of films and coatings. VSP, 95, 1995.

[139] Atkinson A. Generation and relief of stress in ceramic films. Br Ceram Proc 1995;54:1.

[140] Clyne TW. Residual stresses in surface coatings and their effects on interfacial debonding. Key Eng. Mater. Interfacial Effects In Particulate, Fibrous And Layered Composite Materials 1996;116:307.

[141] Pitkethly MJ, Favre JP, Gaur U, Jakubowski J, Mudrich SF, Caldwell DL, et al. A round-robin progamme on interfacial test methods, Compos. Sci Technol 1993;48:205.

[142] Spaepen F. Interfaces and stresses in thin films. Acta Mater 2000;48:31.

[143] Hoffman RW. Stress distribution and thin film mechanical properties. Surf Interf Anal 1981;3:62.

[144] Nix WD. Mechanical properties of thin films. Metall Trans A 1989;20A:2217.

[145] Suo Z. Cracking and debonding of microlaminates. J Vac Sci Technol, A11 1993:1367.

[146] Campbell DS. In: Maissel LI, Glang R, editor. Handbook of thin film technology. New York: MacGraw Hill, 12, 1970.

[147] Thomas ME, Hartnett MP, McKay JE. The use of surface profilometers for the measurement of wafer curvature. J Vac Sci Technol 1988;A6:2570.

[148] Andritschky M, Guimaraes F, Teixeira V. Energy deposition and substrate heating during magnetron sputtering. Vacuum 1993;44:809.

[149] Monticone E, Rossi AM, Rajteri M, Gonnelli RS, Lacquaniti V, Amato G. Structural and morphological properties of evaporated $\mathrm{SiO}_{\mathrm{x}}$ films. Phil Mag B 2000;80:523.

[150] He LN, Inokuma T, Kurata Y, Hasegawa S. Stress in amorphous $\mathrm{SiO}_{\mathrm{x}}: \mathrm{H}$ films prepared by plasmaenhanced chemical vapor deposition. Jpn J Appl Phys Part 1996;1:35 1873.

[151] Tamulevicius S. Stress and strain in the vacuum-deposited thin films. Vacuum 1998;51:127.

[152] Grimberg I, Bouaifi B, Draugelates U, Soifer K, Weiss BZ. Microstructure and adhesion mechanisms of tin coatings on metallized acrylonitrile-butadiene-styrene. Surf Coat Technol 1994;68:166.

[153] Sosman RB. The properties of silica. New York: Reinhold; 1927 p. $362 .$.

[154] Weast RC, editor. Handbook of chemistry and physics. 68th ed. CRC Press, 1987.

[155] Chand N, Kola RR, Opila RL, Comizzoli RB, Krautter H, Sergent AM, et al. Stress-free and moisture insensitive silicon oxide dielectric films formed by molecular-beam deposition. J Appl Phys 1995; 78:3315.

[156] Gonzalez P, Garcia E, Pou J, Fernandez D, Serra J, Leon B, et al. Silicon oxide thin films grown by $\mathrm{Xe}_{2}{ }^{*}$ excimer lamp chemical vapor deposition - the role of the substrate temperature and the window substrate distance. Thin Solid Films 1994;241:348.

[157] Bayer C, Bapin E, von Rohr PR. Overall kinetics of $\mathrm{SiO}_{\mathrm{x}}$ remote-PECVD using different organosilicon monomers. Surf Coat Technol 1999;119:874.

[158] Yamamoto K, Harada T, Tomikawa N, Uyama H, Yang SC, Fujiyama H. Temperature measurement of polymer substrates during plasma irradiation. Thin Solid Films 1999;345:94.

[159] Wendt R, Ellmer K, Wiesemann K. Thermal power at a substrate during ZnO:Al thin film deposition in a planar magnetron sputtering system. J Appl Phys 1997;82:2115.

[160] Trakhtenberg IS, Bakunin OM, Korneyev IN, Plotnikov SA, Rubshtein AP, Uemura K. Substrate surface temperature as a decisive parameter for diamond-like carbon film adhesion to polyethylene substrates. Diamond Rel Mater 2000;9:711.

[161] Neuhauser M, Barwulf S, Hilgers H, Lugscheider E, Riester M. Optical emission spectroscopy studies of titanium nitride sputtering on thermoplastic polymers. Surf Coat Technol 1999;119:981.

[162] Mohnjuk AA, Gusev IV, Belevsky VP. Method and experimental arrangement for Al thin film deposition from RF metal plasma with simultaneous self-ion bombardment. Nucl Instrum Methods Phys Res Sect B 2000;170:375.

[163] Yanaka M, Tsukahara Y, Nasako N, Takeda N. Cracking phenomena of brittle films in nanostructure composites analysed by a modified shear lag model with residual strain. J Mater Sci 1998;33:2111. 
[164] Yanaka M, Miyamoto T, Tsukahara Y, Takeda N. In-situ observation and analysis of multiple cracking phenomena in thin glass layers deposited on polymer-films. Compos Interfaces 1999;6:409.

[165] Leterrier Y, Pellaton D, Andersons J, Månson JA-E. In: Cardon AH, Fukuda H, Reifsnider KL, Verchery G, editors. Recent developments in durability analysis of composite systems, Proc. DURACOSYS'99, Brussels, July 11-14. Rotterdam: A.A. Balkema, 29, 2000.

[166] Robic JY, Leplan H, Pauleau Y, Rafin B. Residual stress in silicon dioxide thin films produced by ion-assisted deposition. Thin Solid Films 1996;291:34.

[167] Stoney GG. The tension of metallic films deposited by electrolysis. Proc Roy Soc London 1909;a82:172.

[168] Leterrier Y, Fayet P. Packaging laminate with gas and aroma barrier properties. International Patent Application WO 99/19229, 1999.

[169] Leterrier Y, Wyser Y, Månson J-AE. Effect of internal stresses on the cohesion and adhesion of a thin silicon oxide coating on poly(ethylene terephthalate). J Adhes Sci Technol 2001;15:841.

[170] Henry BM, Norenberg H, Dinelli F, Grovenor CRM, Briggs GAD, Tsukahara Y, et al. The effect of thermal cycling damage on the permeability and structure of transparent gas barrier films. Chem Eng Technol 1999;22:1010.

[171] Cakmak M, Wang YD. The effect of biaxial orientation and crystallinity on the long-term creep behavior of PET films below glass transition temperature. J Appl Polym Sci 1990;41:1867.

[172] Mukherjee S, Jabarin SA. Aging characteristics of oriented poly(ethylene terephthalate). Polym Eng Sci 1995;35:1145.

[173] Leterrier Y, Mendels D, Månson J-AE. The role of the interfacial stress state on the durability of polymer-based composites systems. Proc. International Workshop on Structural Integrity of Composites and Structures, Isle of Capri, May 20-25, 2001.

[174] Leplan H, Robic JY, Pauleau Y. Kinetics of residual stress evolution in evaporated silicon dioxide films exposed to room air. J Appl Phys 1996;79:6926.

[175] Zuri L, Narkis M, Silverstein MS. Film formation and crack development in plasma-polymerized hexamethyldisiloxane. Polym Eng Sci 1997;37:1188.

[176] Song Y, Sakurai T, Kishimoto K, Maruta K, Matsumoto S, Kikuchi K. Syntheses and optical properties of low-temperature $\mathrm{SiO}_{\mathrm{x}}$ and $\mathrm{TiO}_{\mathrm{x}}$ thin films prepared by plasma-enhanced CVD. Vacuum 1998;51:525.

[177] Haque MS, Naseem HA, Brown WD. Post-deposition processing of low temperature PECVD silicon dioxide films for enhanced stress stability. Thin Solid Films 1997;308-309:68.

[178] Benabdi M, Roche AA. Mechanical properties of thin and thick coatings applied to various substrates 1. An elastic analysis of residual stresses within coating materials. J Adhes Sci Technol 1997; $11: 281$.

[179] Timoshenko S. Analysis of bi-metal thermostats. J Opt Soc Amer 1925;11:233.

[180] Brenner A, Senderoff S. Calculation of stress in electrodeposits from the curvature of plated strip. J Res Natl Bur Stand 1949;42:105.

[181] Hoffman RW. The mechanical properties of thin condensed films. Phys Thin Films 1966;3:211.

[182] Klein CA. How accurate are Stoney's equation and recent modifications. J Appl Phys 2000;88:5487.

[183] VonPreissig FJ. Applicability of the classical curvature-stress relation for thin films on plate substrates. J Appl Phys 1989;66:4262.

[184] van de Riet E. Deflection of a substrate-induced by an anisotropic thin film stress. J Appl Phys 1994;76:584.

[185] Townsend PH, Barnett DM, Brunner TA. Elastic relationships in layered composite media with approximation for the case of thin films on a thick substrate. J Appl Phys 1987;62:4438.

[186] Lawn B. Fracture of brittle solids. 2nd ed. Cambridge: Cambridge University Press; 1993.

[187] Futatsugi T, Ogawa S, Takemoto M, Yanaka MA, Tsukahara Y. Integrity evaluation of $\mathrm{SiO}_{\mathrm{x}}$ film on poly(ethylene terephthalate) by AE characterization and laser microscopy. NDT \& E Int 1996; 29:307.

[188] Rochat G, Delachaux A, Leterrier Y, Månson J-AE, Fayet P. Influence of substrate morphology on the cohesion and adhesion of thin PECVD oxide films on semi-crystalline polymers. Proc. ECASIA'2001, Avignon (F), 30 September-5 October, 2001. 
[189] Poulingue M, Ignat M, Dijon J. The effects of particle pollution on the mechanical behaviour of multilayered systems. Thin Solid Films 1999;348:215.

[190] Leterrier Y. Analysis of fragmentation patterns in nanosized coatings on polymer substrates. Proc. International Workshop on Video-Controlled Material Testing and Microstructural Characterization, Nancy (F), November 16-18, 1999.

[191] Griffith AA. The phenomena of rupture and flow in solids. Phil Trans Roy Soc Lond 1920;A221:163.

[192] Inglis CE. Stresses in a plate due to the presence of cracks and sharp corners. Trans Inst Naval Arch 1913;55:219.

[193] Timoshenko SP, Goodier JN. Theory of elasticity. 3rd ed. Singapore: McGraw Hill; 1970.

[194] Nairn JA. In: Kelly A, Zweben C, editors. Comprehensive composite materials, Vol. 2. Polymermatrix composites, Chap. 12. Elsevier, Oxford, p. 403, 2000.

[195] Nairn JA, Kim S-R. A fracture mechanics analysis of multiple cracking in coatings. Eng Fract Mech 1992;42:195.

[196] Klokholm E. Delamination and fracture of thin films. IBM J Res Dev 1987;31:585.

[197] Hu MS, Evans AG. The cracking and decohesion of thin films on ductile substrates. Acta Metall 1989;37:917.

[198] Leung DK, He MY, Evans AG. The cracking resistance of nanoscale layers and films. J Mater Res 1995;10:1693.

[199] Wang JS, Sugimura Y, Evans AG, Tredway WK. The mechanical performance of DLC films on steel substrates. Thin Solid Films 1998;325:163.

[200] Kim S-R, Nairn JA. Fracture mechanics analysis of coating/substrate systems: I. Analysis of tensile and bending experiments Eng Fract Mech 2000;65:573.

[201] Laws N, Dvorak GJ. Progressive transverse cracking in composite laminates. J Compos Mater 1989;22:900.

[202] Wiederhorn SM. J Amer Ceram Soc 1969;52:99.

[203] Leterrier Y, Månson J-AE. Work of fragmentation of a thin oxide coating on a polymer film. J Mater Sci Lett 1997;16:120.

[204] Tseng HH, Lai FS, Lee CK. Pneumatic bursting characteristics of plastics films. Polym Eng Sci 1993;33:504.

[205] Gohil RM. Morphology-property relationships in oriented PET films: a role of in-plane crystalline orientation distribution on the film properties. J Appl Polym Sci 1993;48:1635.

[206] Gohil RM. Morphology-property relationships in oriented PET films: microstructural reorganization during heat treatment. J Appl Polym Sci 1994;52:925.

[207] Zinck P, Pays MF, Rezakhanlou R, Gerard JF. Mechanical characterisation of glass fibres as an indirect analysis of the effect of surface treatment. J Mater Sci 1999;34:2121.

[208] Affinito JD, Gross ME, Coronado CA, Graff GL, Greenwell EN, Martin PM. A new method for fabricating transparent barrier layers. Thin Solid Films 1996;291:63.

[209] Affinito JD, Eufinger S, Gross ME, Graff GL, Martin PM. PML/Oxide/PML barrier layer performance differences arising from use of UV or electron beam polymerization of the PML layers 1997; 308-309:19.

[210] Schiller S, Morgner H, Schiller N, Straach S. High rate coating of plastic films and plastic sheets with clear oxide layers. Proc. Joint Inter. Meet. Electrochem. Soc. Int. Soc. Electrochem. Symposium, Metallized Plastics VI: Fundamentals and Applied Aspects, Paris, 31 August-5 September, 1912.

[211] Radeva E. A SEM study of plasma-polymerized hexamethyldisiloxane thin films. Vacuum 1997;48: 41.

[212] Benitez F, Martinez E, Esteve J. Improvement of hardness in plasma polymerized hexamethyldisiloxane coatings by silica-like surface modification. Thin Solid Films 2000;377:109.

[213] Haas KH, Ambergschwab S, Rose K, Schottner G. Functionalized coatings based on inorganicorganic polymers $\left(\operatorname{Ormocer}^{\mathbb{R}} \mathrm{s}\right)$ and their combination with vapor-deposited inorganic thin films. Surf Coat Technol 1999;111:72.

[214] Lee SY, Lee JD, Yang SM. Preparation of silica-based hybrid materials coated on polypropylene film. J Mater Sci 1999;34:1233. 
[215] Thyen R, Weber A, Klages CP. Plasma-enhanced chemical vapor deposition of thin films by corona discharge at atmospheric pressure. Surf Coat Technol 1997;97:426.

[216] Vasquez-Borucki S, Jacob W, Achete CA. Amorphous hydrogenated carbon films as barrier for gas permeation through polymer films. Diamond Rel Mater 2000;9:1971.

[217] Vasquez-Borucki S, Achete CA, Jacob W. Hydrogen plasma treatment of poly(ethylene terephthalate) surfaces. Surface and Coatings Technology 2001;138:256.

[218] Moser EM, Urech R, Hack E, Kunzli H, Muller E. Hydrocarbon films inhibit oxygen permeation through plastic packaging material. Thin Solid Films 1998;317:388.

[219] Moser EM, Faller C, Pietrzko S, Eggimann F. Modeling the functional performance of plasma polymerized thin films. Thin Solid Films 1999;356:49.

[220] Moser EM, Muller C. A versatile plasma technique to improve plastic materials against gas and water-vapour permeation. J Mater Sci 1999;34:349.

[221] Schwarzer N. Coating design due to analytical modelling of mechanical contact problems on multilayer systems. Surf Coat Technol 2000;133-134:397.

[222] Chapman BN. Thin-film adhesion. J Vac Sci Technol 1974;11:106.

[223] Mittal KL. Adhesion measurements of thin films. Electrocomp Sci Technol 1976;3:21.

[224] Mittal KL. Adhesion measurements of thin films, thick films and bulk coatings. ASTM. PA: Philadelphia; 1978.

[225] Mittal KL. Selected bibliography on adhesion measurement of films and coatings. J Adhes Sci Technol 1987;1:247.

[226] Mittal KL, editor, Adhesion measurement of films and coatings, VSP. The Netherlands: Utrecht, 1995.

[227] Felder E, Angelelis C, Ducarroir M, Ignat M, Mazot P. Mechanical properties of thin films: problems and testing techniques. Ann Chim Sci Mater 1998;23:791.

[228] Baun WL. In: Mittal KL, editor. Adhesion measurement of thin films, thick films and bulk coatings. ASTM, 41, 1978.

[229] Pitton Y, Hamm SD, Lang FR, Mathieu HJ, Leterrier Y, Månson JAE. Adhesion study of $\mathrm{SiO}_{\mathrm{x}} /$ PET films - comparison between scratch test and fragmentation test. J Adhes Sci Technol 1996;10: 1047.

[230] Hagemeyer A, Hibst H, Heitz J, Bäuerle D. Improvements of the Peel test for adhesion evaluation of thin metallic films on polymeric substrates. J Adhes Sci Technol 1994;8:29.

[231] Naruskevicius LL, Rozovskis GI. The influence of interfacial water on nonmechanical adhesion of copper sulfide and copper coatings to impact-resistant polystyrene. J Adhes Sci Technol 1994;8: 1007.

[232] Park YB, Yu J. Phase-angle in the Cu/polyimide/alumina system. Mater Sci Eng A Struct Mater Prop Microstruct Process 1999;266:109.

[233] Wu SY, Kang ET, Neoh KG, Han HS, Tan KL. Surface modification of poly(tetrafluoroethylene) films by graft-copolymerization for adhesion improvement with evaporated copper. Macromol 1999;32:186.

[234] Wu SY, Kang ET, Neoh KG, Tan KL. Surface modification of poly(tetrafluoroethylene) films by double graft-copolymerization for adhesion improvement with evaporated copper. Polymer 1999; 40:6955.

[235] Benjamin P, Weaver C. Measurement of adhesion of thin films. Proc Roy Soc London, A254 1960: 163.

[236] Valli J. A review of adhesion test methods for thin hard coatings. J Vac Sci Technol, A4 1986:3007.

[237] Perry AJ. Scratch adhesion testing: a critique. Surf Eng 1986;2:193.

[238] Steinmann PA, Hintermann HE. A review of the mechanical tests for assessment of thin film adhesion. J Vac Sci Technol 1989;A7:2267.

[239] Chalker PR, Bull SJ, Rickerby DS. A review of the methods for the evaluation of coating-substrate adhesion. Mater Sci Eng 1991;A140:583.

[240] Venkataraman SK, Nelson JC, Hsieh AJ, Kohlstedt DL, Gerberich WW. Continuous microscratch measurements of thin film adhesion strengths. J Adhes Sci Technol 1993;7:1279. 
[241] Pharr GM, Oliver WC. Measurement of thin film mechanical properties using nanoindentation. MRS Bulletin, July 28, 1992.

[242] Consiglio R, Randall NX, Bellaton B, Vonstebut J. The nano-scratch tester (NST) as a new tool for assessing the strength of ultrathin hard coatings and the mar resistance of polymer films. Thin Solid Films 1998;332:151.

[243] Ollivier B, Matthews A. Adhesion of diamond-like carbon films on polymers - an assessment of the validity of the scratch test technique applied to flexible substrates. J Adhes Sci Technol 1994;8: 651.

[244] Saunders SRJ, Vetters HR. Standardization of test methods for the mechanical properties of thin coatings. Thin Solid Films 1997;299:82.

[245] Rats D, Hajek V, Martinu L. Micro-scratch analysis and mechanical properties of plasma deposited silicon-based coatings on polymer substrates. Thin Solid Films 1999;340:33.

[246] Ramaligan S. Tribological characteristics of thin films and application of thin film technology for friction and wear reduction. Thin Solid Films 1984;118:335.

[247] Agrawal DC, Raj R. Measurement of the ultimate shear strength of a metal-ceramic interface. Acta Metall 1989;37:1265.

[248] Shieu FS, Shiao MH. Measurement of the interfacial mechanical properties of a thin ceramic coating on ductile substrates. Thin Solid Films 1997;306:124.

[249] Harry E, Rouzaud A, Ignat M, Juliet P. Mechanical properties of W and W(C) thin films: Young's modulus, fracture toughness and adhesion. Thin Solid Films 1998;332:195.

[250] Harry E, Ignat M, Rouzaud A, Juliet P. Cracking investigation of W and W(C) films deposited by physical vapor deposition on steel substrates. Surf Coat Technol 1999;111:177.

[251] Chow TS, Liu CA, Penwell RC. Direct determination of interfacial energy between brittle and polymeric films. J Polym Sci 1976;14:1305.

[252] Wojciechowski PH, Mendolia MS. On the multiple fracture of low-elongation thin films deposited on high-elongation substrates. J Vac Sci Technol, A7 1989:1282.

[253] Wojciechowski PH, Mendolia MS. In: Francombe MH, Vossen JL, editors. Physics of thin films. Thin films for emerging applications. Boston: Academic Press, 1992.

[254] Leterrier Y, Rochat G, Fayet P, Månson J-AE. Durability of thin P. E. C.VD coatings on polymer films. Proc. 41st Society of Vacuum Coaters Annual Conference, Boston, April 18-23, SVC, p. 429, 1998.

[255] Touchais-Papet E, Charbonnier M, Romand M. Electroless metallization of carbon substrates. Appl Surf Sci 1999;139:557.

[256] Felts JT. Transparent barrier coatings update: flexible substrates. J Plast Film Sheet 1993;9:139.

[257] Leterrier Y, Wyser Y, Månson J-AE, Hilborn J. A method to measure the adhesion of thin glass coatings on polymer films. J Adhesion 1994;44:213.

[258] Barker CP, Badyal JPS, Kochem K-H, Kelly RSA, Revell KM. Atomic force microscopy and permeability study of stretching-induced gas barrier loss of AlOx layers. Thin Solid Films 1995; 259:46.

[259] Leterrier Y, Andersons J, Pitton Y, Månson J-AE. Adhesion of silicon oxide layers on poly (ethylene terephthalate) II: Effect of coating thickness on adhesive and cohesive strengths. J Polym Sci B Polym Phys 1997;35:1463.

[260] Leterrier Y, Fayet P. Durability of thin oxide coatings on poly(ethylene terephthalate). Proc. Joint Inter. Meet. Electrochem. Soc. Int. Soc. Electrochem. Symposium, Metallized Plastics VI: Fundamentals and Applied Aspects, Paris, 31 August 5 September 1918, (1997).

[261] Leterrier Y, Månson J-AE. Adhesion between poly(ethylene terephthalate) and thin oxide coatings. Proc. European Conf. Macromol. Phys., Surfaces and Interfaces in Polymers and Composites, Lausanne, June 1-6, EPS, 21, 1997.

[262] Volynskii AL, Bazhenov SL, Lebedeva OV, Ozerin AN, Bakeev NF. Cracking of solid coating during tensile drawing of polymer support. Polym Sci Series A 1997;39:1231.

[263] Yanaka M, Kato Y, Tsukahara Y, Takeda N. Effects of temperature on the multiple cracking progress of submicron thick glass films deposited on a polymer substrate. Thin Solid Films 1999; 356:337. 
[264] Gleskova H, Wagner S, Suo Z. Failure resistance of amorphous silicon transistors under extreme inplane strain. Appl Phys Lett 1999;75:3011.

[265] Henry BM, Erlat AG, McGuigan A, Grovenor CRM, Briggs GAD, Tsukahara Y, et al. Characterization of transparent aluminium oxide and indium tin oxide layers on polymer substrates. Thin Solid Films 2001;382:194.

[266] Erlat AG, Henry BM, Ingram JJ, Mountain DB, McGuigan A, Howson RP, et al. Characterisation of aluminium oxynitride gas barrier films. Thin Solid Films 2001;388:78.

[267] Scafidi P, Ignat M. Cracking and loss of adhesion of $\mathrm{Si}_{3} \mathrm{~N}_{4}$ and $\mathrm{SiO}_{2}: \mathrm{P}$ films deposited on $\mathrm{Al}$ substrates. J Adhes Sci Technol 1998;12:1219.

[268] Leterrier Y, Rochat G. Influence of defects and internal stresses on the adhesion of nanosized oxide coatings on polymers. In: Lacombe RH, Mittal KL, editors. Proceedings 2nd international symposium on adhesion aspects of thin films. MST, Newark, N. J., November 5-7, 2001.

[269] Yanaka M, Nasako N, Tsukahara Y, Hsu NH. Investigation of AE signals emitted from an SiOx layer deposited on a PET film. J Acoust Emission 1995;12:23.

[270] Dillard DA, Chen B, Chang TN, Lai YH. Analysis of the notched coating adhesion test. J Adhesion 1999;69:99.

[271] Andersons J, Leterrier Y, Joffe R. Statistical model of coating fragmentation under equibiaxial load. Mater Manuf Process 1998;13:597.

[272] Leterrier Y, Pellaton D, Mendels DA, Glauser R, Andersons J, Månson J-AE. Biaxial fragmentation of thin silicon oxide coatings on poly(ethylene terephthalate). J Mater Sci 2001;36:2213.

[273] Markschlager P, Lukhaub W. Thin metal and metal oxide films deposited by the anodic vacuum are technique. Surf Coat Technol, 87- 1996;8:279.

[274] Menezes M, Robertson IM, Birnbaum HK. Measurement and improvement of the adhesion of copper to polyimide. J Mater Res 1999;14:4025.

[275] Gupta V, Yuan J, Pronin A. Recent developments in the laser spallation technique to measure the interface strength and its relationship to interface toughness with applications to metal-ceramic, ceramic-ceramic and ceramic polymer interfaces. J Adhes Sci Technol 1994;8:713.

[276] Dauskardt R, Lane M, Ma Q, Krishna N. Adhesion and debonding of multilayer thin-film structures. Eng Fract Mech 1998;61:141.

[277] Wang C. Measurements of interfacial strength from the blister test. J Appl Polym Sci 1999;73:1899.

[278] Wan KT, Liao K. Measuring mechanical properties of thin flexible films by a shaft-loaded blister test. Thin Solid Films 1999;352:167.

[279] Handge UA, Leterrier Y, Rochat G, Sokolov IM, Blumen A. Two scaling domains in multiple cracking phenomena. Phys Rev E 2000;62:7807.

[280] Bradley RM, Crosby KM. Pattern-formation in thin-film failure. Phil Mag B 1998;78:143.

[281] Crosby KM, Bradley RM. Pattern-formation during delamination and buckling of thin-films. Phys Rev E 1999;59:R2542.

[282] Volynskii AL, Bazhenov SL, Lebedeva OV, Bakeev NF. Mechanical buckling instability of thin coatings deposited on soft polymer substrates. J Mater Sci 2000;35:547.

[283] Meakin P. A simple model for elastic fracture in thin films. Thin Solid Films 1987;151:165.

[284] Meakin P. Models for material failure and deformation. Science 1991;252:226.

[285] Grosskreutz JC, McNeil MB. The fracture of surface coatings on a strained substrate. J Appl Phys 1969;40:355.

[286] Ignat M. Mechanical response of multilayers submitted to in-situ experiments. Key Eng Mater 1996;116-117:279.

[287] Favre J-P, Sigety P, Jacques D. Stress transfer by shear in carbon fibre model composites: part II Computer simulation of the fragmentation test. J Mater Sci 1991;26:189.

[288] Lacroix T, Keunings R, Desaeger M, Verpoest I. A new data reduction scheme for the fragmentation testing of polymer composites. J Mater Sci 1995;30:683.

[289] Handge UA, Leterrier Y, Månson J-AE, Sokolov IM, Blumen A. An analysis of disorder in thin silicon oxide coatings. Europhys Letters 1999;48:280.

[290] Handge UA, Sokolov IM, Blumen A, Kolb E, Clement E. Patterns of fragmentation for polymer coatings. J Macrom Sci Phys 1999;B38:971. 
[291] Mezin A, Sajid B. Undirectional multiple cracking of coatings described through random sequential placement of rods on a line. Thin Solid Films 2000;358:46.

[292] Zhou L, Kim LK, Baillie C, Mai YW. Fracture mechanics analysis of the fragmentation test. J Compos Mater 1995;29:881.

[293] Fraser WA, Achker FH, DiBenedetto AT. A computer modeled, single filament technique for measuring coupling and sizing agent effects in fiber reinforced composites. Proc. 30th conf. SPI reinforced plastics division. The Society of the Plastics Industry, Section 22, 1975.

[294] Feillard P, Désarmot G, Favre JP. Theoretical aspects of the fragmentation test. Compos Sci Technol 1994;50:265.

[295] Hui CY, Shia D, Berglund LA. Estimation of interfacial shear strength: an application of a new statistical theory for single fiber composite test. Compos Sci Technol 1999;59:2037.

[296] Shia D, Hui CY, Phoenix SL. Statistics of fragmentation in a single-fiber composite under matrix yielding and debonding with application to the strength of multi-fiber composites. Compos Sci Technol 2000;60:2107.

[297] Cox HL. The elasticity and strength of paper and other fibrous materials. Br J Appl Phys 1952;3:72.

[298] Kelly A, Tyson WR. Tensile properties of fibre-reinforced metals: copper/tungsten and copper/ molybdenum. J Mech Phys Sol 1965;13:329.

[299] Curtin WA. Exact theory of fibre fragmentation in a single filament composite. J Mater Sci 1991;26: 5239.

[300] Sokolov IM, Blumen A. Scaling and patterns in surface fragmentation processes. Physica A 1999; 266:299.

[301] Weibull W. A statistical distribution function of wide applicability. J Appl Mech 1951;18:293.

[302] Andersons J, Joffe R, Sandmark R. Constrained fragmentation of composites under uniaxial loading. Mech Compos Mater 1995;31:26.

[303] Suzuki S, Hashimoto N, Oyama T, Suzuki K. Effect of internal stress on adhesion and other mechanical properties of evaporated indium tin oxide (ITO) films. J Adh Sci Technol 1994;8:261.

[304] Felts JT. Transparent gas barrier technologies. J Plast Film Sheet 1993;9:201.

[305] Norenberg H, Miyamoto T, Tsukahara Y, Smith GDW, Briggs GAD. Mass-spectrometric estimation of gas permeation coefficients for thin polymer membranes. Rev Sci Instr 1999;70:2414.

[306] Slee JA, Orchard GAJ, Bower DI, Ward IM. The transport of oxygen through oriented poly(ethylene terephthalate). J Polym Sci: B: Polym Phys 1989;27:71.

[307] Hernandez RJ. Effect of water vapor on the transport properties of oxygen through polyamide packaging materials. J Food Eng 1994;22:495.

[308] Gopalakrishnan R, Schultz JM, Gohil RM. Effect of blend rheology on the transport property of oriented poly(ethylene terephthalate) blends. J Appl Polym Sci 1995;56:1749.

[309] Holsti-Miettinen RM, Perttila KP, Seppala JV, Heino MT. Oxygen barrier properties of polypropylene/polyamide-6 blends. J Appl Polym Sci 1995;58:1551.

[310] Liquid crystalline polymers vectra. Report Hoechst High Chem., Hoechst Aktiengesellschaft Vertrieb Kunstoffe Deutschland.

[311] Brennan DJ, White JE, Haag AP, Kram SL, Mang MN, Pikulin S, et al. Poly(hydroxy amide ethers) - new high barrier thermoplastics. Macromol 1996;29:3707.

[312] Brennan DJ, Haag AP, White JE, Brown CN. High-barrier poly(hydroxy amide ethers)-effect of polymer structure on oxygen transmission rates-2. Macromol 1998;31:2622.

[313] Brennan DJ, White JE, Brown CN. High barrier poly(hydroxy amide ethers) - effect of polymer structure on oxygen transmission rates-3. Macromol 1998;31:8281.

[314] Xanthos M, Faridi N, Li Y. Processing/structure relationships of mica-filled PE-films with low oxygen permeability. Int Polym Process 1998;13:58.

[315] Misiano C, Simonetti E, Cerolini P, Staffetti F. Silicon oxide barrier improvement on plastic substrate. Proc. 33th society of vaccuum coaters annual conference, SVC, 1991, p. 105.

[316] Azuta K, Tadanaga K, Minami T. Water and oxygen permeability of silica thin films containing organic polymers coated on poly(ethylene terephthalate) substrate by the sol-gel method. J Ceram Soc Japan 1999;107:293.

[317] Klemberg-Sapiepha JE, Martinu L, Küttel OM, Wertheimer M. Transparent gas barrier coatings 
by dual frequency PECVD. Proc. 36th society of vaccuum coaters annual conference, SVC, 1993, p. 445.

[318] Izu M, Dotter B, Ovshinski SR. High performance clear coat ${ }^{\mathrm{TM}}$ barrier film. Proc. 36th society of vaccuum coaters annual conference, SVC, 1993, p. 333.

[319] Freund LB, Floro JA, Chason E. Extensions of the Stoney formula for substrate curvature to configurations with thin substrates or large deformations. Appl Phys Lett 1999;74:1987.

[320] Rats D, Bimbault L, Vandenbulcke L, Herbin R, Badawi KF. Crystalline quality and residual stresses in diamond layers by Raman and X-ray-diffraction analyses. J Appl Phys 1995;78:4994.

[321] Inoue Y, Kobatake Y. Mechanics of adhesive joints Part III. Evaluation of residual stresses. Appl Sci Res, A7 1958:314.

[322] Glang RR, Holmwood RA, Rosenfeld RL. Determination of stress in films on single crystalline silicon substrates. Rev Sci Instr 1965;36:7.

[323] Röll K. Analysis of stress and strain distribution in thin films and substrates. J Appl Phys 1976;47: 3224.

[324] Schafer JD, Nafe H, Aldinger F. Macrostress and microstress analysis in sol-gel derived $\mathrm{Pb}\left(\mathrm{Zr}_{\mathrm{x}} \mathrm{Ti}_{1-\mathrm{x}}\right) \mathrm{O}_{3}$ thin films. J Appl Phys 1999;85:8023. 